\title{
A GLOBAL MODEL FOR FRACTURE FALLOFF ANALYSIS
}

\author{
A Dissertation \\ by \\ MATTEO MARONGIU-PORCU \\ Submitted to the Office of Graduate and Professional Studies of \\ Texas A\&M University \\ in partial fulfillment of the requirements for the degree of \\ DOCTOR OF PHILOSOPHY
}

$\begin{array}{ll}\text { Chair of Committee, } & \text { Christine Ehlig-Economides } \\ \text { Committee Members, } & \text { Hisham Nasr-El-Din } \\ & \begin{array}{l}\text { Peter Valkó } \\ \text { Yuefeng Sun }\end{array} \\ \text { Head of Department, } & \text { Daniel Hill }\end{array}$

December 2014

Major Subject: Petroleum Engineering

Copyright 2014 Matteo Marongiu-Porcu 


\section{ABSTRACT}

The reservoir permeability is an essential input for the optimum design of modern hydraulic fracture treatments, which are undeniably the crucial technology involved in the development of tight and/or unconventional gas reservoirs. The fracture geometry and pumping execution, as well as the well architecture, can be designed to maximize the well productivity, provided the reservoir permeability is known, but in tight formations estimation of permeability and pressure can be impractical or even impossible to determine by conventional pressure buildup transient tests because no flow will occur without hydraulic fracture stimulation.

Various authors have shown how fracture calibration tests, intended for the final fracture treatment calibration (i.e. estimation of closure stress, leakoff coefficient and fracture fluid efficiency) can be used to estimate reservoir permeability as well. However, all the proposed techniques depend on specialized plots that are designed to show a straight line for a portion of the data, from which parameters are determined either from the slope of the line or from its endpoints, and there is a risk that apparent straight lines may lead to erroneous results, particularly when the absence of late time pseudo-radial flow data is ignored or not recognized.

This dissertation introduces a new global model for the before-closure and afterclosure analysis of the pressure falloff following a step-rate or constant rate fracture calibration test, using a single log-log diagnostic plot, as common practice within the pressure transient analysis literature. This model provides a complete assessment tool that allows quantification of all fracture parameters (closure stress, closure time, fracture fluid efficiency, leakoff coefficient and estimate of the induced fracture geometry) as well as reservoir permeability and formation pressure, provided that enough time is allowed for the falloff to reach pseudo-radial flow regime. Both oil and gas reservoirs can be effectively studied. 
Another major advantage provided by this approach is that this model can be used to optimize a priori the design of the fracture calibration test that would allow determination of all the involved parameters, including reservoir permeability.

Field data will be used to validate the model and demonstrate its added value over current interpretation methods. 


\section{DEDICATION}

To my mother Bianca 


\section{ACKNOWLEDGEMENTS}

I would like to thank my committee chair, Dr. Christine Ehlig-Economides for her perseverant guidance and support throughout the course of this research.

Also, thanks to Dr. Hisham Nasr-El-Din, Dr. Peter Valkó and Dr. Yuefeng Sun for their availability and patience in serving as my committee members and assessing this work.

A mention of my gratitude goes also to BP, Shell, and Apache Canada, Ltd. for providing a large amount of field data for this research.

Finally, I would like to express my unconditional gratitude and appreciation to my life mentor, the late Dr. Michael Economides, Professor of Chemical Engineering at the University of Houston, not only for all the precious advices and support I received from him over my academic and professional career, but also and especially for his fatherly guidance through the last ten years of my life. 


\section{NOMENCLATURE}

\begin{tabular}{|c|c|}
\hline $\mathrm{AC}$ & $=$ after closure \\
\hline $\mathrm{A}_{\mathrm{e}}$ & $=$ equivalent surface area of one face of one fracture wing, $\mathrm{L}^{2}, \mathrm{ft}^{2}$ \\
\hline B & $=$ formation volume factor, $\mathrm{L}^{3} / \mathrm{L}^{3}, \mathrm{RB} / \mathrm{STB}$ \\
\hline $\mathrm{BC}$ & $=$ before closure \\
\hline$b_{N}$ & $=$ intercept, Nolte-Shlyapobersky method, $\mathrm{ML}^{-1} \mathrm{~T}^{-2}$ \\
\hline$b_{M}$ & $=$ intercept, slope, method of Mayerhofer, Economides and Ehlig- \\
\hline & Economides, dimensionless \\
\hline$C_{f D}$ & $=$ dimensionless fracture conductivity \\
\hline $\mathrm{c}_{\mathrm{g}}$ & $=$ gas compressibility, $\mathrm{Lt}^{2} / \mathrm{m}, 1 / \mathrm{psi}$ \\
\hline$C_{L}$ & $=$ leakoff coefficient, $\mathrm{Lt}^{-1 / 2}, \mathrm{ft} / \mathrm{min}^{0.5}$ \\
\hline$c_{0}$ & $=$ oil compressibility, $\mathrm{Lt}^{2} / \mathrm{m}, 1 / \mathrm{psi}$ \\
\hline$c_{t}$ & $=$ total compressibility, $\mathrm{Lt}^{2} / \mathrm{m}, 1 / \mathrm{psi}$ \\
\hline $\mathrm{E}^{\prime}$ & $=$ plane-strain modulus, $\mathrm{m} / \mathrm{Lt}^{2}, \mathrm{psi}$ \\
\hline $\mathrm{E}$ & $=$ Young's modulus, $\mathrm{ML}^{-1} \mathrm{~T}^{-2}$, psi \\
\hline FCT & $=$ Fracture Calibration Test \\
\hline $\mathrm{g}$ & $=\mathrm{g}$-function, dimensionless \\
\hline G & $=\mathrm{G}-$ function, dimensionless \\
\hline $\mathrm{h}$ & $=$ formation thickness, $\mathrm{L}, \mathrm{ft}$ \\
\hline$h_{f}$ & $=$ fracture height, $\mathrm{L}, \mathrm{ft}$ \\
\hline ISIP & $=$ instantaneous shut-in pressure \\
\hline
\end{tabular}


$\mathrm{k}$

KGD $=$ Khristianovitch-Geertsma-De Klerk fracture propagation model

$$
\text { m' }
$$

$\mathrm{m}_{\mathrm{H}}$

$\mathrm{mM}$

$\mathrm{m}(\mathrm{p})$

$\mathrm{p}$

PDA $\quad=$ production data analysis

PDL

PKN

$\mathrm{q}_{\mathrm{F}(\mathrm{TOT})}$

$\mathrm{q}_{\mathrm{i}}$

$\mathrm{q}_{\mathrm{i}(\mathrm{TOT})}$

$\mathrm{q}_{\mathrm{L}(\mathrm{TOT})}$

$\mathrm{r}_{\mathrm{w}}$

$\mathrm{R}_{\mathrm{f}}$

S

S

$\mathrm{S}_{\mathrm{f}}$

$\mathrm{S}_{\mathrm{p}}$

$t_{p}$

=permeability, $\mathrm{L}^{2}$, md

$=$ constant derivative level in a log-log plot

$=$ slope of data on Horner plot, $\mathrm{m} / \mathrm{Lt}^{2}$, psi

=slope, slope, method of Mayerhofer, Economides and Ehlig-

Economides, dimensionless

$=$ real gas potential function

$=$ pressure, $\mathrm{m} / \mathrm{Lt}^{2}, \mathrm{psi}$

$=$ pressure-dependent leakoff

$=$ Perkins-Kern-Nordgren fracture propagation model

$=$ average total leakoff rate during the shut-in, $\mathrm{L}^{3} \mathrm{t}^{-1}, \mathrm{bbl} / \mathrm{min}$

=equivalent injection rate into one wing of the fracture, $\mathrm{L}^{3} \mathrm{t}^{-1}, \mathrm{bbl} / \mathrm{min}$

$=$ surface injection rate during the FCT injection, $\mathrm{L}^{3} \mathrm{t}^{-1}, \mathrm{bbl} / \mathrm{min}$

$=$ average total leakoff rate during the FCT injection, $\mathrm{L}^{3} \mathrm{t}^{-1}, \mathrm{bbl} / \mathrm{min}$

=wellbore radius, $\mathrm{L}, \mathrm{ft}$

$=$ fracture radius, $\mathrm{L}, \mathrm{ft}$

$=$ Laplace transform variable, dimensionless

$=$ skin effect

$=$ fracture stiffness, $\mathrm{m} / \mathrm{L}^{2} \mathrm{t}^{2}, \mathrm{psi} / \mathrm{ft}$

$=$ spurt loss coefficient, L, m

$=$ production time, $\mathrm{t}, \mathrm{hr}$ 

$t_{e} \quad=$ equivalent injection time, $\mathrm{t}, \mathrm{min}$
$v_{\mathrm{L}} \quad=$ leakoff velocity, $\mathrm{Lt}^{-1}, \mathrm{ft} / \mathrm{min}$
$\mathrm{V}_{\mathrm{i}} \quad=$ total injected fluid volume in one fracture wing, $\mathrm{L}^{3}, \mathrm{bbl}$
$\mathrm{V}_{\mathrm{F}} \quad=$ volume at the end of the injection for one fracture wing, $\mathrm{L}^{3}, \mathrm{bbl}$
$\mathrm{V}_{\mathrm{L}} \quad=$ leakoff volume in one fracture wing, $\mathrm{L}^{3}, \mathrm{bbl}$
$\mathrm{w}_{\mathrm{e}} \quad=$ fracture width at the end of the injection, $\mathrm{L}, \mathrm{ft}$
$\mathrm{w}_{\mathrm{L}} \quad=$ fracture lost width, $\mathrm{L}, \mathrm{ft}$
$\mathrm{x}_{\mathrm{f}} \quad=$ fracture half-length, $\mathrm{L}, \mathrm{ft}$
$\mathrm{Z} \quad=$ real gas deviation factor, dimensionless

Greek

$\alpha \quad=$ fracture growth exponent, dimensionless

$\Delta \quad=$ difference, dimensionless

$\phi \quad=$ porosity, dimensionless

$\eta \quad=$ fracture fluid efficiency, $\%$

$\mu \quad=$ viscosity, $\mathrm{m} / \mathrm{Lt}, \mathrm{cp}$

$\mathrm{v} \quad=$ Poisson's ratio, dimensionless

$\tau \quad=$ superposition time, dimensionless

$\theta \quad=$ generic time during fracture injection, $t$, min 


$\begin{array}{ll}\text { Subscript } & \\ \mathrm{c} & =\text { closure } \\ \mathrm{D} & =\text { dimensionless } \\ \mathrm{e} & =\text { end of pumping } \\ \mathrm{hf} & =\text { hydraulic fracture } \\ \mathrm{r} & =\text { reservoir } \\ \mathrm{i} & =\text { injected } \\ \mathrm{n} & =\text { time step }\end{array}$




\section{TABLE OF CONTENTS}

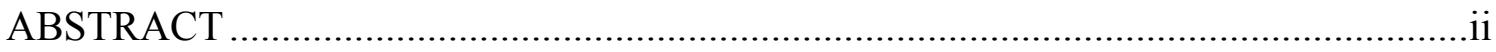

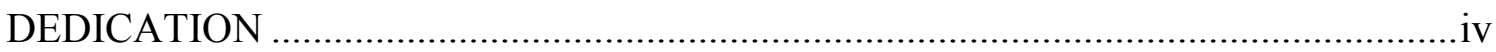

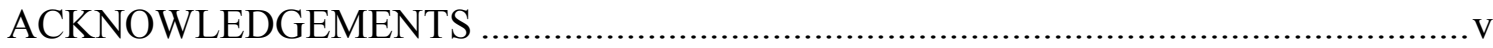

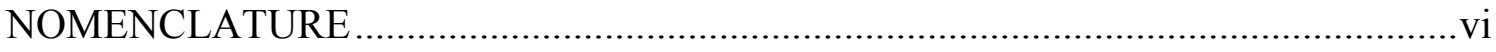

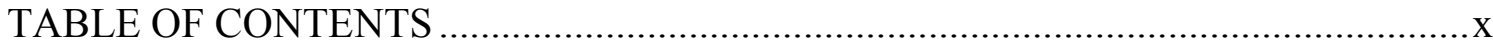

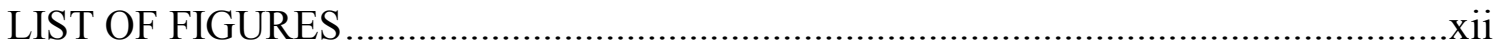

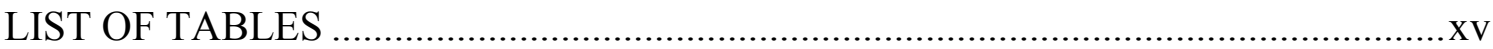

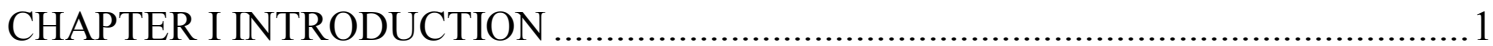

1.1 Overview on Existing Fracture Calibration Test Analysis Models.................2

1.2 Problem Definition and Objectives ...........................................................6

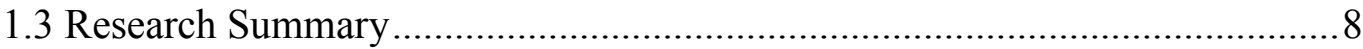

CHAPTER II CLASSICAL FRACTURE CALIBRATION TEST AND

INJECTION/FALLOFF TEST MODELS .............................................................

2.1 Nolte's Fracture Calibration Test Model ...................................................... 9

2.1.1 G-Function Derivative Technique for Before Closure Analysis ........16

2.2 Cylindrical-Source Solution for After Closure Analysis .............................. 18

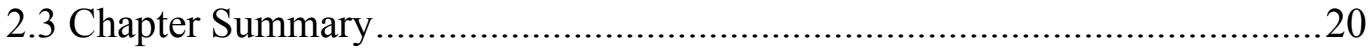

CHAPTER III GLOBAL FRACTURE CALIBRATION TEST MODEL

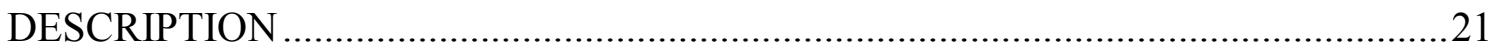

3.1 The Log-Log Diagnostic Plot Representation for Fracture Calibration Test.22

3.2 Theoretical Support for the Before Closure 3/2 Slope in the Log-Log

Diagnostic Plot .26

3.3 Analogies between the G-Function Derivative Technique and the Log-Log Diagnostic Representation for Leakoff Characterization ............................30

3.4 Rationale for a Piecewise Global Fracture Calibration Test ...........................33

3.5 Global Fracture Calibration Test Modeling ............................................. 40

3.5.1 Global Fracture Calibration Test Analysis Model ............................. 41

3.5.2 Global Fracture Calibration Test Design Model................................57 


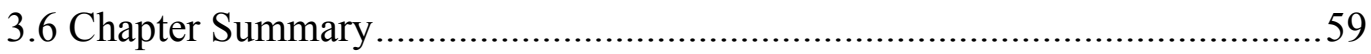

CHAPTER IV FIELD DATA ANALYSIS CASES .............................................. 60

4.1 Cotton Valley Tight Gas Well....................................................................61

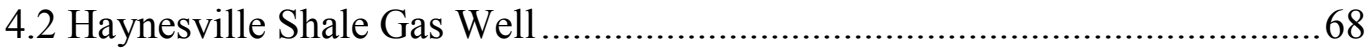

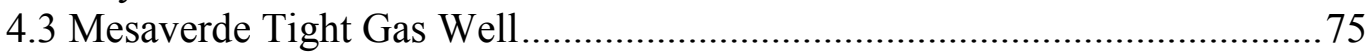

4.4 Optimized Fracture Calibration Test Designs .............................................86

4.4.1 Parametric Studies with the Global Fracture Calibration Test Design

Model Based on the Mesaverde Tight Gas Well Example...............86

4.4.2 Optimized Fracture Calibration Test Design Based on the Cotton

Valley Gas Well and the Haynesville Shale Gas Well Examples ....92

CHAPTER V SUMMARY, CONCLUSIONS AND RECOMMENDATIONS ............97

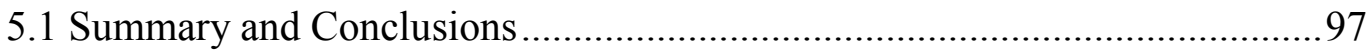

5.2 Recommendations for Future Research .................................................. 98

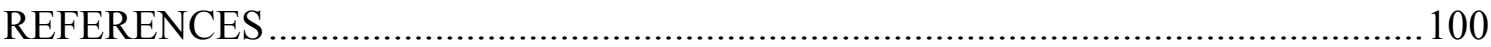




\section{LIST OF FIGURES}

Page

Figure 1.1 Mayerhofer Specialized Plot (from Mayerhofer et al., 1995) ..................4

Figure 2.1 Bottomhole Pressure Falloff That Exhibits Linear Trend with Respect

to the g-Function up to Fracture Closure ............................................. 14

Figure 2.2 Fracture Closure Identification with the Superposition Derivative Method by Barree and Mukherjee (1996) ............................................ 17

Figure 3.1 Schematic Sequence of Events in a FCT ….........................................23

Figure 3.2 Idealization of a FCT Represented in a Log-Log Diagnostic Plot ..........25

Figure 3.3 g-Function and its Derivative Computed for Different Values of $\alpha \ldots \ldots . .27$

Figure 3.4 Example of PDL Behavior (from Xue and Ehlig-Economides, 2013) ....32

Figure 3.5 Example of Fracture Height Recession Behavior (from Xue and Ehlig-Economides, 2013) ...................................................................... 32

Figure 3.6 Pressure Match Analysis Performed on a FCT with the FracCade ${ }^{\text {TM }}$ Hydraulic Fracturing Simulator (from Marongiu-Porcu, 2003)...............34

Figure 3.7 Pressure Match Analysis Performed on a FCT with the MFrac ${ }^{\text {TM }}$ Hydraulic Fracturing Simulator (from Marongiu-Porcu, 2003)...............35

Figure 3.8 Simulation of a FCT with the FracPRO $2011^{\mathrm{TM}}$ Hydraulic Fracturing

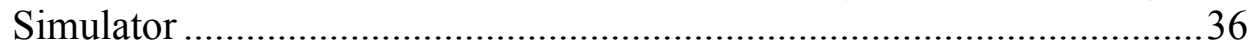

Figure 3.9 Log-Log Representation for the Simulation of a FCT with the FracPRO $2011^{\text {TM }}$ Hydraulic Fracturing Simulator.

Figure 3.10 Log-Log Representation for the Simulation of a FCT Generated and Presented by Ribeiro and Horne (2013) 38

Figure 4.1 East Texas and Northwest Louisiana Stratigraphic Columns (from Thompson et al., 2010)

Figure 4.2 Bottomhole Pressure and Injection Profile for the Cotton Valley FCT ...62

Figure 4.3 Gamma-Ray Log for the Cotton Valley Formation (from U.S. SEC website, 2007)

xii 
Figure 4.4 Log-Log Diagnostic Plot for the Recorded Wellbore Pressure Falloff Data of the Cotton Valley FCT …………………………………….......65

Figure 4.5 Final Global Model Match for the Cotton Valley FCT ............................67

Figure 4.6 Bottomhole Pressure and Injection Profile for the Haynesville FCT .......69

Figure 4.7 Gamma-Ray Log for the Haynesville Shale Formation (from Hammes

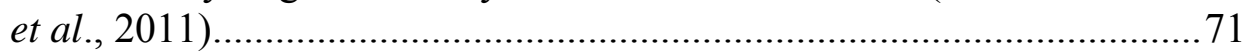

Figure 4.8 Log-Log Diagnostic Plot for the Recorded Wellbore Pressure Falloff Data of the Haynesville FCT ..................................................................72

Figure 4.9 Final Global Model Match for the Haynesville FCT ………………........74

Figure 4.10 Stratigraphic Column Showing the Mesaverde Sandstone (from Dolan Integration Group Website, 2014) ................................................76

Figure 4.11 Bottomhole Pressure and Injection Profile for the Mesaverde FCT ........77

Figure 4.12 Interpretation of the Post-FCT Buildup Performed with Saphir ${ }^{\mathrm{TM}}$ for the Mesaverde Well (from Mohamed, Nasralla, Sayed, MarongiuPorcu, and Ehlig-Economides, 2011)

Figure 4.13 Gamma-Ray Log and Petrophysics Interpretation for the Mesaverde Sandstone (from University of Kansas Center for Research, Inc., 2009)

Figure 4.14 Log-Log Diagnostic Plot for the Recorded Wellbore Pressure Falloff Data of the Mesaverde FCT

Figure 4.15 Log-Log Diagnostic Plot for the Combined Recorded Wellbore Pressure Falloff Data of the Mesaverde FCT and the Subsequent Buildup

Figure 4.16 Global Model Match for the Mesaverde FCT with 2D PKN

Propagation Model

Figure 4.17 Global Model Match for the Mesaverde FCT with 2D Radial

Propagation Model

Figure 4.18 Series of FCT Designs Based on the Mesaverde FCT for Different Values of Reservoir Permeability

Figure 4.19 Series of FCT Designs Based on the Mesaverde FCT for Different Values of Time to Achieve Pseudo-radial Flow 
Figure 4.20 Series of FCT Designs Based on the Mesaverde FCT for Different Values of Leakoff Coefficient .................................................................91

Figure 4.21 Series of FCT Designs Based on the Mesaverde FCT for Different Values of Closure Time........................................................................92

Figure 4.22 Alternative Optimized FCT Design for the Cotton Valley Gas Well

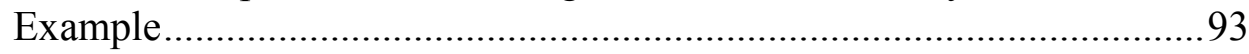

Figure 4.23 Set of Log-log Diagnostic Plots Showing a Global Model Match for the Haynesville FCT and Alternative FCT Designs.................................95 


\section{LIST OF TABLES}

Page

Table 1.1 Equations for the Mayerhofer Method (from Craig and Blasingame, 2006)

Table 2.1 Fracture Stiffness Expressions for 2D Fracture Geometry Models

Table 2.2 Fracture Calibration Test Analysis Model Based on the Shlyapobersky et al. (1998) Assumption

Table 3.1 Complete Set of Parameters Needed for the Generation of the Global FCT Model ............................................................................... 52

Table 4.1 Input Parameters for the Cotton Valley FCT Analysis ..........................64

Table 4.2 Input Parameters for the Haynesville FCT Analysis ............................. 70

Table 4.3 Input Parameters for the Mesaverde FCT Analysis ............................... 77 


\section{CHAPTER I}

\section{INTRODUCTION}

The Fracture Calibration Test, often also referred as "Fracture-Injection/Falloff Test", "Minifrac", "Datafrac" or "DFIT", is generally performed prior to the main hydraulic fracturing treatment to determine critical parameters required for the optimal tuning of the stimulation design, and involves a controlled injection of the same type of fluid to be used for the main treatment (typically without the use of any proppant material), with the intention of inducing formation breakdown and subsequent fracture propagation. Immediately after the shutdown of the pumps, the increased wellbore pressure is then allowed to falloff, properly monitored and recorded by downhole (highly recommended) or surface gauges, and a series of characteristic events is expected to happen.

First, the instantaneous dissipation of all friction loss contributions in the string and in the near-wellbore region as the pressure drops to the instantaneous shut in pressure (ISIP). Second, "before-closure" (BC) behavior, during which the fracture closes while the fracture fluid that contributed to create the fracture is forced to leakoff through the moving fracture walls under the formation minimum stress. Third, what in the vernacular of hydraulic fracturing is called "closure", occurring when the two walls of the created fracture touch each other. Fourth, "after-closure" (AC) behavior, which may include linear flow due to the effectively infinite conductivity fracture, followed by pseudo-radial flow. 


\subsection{Overview on Existing Fracture Calibration Test Analysis Models}

The pioneer and most acclaimed contributor to the pressure falloff analysis is Nolte $(1979 ; 1986 ; 1988)$, who introduced a methodology for the determination of design key parameters, such as the leakoff coefficient, the fracture fluid efficiency, the fracture closure stress and the fracture dimensions, provided the fracture propagation mode is known or assumed to be one of the convenient 2D models including radial, PKN, or KGD, that come from the original work of Khristianovitch and Zheltov (1955), Perkins and Kern (1961) Geertsma and De Klerk (1969) and Nordgren (1972).

Nolte's approach is based on a simple material balance scheme, which allocates the fluid injected for the FCT as either lost into the formation (through the fracture walls) or contributing to the fracture propagation within the reservoir rock. The analysis of the recorded pressure falloff data is possible by means of a special dimensionless function (g-function) which is introduced and explained in the next chapter, and which allows to formally describe the evolution with time of the actual fracture wall surface exposed to fluid leakoff into the formation.

The recent escalation of unconventional hydrocarbons exploitation in tight gas, shale gas and shale oil reservoirs involves heavily the use of hydraulic fracturing (almost always aiming to create transverse fractures from a horizontal well), and the accurate knowledge of reservoir permeability becomes of paramount importance for optimizing the spacing between adjacent transverse fractures (Song et al., 2011) and adjacent horizontal drains.

Furthermore, Economides et al. (2002) introduced the Unified Fracture Design (UFD) approach, which provides the fracture geometry (fracture half-length, fracture width and dimensionless conductivity) that maximizes the well productivity for a given proppant mass to be injected during the treatment, provided that a reliable value for the formation permeability is known as well as the approximate well drainage area. The UFD approach can be applied for each fracture in the multiple transverse fracture horizontal well. 
Pressure buildup analysis represents the standard technique used for reservoir permeability determination, but in very low permeability reservoirs this is difficult or virtually impossible, because without stimulation the formation flow is minimal. BC and (mainly) AC analysis following a fracture calibration test offer a workable mechanism for permeability determination in very low permeability reservoirs. Several methods for determining permeability and other calibration test parameters are found in the literature.

Gu et al. (1993) presented an AC analysis method based on the notion of an "impulse fracture", consisting of a small volume of fluid injected in order to generate a short fracture and a shut-in period afterwards to record pressure falloff. This method relies on the identification of a late time straight trend of the bottom hole recorded pressure versus the reciprocal of the shut in time.

Nolte et al. (1997) provided a complex framework, based on another dimensionless time function ( $F$-function) for AC pressure analysis; they introduced a specialized plot (pressure versus squared values of dimensionless F-function) from which reservoir permeability can be determined from a late time negative unit slope indicating achievement of pseudo-radial flow. Benelkadi and Tiab (2004) criticized Nolte's approach and the difficulties associated in the identification of after-closure linear flow regime and pseudo-radial, and provided a slightly modified approach, still based on Nolte's specialized plot, using in addition a pressure derivative with respect to squared values of the dimensionless F-function for more reliable characterization of linear flow and pseudo-radial flow regimes and determination of reservoir permeability and extrapolated reservoir pressure.

Mayerhofer and Economides (1993; 1997) and Mayerhofer et al. (1995) provided a $\mathrm{BC}$ straight-line technique for determination of reservoir permeability and fracture face resistance by representing the recorded $\mathrm{BC}$ fracture falloff data in a new specialized plot.

They modeled the total pressure gradient from the fracture into the reservoir as the sum of two contributing terms: the pressure drop in the reservoir as effect of an infinite conductivity fracture and the pressure drop across the fracture face. Superposition was used to obtain a transient pressure drop in the reservoir that accounted 
for variable leakoff rates through the fracture faces during injection and shut-in, but the proposed techniques to calculate these leakoff rates require information not realistically available, such as the total pressure difference between the fracture and the reservoir and the evolution of the leakoff process through the increasing fracture area during injection.

For this reason, Valkó and Economides (1999) and Craig and Blasingame (2006) proposed respectively two modified approaches of Mayerhofer technique, both based on the simplified assumption that the leakoff rate during injection is constant. The Mayerhofer method is intended for a reservoir containing a slightly compressible fluid and requires preparing the specialized plot of $y_{n}$ vs. $x_{n}$ (as shown in Figure 1.1) based on the set of equations shown in Table 1.1, which also contains the set of re-casted equations in terms of adjusted pseudo-pressure and adjusted pseudo-time proposed by Craig and Blasingame (2006) to account for compressible reservoir fluid.

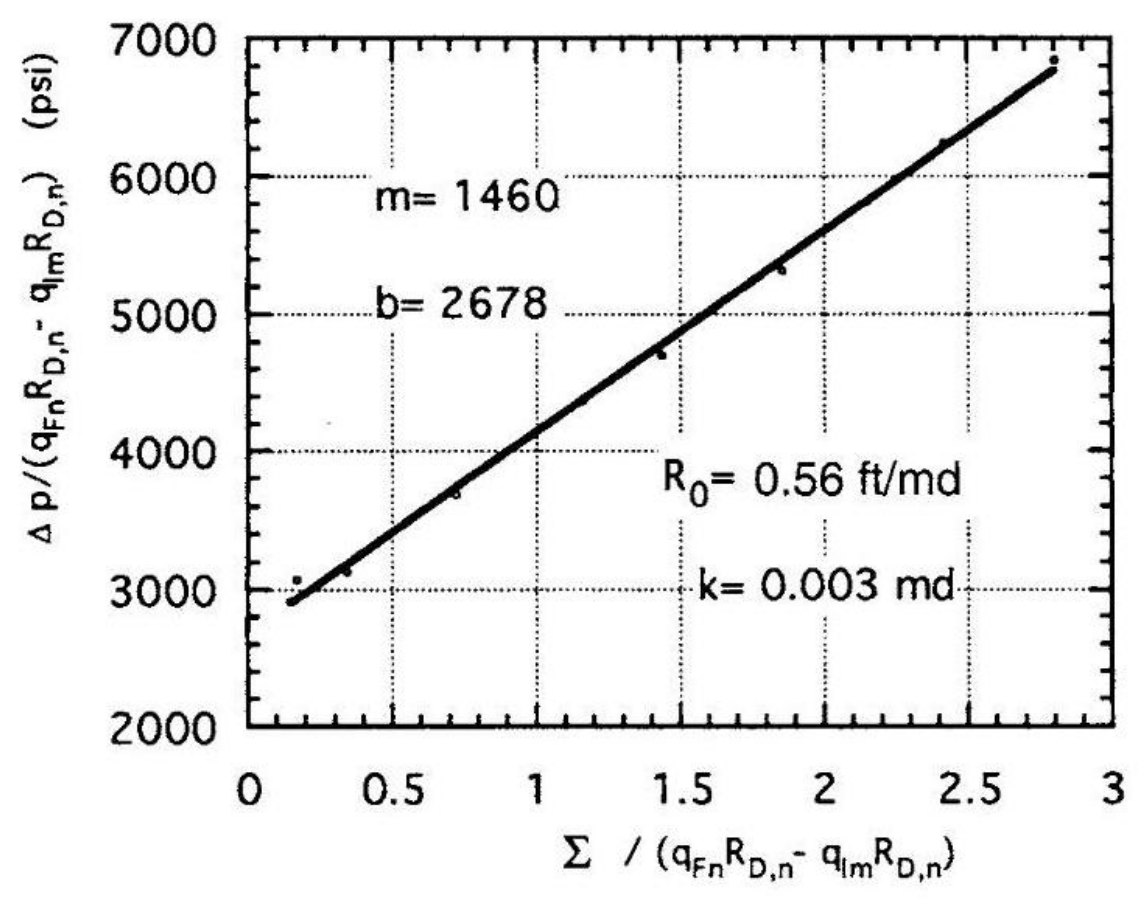

Figure 1.1 Mayerhofer Specialized Plot (from Mayerhofer et al., 1995) 
Table 1.1 Equations for the Mayerhofer Method (from Craig and Blasingame, 2006)

\begin{tabular}{|c|c|c|}
\hline Description & Pressure and Time & $\begin{array}{l}\text { Adjusted Pseudopressure and } \\
\text { Adjusted Pseudotime }\end{array}$ \\
\hline $\begin{array}{l}\text { Basic } \\
\text { Equation }\end{array}$ & $y_{n}=b_{M}+m_{M} x_{n}$ & $\left(y_{a p}\right)_{n}=b_{M}+m_{M}\left(x_{a p}\right)_{n}$ \\
\hline$y_{n}$ or $\left(y_{a p}\right)_{n}$ & $y_{n}=\frac{\left(p_{w}\right)_{n}-p_{i}}{d_{n} \sqrt{t_{n}} \sqrt{t_{n e}}}$ & $\left(y_{a p}\right)_{n}=\frac{\left(p_{a w}\right)_{n}-p_{a i}}{\left(d_{a p}\right)_{n} \sqrt{t_{n}} \sqrt{t_{n e}}}$ \\
\hline$x_{n}$ or $\left(x_{a p}\right)_{n}$ & $x_{n}=\left[\begin{array}{l}\frac{d_{n e+2}}{d_{n}}\left(\frac{t_{n}-t_{n e+1}}{t_{n} t_{n e}}\right)^{1 / 2} \\
+\sum_{j=n e+3}^{n} \frac{\left[d_{j}-d_{j-1}\right]}{d_{n}}\left(\frac{t_{n}-t_{j-1}}{t_{n} t_{n e}}\right)^{1 / 2}\end{array}\right]$ & 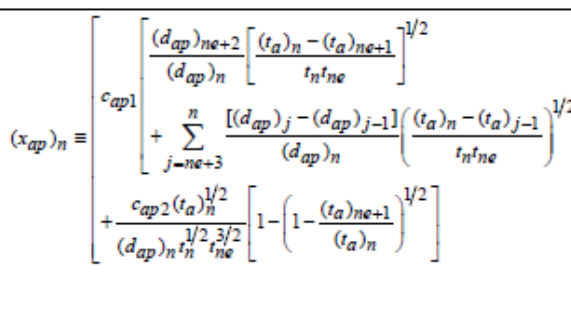 \\
\hline$d_{j}$ or $\left(d_{a p}\right)_{j}$ & $d_{j}=\frac{p_{j-1}-p_{j}}{t_{j}-t_{j-1}}$ & $\left(d_{a p}\right)_{j}=\frac{\left(c_{t}\right)_{i}}{\left(c_{t}\right)_{j}}\left[\frac{\left(p_{a}\right)_{j-1}-\left(p_{a}\right)_{j}}{\left(t_{a}\right)_{j}-\left(t_{a}\right)_{j-1}}\right]$ \\
\hline$c_{1}$ or $c_{a p 1}$ & $c_{1}=\sqrt{\frac{\mu}{\phi c_{t}}}$ & $c_{a p 1}=\sqrt{\frac{\mu_{i}}{\phi c_{t i}}}$ \\
\hline$c_{2}$ or $c_{a p 2}$ & $c_{2}=S_{f} w_{L} \sqrt{\frac{\mu}{\phi c_{t}}}$ & $c_{a p 2}=S_{f} w_{L} \frac{B_{g i}}{\left(B_{g}\right)_{n e}} \sqrt{\frac{\mu_{i}}{\phi c_{t i}}}$ \\
\hline$b_{M}$ & $b_{M}=\frac{1}{2 \pi} \frac{R_{0}}{r_{p} S_{f}} \frac{1}{t_{n e}}$ & $b_{M}=\frac{1}{2 \pi} \frac{R_{0}}{r_{p} S_{f}} \frac{1}{t_{n e}}$ \\
\hline$m_{M}$ & $m_{M}=\frac{1}{\sqrt{\pi}} \frac{1}{r_{p} S_{f} \sqrt{k}}$ & $m_{M}=\frac{1}{\sqrt{\pi}} \frac{1}{r_{p} S_{f} \sqrt{k}}$ \\
\hline
\end{tabular}

Craig and Blasingame (2006) also proposed a novel single-phase fracture injection/falloff model (referred in their publication as "type-curve analysis") that accounts for fracture creation, propagation and closure as storage phenomena; specifically, fracture propagation was modeled as time-dependent storage, while the $\mathrm{BC}$ and $\mathrm{AC}$ pressure falloff were modeled as constant (but possibly different) storages. Since 
each storage coefficient was derived from fundamental principles, the main parameters involved can be then interpreted from the changes observed in these storage coefficients.

Even considering that this approach uses all falloff data from the end of the injection to the after-closure lineal flow and pseudo-radial flow, and thus it seems conceptually more advanced than other $\mathrm{AC}$ analysis techniques, it presents the important shortfall that both the initial reservoir pressure and fracture length must be known a priori, which can introduce macroscopic uncertainties in the calculation of reservoir permeability and transmissibility. Furthermore, the indiscriminate use of several different and somewhat convoluted storage coefficients that lack intuitive physical meaning introduces many levels of abstraction that may make this technique too complex and impractical for the vast majority of the field engineers and hydraulic fracturing professionals.

Soliman et al. (2005) developed an after-closure analysis technique postulating three types of possible after closure flow regimes (i.e., pseudo-bilinear flow, pseudolinear flow and pseudo-radial flow), using analogous considerations to the conventional pressure transient test analysis, as well as a set of adapted equations. Based on such flow regime classification, the Soliman et al. (2005) methodology requires a preliminary determination of closure time, after which the AC portion of the recorded falloff should be used to create a derivative graph by plotting $\log (t \partial p / \partial t)$ vs. $\log \left(t_{p}+\Delta t\right)$. The derivative representation should provide straight trends with slopes corresponding to the expected flow regimes. Then, different specialized plots are to be used for reservoir permeability determination, according to the identified flow regime(s).

\subsection{Problem Definition and Objectives}

All the $\mathrm{BC}$ and $\mathrm{AC}$ analysis methods described above depend on specialized plots that are designed to show a straight line for a portion of the data, from which parameters are determined either from the slope of the line or from its endpoints, and 
there is a risk that apparent straight lines may lead to erroneous results, particularly when the (frequent) absence of late time pseudo-radial flow data is ignored or not recognized at all.

In an effort to avoid this potential source of errors in current $\mathrm{BC}$ and $\mathrm{AC}$ analysis methods, the objective of this research work is to develop a global model for FCT analysis that is capable of simulating the complete $\mathrm{BC}$ and $\mathrm{AC}$ wellbore pressure falloff behavior following a step-rate or constant rate injection test, and to represent all of the falloff behavior on the single log-log diagnostic plot commonly used in the pressure transient analysis literature.

This approach provides a robust and complete assessment tool that allows rigorous matching of the entire fracture pressure falloff response, which in turn allows quantification of all the key fracture parameters (closure stress, closure time, fracture fluid efficiency, leakoff coefficient and estimate of the induced fracture geometry), as well as reservoir permeability and formation pressure, provided that enough time is allowed for the falloff to reach the pseudo-radial flow regime. Both oil and gas reservoirs can be effectively evaluated.

Another major advantage provided by this approach is that the same model can be used for design of the fracture calibration test by providing an injection rate and fluid injected volume that would allow determination of all the involved parameters, including reservoir permeability. This becomes of instrumental importance for tight sands and shale formations, where the challenge is to find an injection volume sufficient to create a suitable fracture, concurrently minimizing the fracture closure time and the time required to observe the $\mathrm{AC}$ transient features that are used for estimation of formation pressure and permeability. For moderate to higher permeability formations the model enables estimation of the total test time including $\mathrm{AC}$ pseudo-radial flow from which estimates of formation pressure and permeability are straightforwardly determined without the need for a pretreatment pressure buildup test. 


\subsection{Research Summary}

Chapter I of this dissertation provided a general introduction to the vast area concerning analysis and design of FCT, as well as an overview on existing interpretation and analysis models. The specific targeted research problem was defined and the objectives presented.

Chapter II presents a detailed description of the derivations, rationale and main features pertinent to the two existing models that are used to formulate the global FCT model subject of this dissertation.

Chapter III introduces and formally defines the global FCT model, presents a detailed analysis of the main assumptions and hypothesis upon which it is formulated, and shows the main algorithms that have been constructed for the use of this model in field data interpretation mode as well as design mode.

Field data are used in Chapter IV to show examples of analysis using the global model, as well as validate it and demonstrate its added value over current interpretation methods. Different ranges of reservoir permeability and features are intentionally selected for these examples, in order to show applicability and issues within different reservoir conditions. Then, the last section discusses how to improve existing design approaches and how to generate optimized FCT designs.

Chapter $\mathrm{V}$ provides a set of conclusions for this research work and establishes some recommendation for possible further research. 


\section{CHAPTER II}

CLASSICAL FRACTURE CALIBRATION TEST AND INJECTION/FALLOFF TEST MODELS

Chapter I presented a broad overview on existing FCT analysis methods and their idiosyncrasies, and then provided the main rationale behind the scope of this research work.

The novel FCT interpretation and design model being presented in this dissertation relies heavily on Nolte's $(1979 ; 1986 ; 1988)$ classical BC analysis approach, and the Van Everdingen and Hurst (1949) cylindrical-source solution for the AC portion of the recorded pressure falloff data. This Chapter presents a detailed description of the derivations and main features pertinent to these models, while Chapter III presents how they are coherently merged into a new fully consistent wellbore pressure falloff model.

\subsection{Nolte's Fracture Calibration Test Model}

Nolte's $(1979 ; 1986 ; 1988)$ approach is based on a material balance scheme, in which the injected fluid for the FCT is allocated either as lost into the formation (leaking off through the fracture walls), or as contributing to the fracture propagation within the reservoir rock:

$$
V_{i}=V_{F}+V_{L}
$$

where $V_{i}$ is the volume of fluid injected into one fracture wing (i.e., half of the total injected fluid volume), $V_{F}$ is the volume obtained at the end of the injection for one fracture wing and $V_{L}$ is the leakoff fluid volume during injection throughout one fracture wing.

Specifically, the leakoff volume is quantified starting from classical Carter's leakoff velocity equation (Howard and Fast, 1957): 


$$
v_{L}=\frac{C_{L}}{\sqrt{t}}
$$

where $C_{L}$ is the leakoff coefficient.

In fact, a differential equation can be written for the leakoff rate thru a generic surface element $d A$ of fracture wall at a generic opening time $\theta$ :

$$
d V_{L}=d A \frac{C_{L}}{\sqrt{t-\theta}} d t
$$

During the fluid injection the fracture surface increases from zero to a final value $A_{e}$ (referring for convenience to only one face of one fracture wing) over the total time of injection $t_{e}$. The fluid leakoff volume is thus expressed as the following double integral with respect to surface area and time:

$$
V_{L e}=2 \int_{0}^{A_{e} \int_{e}} \frac{C_{L}}{\sqrt{t-\theta}} d t d A
$$

Nolte (1979) assumed that (under constant injection rate) the fracture surface evolves according to a power-law,

$$
\frac{A}{A_{e}}=\left(\frac{t}{t_{e}}\right)^{\alpha}
$$

The opening time $\theta$ can now be introduced in this relation and recast in terms of the following dimensionless parameters:

$$
A_{D}=\frac{A}{A_{e}} ; t_{D}=\frac{t}{t_{e}}
$$

Substituting Eqs. 2.5 and 2.6 into Eq. 2.4, the leakoff fluid volume can be written as:

$$
V_{L e}=2 C_{L} A_{e} \sqrt{t_{e}} \int_{0}^{1} \int_{A_{D}^{1 / \alpha}}^{1} \frac{1}{\sqrt{t_{D}-A_{D}^{1 / \alpha}}} d t_{D} d A_{D}
$$


Equation 2.7 contains the definition of the fundamental dimensionless lossvolume function at the end of injection, $g_{0}(\alpha)$, which is intimately related to the opening-time distribution factor (Valkó and Economides, 1995), and is expressed as:

$$
g_{0}(\alpha)=\int_{0}^{1} \int_{A_{D}^{1 / \alpha}}^{1} \frac{1}{\sqrt{t_{D}-A_{D}^{1 / \alpha}}} d t_{D} d A_{D}
$$

This definition can be integrated analytically and expressed in closed form as (Valkó and Economides, 1995):

$$
g_{0}(\alpha)=\frac{\alpha \sqrt{\pi} \Gamma(\alpha)}{\Gamma(1.5+\alpha)}
$$

where $\Gamma(\alpha)$ is the Euler gamma function.

Considering now what happens once the injection has been concluded, during the shut-in period prior to fracture closure, Nolte (1979) postulated that the fracture surface area remains constant $\left(A_{e}\right)$. Then an analogous derivation technique can be followed to quantify the total volume of fluid leaked off throughout the fracture (one wing) wall during the injection period and the shut-in period up to the time $t_{e}+\Delta t$ :

$$
V_{L\left(t_{e}+\Delta t\right)}=2 \int_{0}^{A_{e} t_{e}+\Delta t} \int_{\theta} \frac{C_{L}}{\sqrt{t-\theta}} d t d A
$$

Introducing the dimensionless shut-in time,

$$
\Delta t_{D}=\frac{t-t_{e}}{t_{e}}=\frac{\Delta t}{t_{e}}
$$

and substituting Eq. 2.11 into Eq. 2.10, the total volume of fluid leaked off throughout the fracture (one wing) walls during the injection and shut-in periods can be defined, where analogously to Eq.2.8, the fundamental dimensionless loss-volume function at any shut-in time after the end of injection is:

$$
g_{0}\left(\Delta t_{D}, \alpha\right)=\frac{V_{L\left(t_{e}+\Delta t\right)}}{2 C_{L} A_{e} \sqrt{t_{e}}}=\int_{0}^{1} \int_{A_{D}^{1 / \alpha}}^{1+\Delta t_{D}} \frac{1}{\sqrt{t_{D}-A_{D}^{1 / \alpha}}} d t_{D} d A_{D}
$$


Valkó and Economides (1995) provided an analytical expression for $g_{0}\left(\Delta t_{D}, \alpha\right)$ at any value of $\alpha$, based on the Hypergeometric function ( $F[\mathrm{a}, \mathrm{b}, \mathrm{c}, \mathrm{d}])$, available in form of tables (Abramowitz and Stegun, 1972) and computing algorithms (Wolfram, 1991),

$$
g\left(\Delta t_{D}, \alpha\right)=\frac{4 \alpha \sqrt{\Delta t_{D}}+2 \sqrt{1+\Delta t_{D}} \times F\left[\frac{1}{2}, \alpha ; 1+\alpha ;\left(1+\Delta t_{D}\right)^{-1}\right]}{1+2 \alpha}
$$

where

$$
F[a, b ; c ; z]=\sum_{n=0}^{\infty} \frac{(a)_{n} \cdot(b)_{n}}{(c)_{n}} \frac{d^{n}}{n !}
$$

Approximate equations for the g-function were provided by Nolte (1979) for the two asymptotic values of the fracture growth exponent $\alpha$, i.e. $1 / 2$ (corresponding to the high leakoff lower bound) and 1 (corresponding to the low leakoff upper bound):

$$
\begin{array}{ll}
g\left(\Delta t_{D}\right)=\left(1+\Delta t_{D}\right) \sin ^{-1}\left(1+\Delta t_{D}\right)^{-1 / 2}+\Delta t_{D}{ }^{1 / 2} & \text { for } \alpha=1 / 2 \\
\left.g\left(\Delta t_{D}\right)=\frac{4}{3}\left[\left(1+\Delta t_{D}\right)^{3 / 2}-\Delta t_{D}{ }^{3 / 2}\right)\right] & \text { for } \alpha=1
\end{array}
$$

In Chapter III a particularly convenient use of the upper bound form for $\alpha=1$ is made, which corresponds to negligible leakoff throughout the fracture walls, a condition that is particularly well-suited for low and very low permeability formations such as tight gas sandstones and shale gas.

Valkó and Economides (1995) also suggested values for $\alpha=4 / 5,2 / 3$, and 8/9 to be used for the 2D fracture propagation models PKN, KGD, and radial, respectively.

Finally the concept of "spurt loss", which indicates the fraction of fluid loss in formation at the very early stages of the leakoff process, before formation of a fracture wall filter cake, is introduced to account for fluid loss not described by Carter's leakoff function. With this it is possible to define a material balance relation for one wing of the created fracture at the end of pumping:

$$
V_{F}=V_{i}-2 S_{p} A_{e}-V_{L\left(t_{e}+\Delta t\right)}
$$

where $S_{p}$ is the spurt loss coefficient. 
Considering now that the fracture volume can be expressed as the product of the constant fracture surface area $A_{e}$ and the time-varying average fracture width, Eq. 2.16 can be rearranged as:

$$
\bar{w}_{\left(t_{e}+\Delta t\right)}=\frac{V_{i}}{A_{e}}-2 S_{p}-2 C_{L} \sqrt{t_{e}} g\left(\Delta t_{D}, \alpha\right)
$$

Linear elasticity (Valkó and Economides, 1995) allows relating the (decreasing) average fracture width during the closing process to the fracture net pressure via the socalled fracture stiffness $S_{f}$, which is the elastic energy or "strain energy" created by an

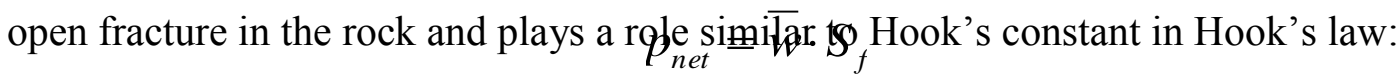

where the fracture stiffness $S_{f}$ is also defined as the reciprocal of the fracture compliance.

Assuming that during closure there is no fluid flow along the fracture and the pressure along the fracture length is constant at each shut-in time, Nolte (1986) presented convenient analytical expressions for the fracture stiffness $S_{f}$ for the 2D fracture propagation models PKN, KGD, and radial, shown in Table 2.1:

Table 2.1 Fracture Stiffness Expressions for 2D Fracture Geometry Models

\begin{tabular}{|c|c|c|c|}
\hline & PKN & KGD & Radial \\
\hline$S_{f}$ & $\frac{2 E^{\prime}}{\pi h_{f}}$ & $\frac{E^{\prime}}{\pi x_{f}}$ & $\frac{3 \pi E^{\prime}}{16 R_{f}}$ \\
\hline
\end{tabular}

The parameter $E^{\prime}$ contained in all relations shown in Table 2.1 is the plane strain modulus, and it is related to the Young's modulus, E, by: 


$$
E^{\prime}=\frac{E}{1-v^{2}}
$$

Combining Eqs. 2.17 and 2.18 provides the final expression for Nolte's BC fracture pressure falloff model:

$$
p_{w}=\left(p_{C}+S_{f} V_{i} / A_{e}-2 S_{f} S_{p}\right)-\left(2 S_{f} C_{L} \sqrt{t_{e}}\right) g\left(\Delta t_{D}, \alpha\right)
$$

Equation 2.20 suggests that, during a FCT falloff, the bottomhole pressure decreases linearly with the g-function until the fracture closes, after which the pressure trend departs from this linear trend, as illustrated in Figure 2.1, and the leakoff coefficient is proportional to the slope, $m_{N}$, of the straight line.

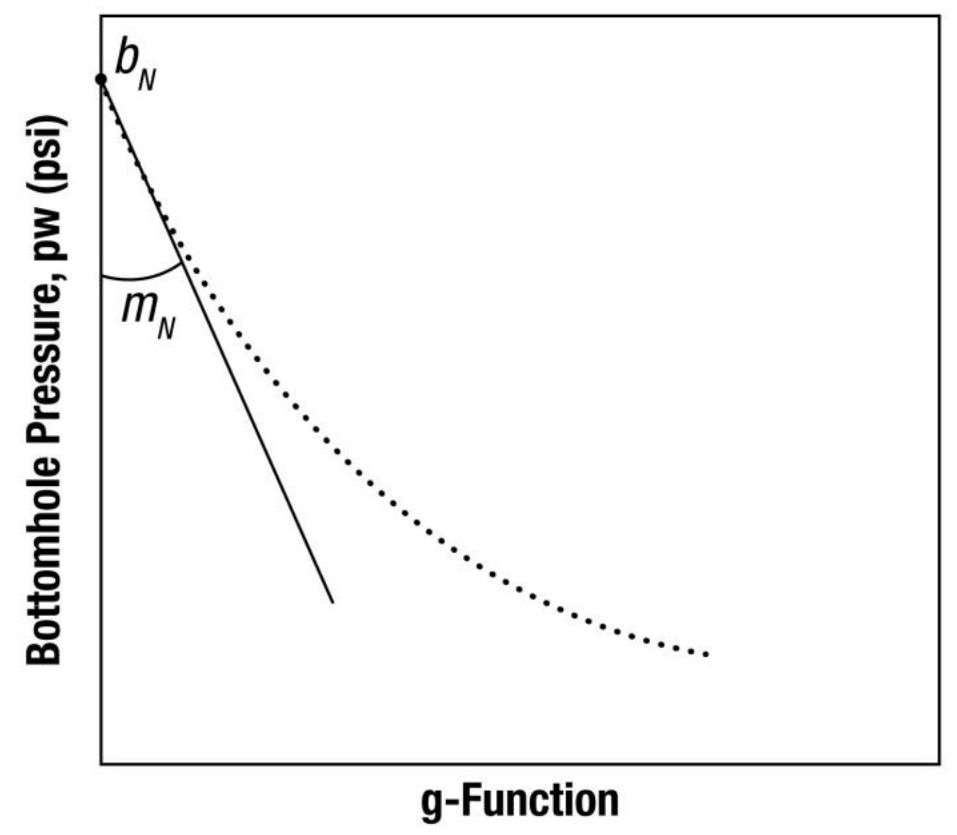

Figure 2.1 Bottomhole Pressure Falloff That Exhibits Linear Trend with Respect to the g-Function up to Fracture Closure

Assuming negligible spurt loss, Shlyapobersky et al. (1998) recast Eq. (2.20) as a straight line of intercept $b_{N}$ and slope $m_{N}$ : 


$$
p_{w}=b_{N}+m_{N} g\left(\Delta t_{D}, \alpha\right)
$$

where

$$
\begin{gathered}
b_{N}=p_{C}+S_{f} V_{i} / A_{e} \\
m_{N}=-2 S_{f} C_{L} \sqrt{t_{e}}
\end{gathered}
$$

Valkó and Economides $(1995 ; 1999)$ presented a global set of equations for the familiar 2D fracture geometry models to calculate the leakoff coefficient, the fracture extent, the fracture average width (at end of pumping) and the fracture fluid efficiency.

All these equations are presented in Table 2.2, and we can notice that $b_{N}$ and $\mathrm{m}_{N}$ are necessary input parameters for the analysis, while different characteristic geometric fracture parameters appear in each equation for each of the 2D fracture propagation models.

Table 2.2 Fracture Calibration Test Analysis Model Based on the Shlyapobersky et al. (1998) Assumption

\begin{tabular}{|c|c|c|c|}
\hline $\begin{array}{c}\text { Leakoff } \\
\text { coefficient, } \\
C_{L}\end{array}$ & $\frac{\pi h_{f}}{4 \sqrt{t_{e}} E^{\prime}}\left(-m_{N}\right)$ & $\frac{\pi x_{f}}{2 \sqrt{t_{e}} E^{\prime}}\left(-m_{N}\right)$ & $\frac{8 R_{f}}{3 \pi \sqrt{t_{e}} E^{\prime}}\left(-m_{N}\right)$ \\
\hline $\begin{array}{c}\text { Fracture } \\
\text { Extent }\end{array}$ & $x_{f}=\frac{2 E^{\prime} V_{i}}{\pi h_{f}^{2}\left(b_{N}-p_{C}\right)}$ & $x_{f}=\sqrt{\frac{E^{\prime} V_{i}}{\pi h_{f}\left(b_{N}-p_{C}\right)}}$ & $R_{f}=\sqrt[3]{\frac{3 E^{\prime} V_{i}}{8\left(b_{N}-p_{C}\right)}}$ \\
\hline $\begin{array}{c}\text { Fracture } \\
\text { Width }\end{array}$ & $\bar{w}_{e}=\frac{V_{i}}{x_{f} h_{f}}-$ & $\bar{w}_{e}=\frac{V_{i}}{x_{f} h_{f}}-$ & $\bar{w}_{e}=\frac{V_{i}}{R_{f}^{2} \frac{\pi}{2}}-$ \\
\hline $\begin{array}{c}\text { Fluid } \\
\text { Efficiency }\end{array}$ & $-2.830 C_{L} \sqrt{t_{e}}$ & $-2.956 C_{L} \sqrt{t_{e}}$ & $-2.754 C_{L} \sqrt{t_{e}}$ \\
\hline $\bar{w}_{e} x_{f} h_{f}$ & $\eta_{i}=\frac{\bar{w}_{e} x_{f} h_{f}}{V_{i}}$ & $\eta_{e}=\frac{\bar{w}_{e} R_{f}^{2} \frac{\pi}{2}}{V_{i}}$ \\
\hline
\end{tabular}




\subsubsection{G-Function Derivative Technique for Before Closure Analysis}

Nolte's FCT model described in Section 2.1 allows fracture closure identification as the point where the pressure data (plotted against the dimensionless loss-volume gfunction at any shut-in time after the end of injection) begin to deviate from the straight line with intercept $b_{N}$ and slope $m_{N}$.

In an attempt to improve the accuracy and reliability of this fracture closure identification technique, Castillo (1987) suggested to use the dimensionless difference G-function (i.e., a representation of the elapsed time after shut-in normalized with respect to the duration of fracture extension) defined as

$$
G\left(\Delta t_{D}, \alpha\right)=\frac{4}{\pi}\left[g\left(\Delta t_{D}, \alpha\right)-g_{0}(\alpha)\right]
$$

and prepare a specialized plot with the derivative $d p_{w} / d G$ of the wellbore pressure falloff data $p_{w}$ versus the G-function itself. Castillo (1987) observed that a constant pressure derivative before fracture closure is an indication of a fracture closing elastically within an homogeneous-acting reservoir, while a fluctuating derivative is an indication of pressure-dependent leakoff.

Barree and Mukherjee (1996) introduced and described the technique that remains the most widely used $\mathrm{BC}$ specialized plot for fracture closure pressure identification, and similarly to Castillo (1987) they suggested to use the dimensionless difference G-function defined in Eq. 2.24 to prepare a specialized plot with the "superposition" derivative $G d p_{w} / d G$ versus the G-function itself.

With this representation, the $\mathrm{BC}$ portion of the superposition derivative data falls along a straight line that passes through the origin, and the fracture closure event is identified by a sharp departure downward from the straight line trend. The upper left quadrant in Figure 2.2 depicts this behavior, while the other three quadrants depict other three possible scenario of abnormal fracture closure behavior introduced and described by Barree and Mukherjee (1996) and Craig et al. (2000). 

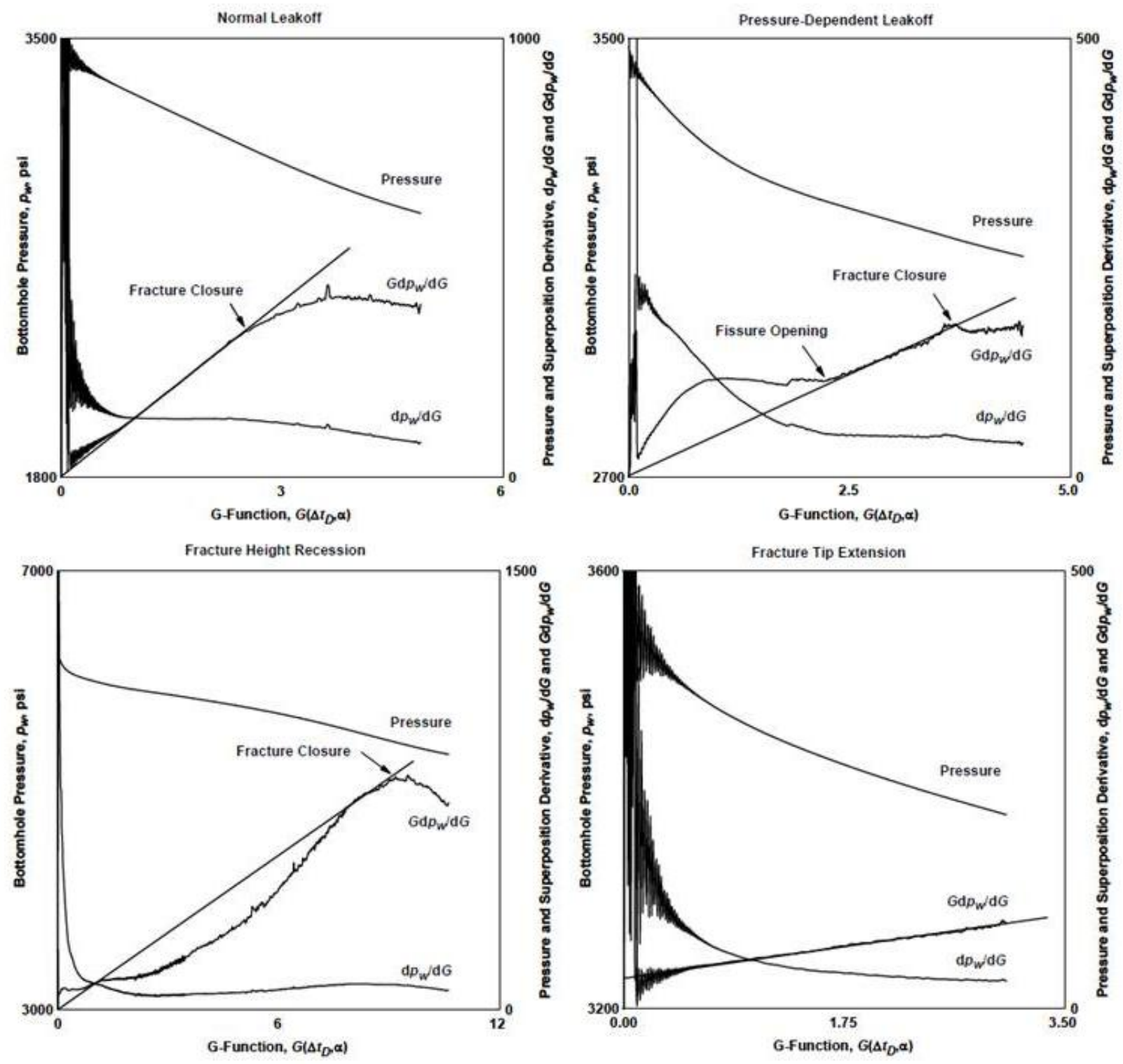

Figure 2.2 Fracture Closure Identification with the Superposition Derivative Method by Barree and Mukherjee (1996)

The upper right quadrant in Figure 2.2 depicts the "pressure-dependent" leakoff (PDL) behavior, which is generally caused by dilated natural fractures and fissures that determine an abnormal higher leakoff and that manifests itself as a distinguishing "hump" of the superposition derivative that lies above the straight line trend that 
connects the origin with the normal leakoff portion of the $\mathrm{BC}$ falloff data. The fracture closure event is identified, as for the normal leakoff case, by the same sharp departure downward from the straight line trend, and an estimate of the fissure opening pressure can be inferred by the end of the hump in the superposition derivative.

The lower left quadrant in Figure 2.2 depicts the "fracture height recession" leakoff behavior, which is generally caused by peripheral zones of the fracture that close faster by virtue of higher closure stress (for instance, after a partial fracture height migration in a adjacent shale layer) that determine an abnormal lower leakoff and that manifests itself as a distinguishing "bottom belly" of the superposition derivative that lies below the straight line trend that connects the origin with the normal leakoff portion of the $\mathrm{BC}$ falloff data. The fracture closure event is still identified, as for the previous cases, by the same sharp departure downward from the straight line trend.

Finally, the lower right quadrant in Figure 2.2 depicts the "fracture Fracture tip extension" leakoff behavior, which generally occurs in very low permeability reservoirs where leakoff throughout fracture walls may be occurring simultaneously to fluid displacement towards the fracture tip, resulting in fracture length extension after the end of the injection. This phenomenon is characterized by superposition derivative data that lie along a straight line trend that extrapolates above the plot origin. As before the fracture closure event is identified by the same sharp departure downward from the straight line trend.

\subsection{Cylindrical-Source Solution for After Closure Analysis}

For constant rate flow to a cylindrical wellbore in an effectively-infinite reservoir, Van Everdingen and Hurst (1949) showed that the Laplace transform of the dimensionless pressure is:

$$
\bar{p}_{w D}=\frac{K_{0}\left(r_{D} \sqrt{s}\right)}{s^{3 / 2} K_{1}(\sqrt{s})}+\frac{S}{s}
$$


where $\mathrm{s}$ is the Laplace transform parameter, $K_{0}$ is the modified Bessel function of the second kind of order zero, $K_{l}$ is the modified Bessel function of the second kind of order one, the dimensionless radius $r_{D}$ is evaluated at the wellbore (thus its value is 1 ), and $\mathrm{S}$ is the dimensionless skin factor that accounts for an additional pressure drop at the wellbore face (that is positive in the presence of near wellbore damage and negative in the presence of near wellbore stimulation).

The dimensionless pressure and dimensionless time are defined (in oilfield units) as, respectively:

$$
\begin{gathered}
p_{w D}=\frac{\left(p_{w}(t)-p_{i}\right) k h}{141.2 q B \mu} \\
t_{D}=\frac{0.0002637 k t}{\phi \mu c_{t} r_{w}^{\prime 2}}
\end{gathered}
$$

where the rates and fluid propertied are defined with the proper units, according to the nature of the reservoir fluid (liquid or gas).

Matthews and Russell (1967) defined the effective wellbore radius, $r_{w}{ }^{\prime}$, as a function of the skin factor:

$$
r_{w}^{\prime}=r_{w} e^{-s}
$$

The presence of an infinite conductivity hydraulic fracture can be conveniently accounted for by using the Prats (1961) finding that relates the effective wellbore radious with the hydraulic fracture half length $x_{f}$ :

$$
r_{w}^{\prime}=\frac{x_{f}}{2}
$$

A less likely presence of a finite conductivity fracture could be modeled, in principle, using Cinco-Ley and Samaniego (1981) classical work based on their equivalent fracture skin, but Chapter III explains why this possibility is not likely, and it is not considered in the model presented in this dissertation.

The Stehfest (1970) algorithm allows a fast and convenient numerical inversion of Eq. 2.25 from the Laplace domain to the time domain. 


\subsection{Chapter Summary}

This chapter has provided the essential elements for generation of a global model for the injection falloff behavior in a fracture calibration test. The next chapter shows how to construct the model for field data interpretation as well as design of proposed FCTs. 


\section{CHAPTER III}

\section{GLOBAL FRACTURE CALIBRATION TEST MODEL DESCRIPTION*}

Chapter II presented a detailed description of the derivations, rationale and main features pertinent to the two existing models that are extensively used in this chapter to construct the global FCT model. This chapter presents a detailed analysis of the main assumptions and hypothesis upon which it is formulated, and shows the main algorithms that have been constructed for the use of this model in field data interpretation mode as well as design mode.

At the moment of writing this dissertation, a bibliography composed by three articles has already presented this global FCT model to the industry ${ }^{*}$. For this reason, the following discussion cites several references of very recent publications by other researches that have already adopted and applied the principles of this research work.

\footnotetext{
"Reproduced with permission of SPE from "Evaluation of After-Closure Analysis Techniques for Tight and Shale Gas Formations" by Mohamed, I.M., Nasralla, R.A., Sayed, M.A., Marongiu-Porcu, M., and Ehlig-Economides, C.A., 2011. SPE-140136-MS presented at the Hydraulic Fracturing Technology Conference, The Woodlands, Texas. Copyright 2011, Society of Petroleum Engineers. Further reproduction prohibited without permission.

"Reproduced with permission of SPE from "Global Model for Fracture Falloff Analysis" by Marongiu-Porcu, M., Ehlig-Economides, C.A., and Economides, M.J., 2011. SPE144028-MS presented at the North American Unconventional Gas Conference and Exhibition, The Woodlands, Texas. Copyright 2011, Society of Petroleum Engineers. Further reproduction prohibited without permission.

*Reproduced with permission of SPE from "Comprehensive Fracture Calibration Test Design" by Marongiu-Porcu, M., Ehlig-Economides, C.A., Retnanto, A., and Economides, M.J., 2014. SPE-168634-MS. presented at the Hydraulic Fracturing Technology Conference, The Woodlands, Texas. Copyright 2014, Society of Petroleum Engineers. Further reproduction prohibited without permission.
} 


\subsection{The Log-Log Diagnostic Plot Representation for Fracture Calibration Test}

Bourdet et al. (1989) introduced the log-log diagnostic plot representation for pressure drawdown and pressure buildup tests, where the pressure differences are calculated, respectively, as differences between the initial reservoir pressure and bottomhole flowing pressures (drawdown tests) or as differences between the bottomhole shut-in pressures and bottomhole flowing pressure at shut-in (buildup tests).

For drawdown tests the pressure derivative, $\Delta p^{\prime}$, is computed numerically with

respect to the natural logarithm of the elapsed flowing time. In turn, the pressure derivative for buildup tests is calculated with respect to the natural logarithm of the superposition time:

$$
\Delta p^{\prime}=\frac{d p}{d \ln \tau}
$$

where $\tau$ is the superposition time function computed rigorously from the complete injection flow rate history (Lee et al., 2003). In case of a single constant rate flow period prior to the shut-in, this superposition time function is reduced to the simple form

$$
\tau=\frac{t_{p}+\Delta t}{\Delta t}
$$

where $t_{p}$ is the production time. This $t_{p}$ is also referred as "material balance time" (Blasingame and Lee, 1986) when variable production rates before shut-in are accounted by Horner's approximation (Horner, 1967), in which $t_{p}$ is calculated as the cumulative hydrocarbon production divided by the last production rate.

The first major tenet of this research work has been the realization that FCTs can also be represented and analyzed using this methodology. In fact, Eqs. 3.1 and 3.2 are still valid, even thou the production time is now replaced by an injection time (or equivalent material balance injection time) $t_{e}$.

Figure 3.1 shows the typical schematic sequence of events in a FCT. First, the injection of the same type of fluid to be used for the main treatment at constant injection rate pressurizes the formation until the rock breakdown is achieved. After breakdown, 
the fracture propagates following a certain pattern until the pumps are shut down. At this point the wellbore pressure begins to decline. First may appear an instantaneous pressure drop due to friction losses, down to the value labeled as ISIP (Instantaneous Shut-In Pressure), as in Figure 3.1. Visually, this pressure drop may be large if the pressure data acquisition is performed at the wellhead. When bottomhole pressure is recorded, this instantaneous pressure drop would be of much lower magnitude, mainly due to the dissipation of the pumping friction losses in the near wellbore area. As shown in Figure 3.1, the ISIP is being systematically used as reference pressure for the calculation of the wellbore pressure difference, $\Delta p$. The closure event is marked in the figure and labeled as $p_{c}$, even though it is basically never apparent from this wellbore pressure falloff data representation.

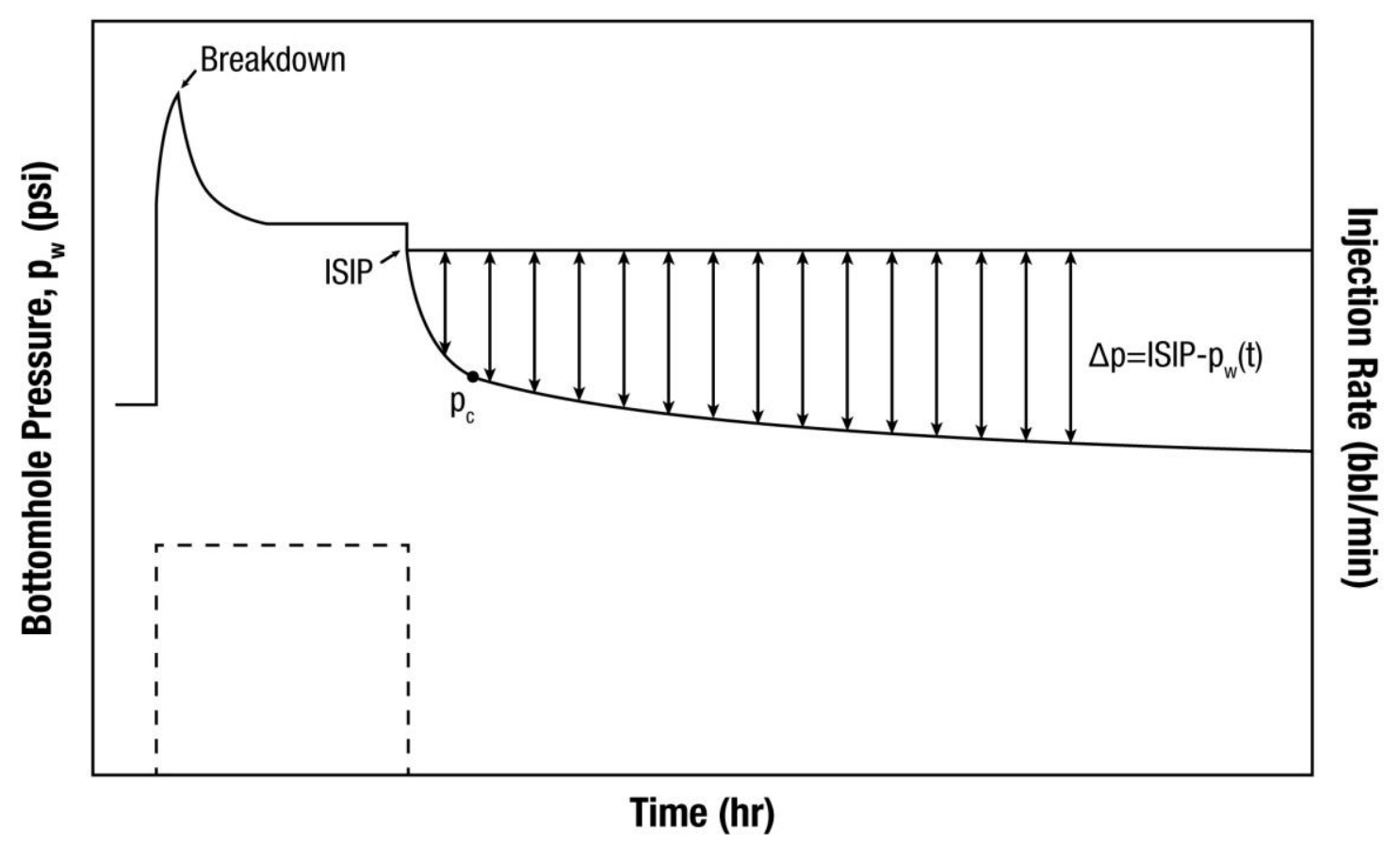

Figure 3.1 Schematic Sequence of Events in a FCT 
Figure 3.2 shows a schematic idealization of an FCT represented on a log-log diagnostic plot. The wellbore pressure derivative exhibits a characteristic progression of flow regimes, which transition from one another in a generally smooth and regular way.

This idealized behavior has actually been observed and identified systematically in a vast variety of FCT field case data processing and assessment during the early stages of this research work, on a large pool of lithology, reservoir permeability and well configuration scenarios. Mohamed, Nasralla, Sayed, Marongiu-Porcu, and EhligEconomides (2011) presented the first article that was published to present these qualitative findings.

This succession of events and flow regimes includes:

- A newly identified elastic closure-dominated flow regime (3/2 slope).

- The main fracture closure event (identified by the departure of the wellbore pressure derivative from the $3 / 2$ slope trend).

- An AC flow regime that, in principle, could be either a linear or bilinear flow, consistent with the AC flow regime descriptions provided by, among others, Soliman et al. (2005), Craig and Blasingame (2006), and Barree et al. (2009). Nevertheless, the analysis of the vast variety of FCT field case data performed within this research work suggested excluding with high confidence the possibility of encountering $\mathrm{AC}$ bilinear flow, restricting the anticipation for $\mathrm{AC}$ flow regime in FCTs of only formation-linear flow ( $1 / 2$ slope).

- A late-time infinite-acting pseudo-radial flow (0 slope). 


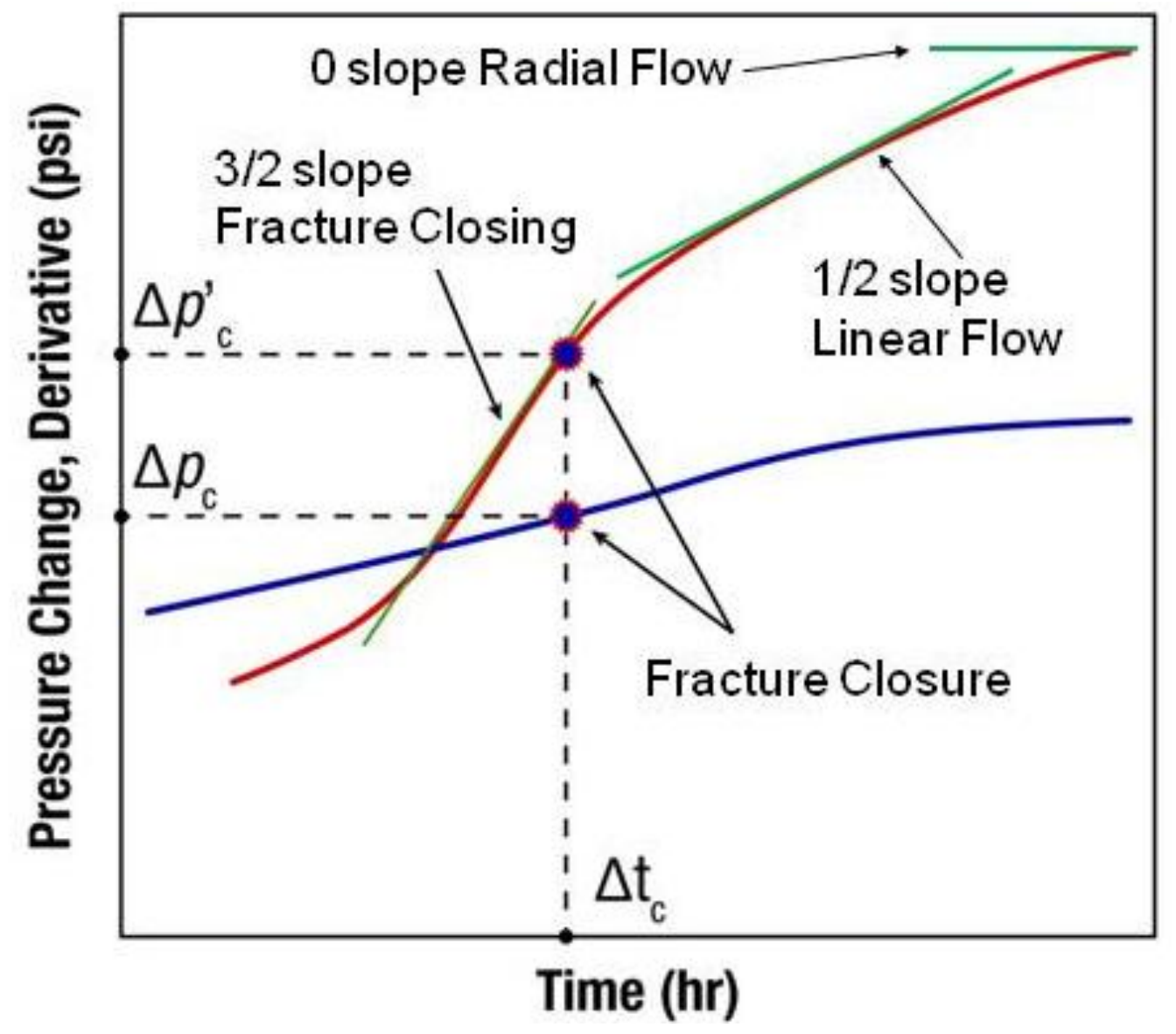

Figure 3.2 Idealization of a FCT Represented in a Log-Log Diagnostic Plot

The FCT representation in a log-log diagnostic plot is of paramount importance for the technique presented in this dissertation, not only for the manifest advantages provided for the simulation methodology and overall visualization of the global $\mathrm{BC}+$ $\mathrm{AC}$ wellbore pressure falloff (next paragraphs discuss this statement in detail), but also for providing a new reliable, consistent and very easy method for fracture closure pressure identification. In fact, the analysis of all the numerous FCT field case data performed within this research work found compelling agreement between this new technique and the established superposition derivative method by Barree and Mukherjee (1996) discussed in Section 2.1.1. 
Chapter IV supports these findings by showing different FCT field case data interpretations with both techniques for comparison.

\subsection{Theoretical Support for the Before Closure 3/2 Slope in the Log-Log Diagnostic Plot}

The origin and the consistent manifestation of the 3/2 slope deserve some further discussion. Recalling what Nolte (1979) indicated as the two asymptotic expressions (2.16 a-b) for the g-function $g\left(\Delta t_{D}\right)$ for the high leakoff lower bound and the low leakoff upper bound, it is evident that these two expressions provide the same values as by computing the g-function rigorously using Eq. 2.14 for $\alpha=1$ and $1 / 2$, respectively.

In Figure 3.3 the functions in Eq.s 2.16-a and 2.16-b are graphed together, along with g-function curves computed for $\alpha=4 / 5,2 / 3$, and $8 / 9$ corresponding to PKN, KGD, and radial fracture geometries, respectively. Figure 3.3 also shows the logarithmic Bourdet derivatives computed with respect to $\Delta t_{D}$ for the two bound limiting forms; it is obvious that these derivative trends are essentially identical. Furthermore, and more relevant, for dimensionless time $\Delta t_{D}$ less than 1 , the derivative slope is 1 , while for dimensionless time $\Delta t_{D}$ greater than 10 the derivative slope turns to $3 / 2$.

Although Eq.s 2.16-a and 2.16-b for the g-function bracket the entire ideal leakoff range, independently by the actual reservoir permeability value, it is relevant considering that operators generally use additives in the fracturing fluid to reduce leakoff in high permeability reservoirs in order to maintain efficiency values of at least $40 \%$ or higher, in both the FCT and actual fracturing treatment. If this is not done, it is unlikely that a controllable fracture without screen out risk can be created.

If an apparent closure event appears when the log-log derivative has unit slope or slope between 1 and $3 / 2$, a check whether the dimensionless closure time is less than 10 
indicates whether the behavior before the apparent closure event is consistent with elastic closure (Nolte g-function) behavior.

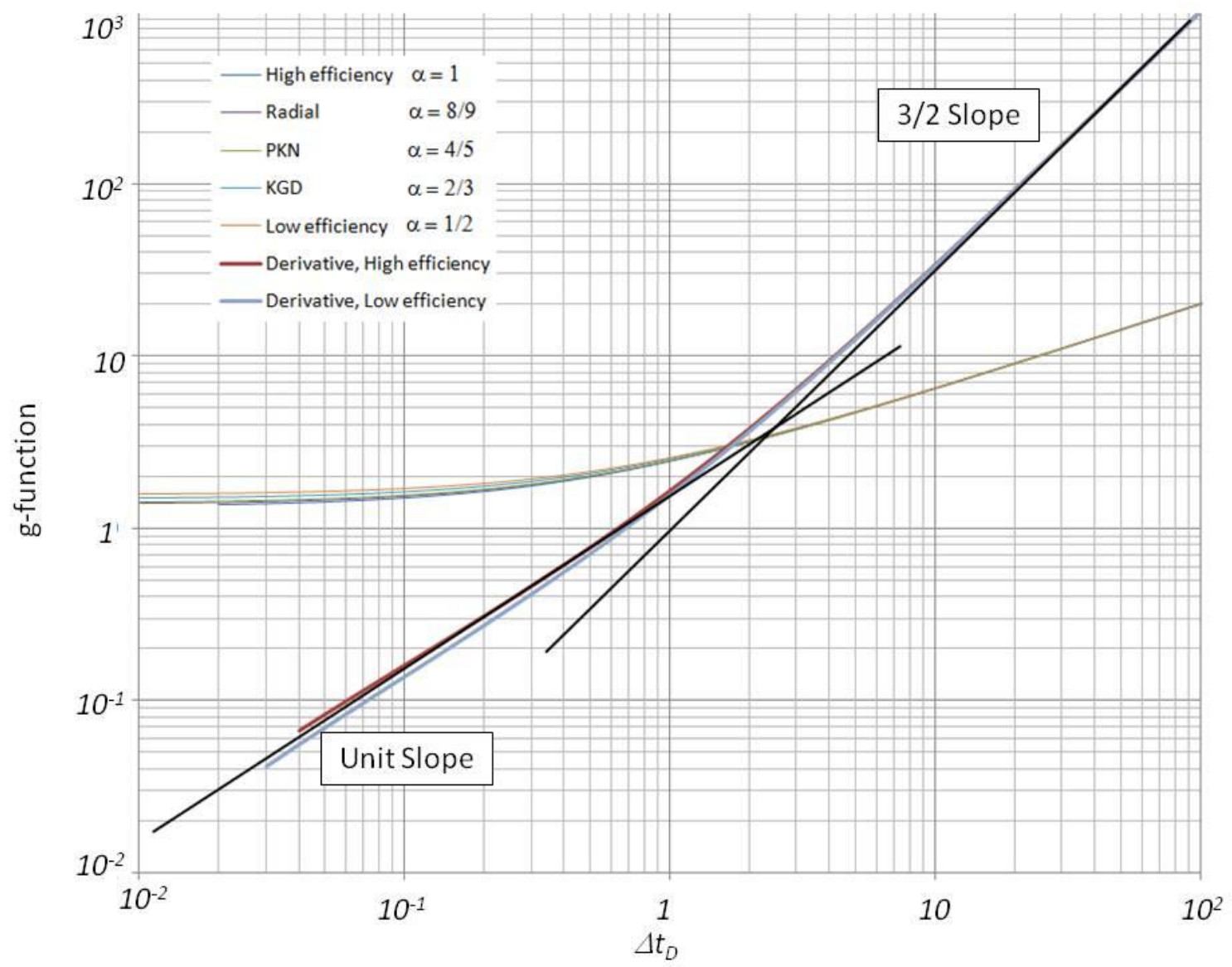

Figure 3.3 g-Function and its Derivative Computed for Different Values of $\alpha$

Seeking for an additional evidence for the origin and the consistent manifestation of the $3 / 2$ slope for the pressure superposition derivative on the log-log representation of Nolte's (1979) leakoff, it is then convenient to start from Eq. 2.22 and substituting into it the low leakoff upper bound approximation for the g-function (Eq. 2.16-b):

$$
\left.p_{w}=b_{N}+m_{N} \frac{4}{3}\left[\left(1+\Delta t_{D}\right)^{3 / 2}-\Delta t_{D}^{3 / 2}\right)\right]
$$


In order to determine an analytical equation for the pressure superposition derivative $\frac{d \Delta P}{d \ln \tau}$, lets proceed with a preliminary computation of the derivative $\frac{d \Delta p}{d \Delta t_{D}}$ :

$$
\left.\frac{d \Delta p}{d \Delta t_{D}}=2 m_{N}\left[\left(1+\Delta t_{D}\right)^{1 / 2}-\Delta t_{D}^{1 / 2}\right)\right]
$$

Recalling then the definition of the superposition time function $\tau$ adapted to the notation used for a wellbore pressure falloff (Eq. 3.2), and the dimensionless shut-in time (Eq. 2.12) trivial substitution, manipulation and derivation provides:

$$
\begin{aligned}
& \tau=\frac{t_{e}+\Delta t_{D}}{\Delta t_{D}}=\frac{1}{\Delta t_{D}}+1 \\
& d \tau=-\frac{1}{\left(\Delta t_{D}\right)^{2}} d \Delta t_{D}
\end{aligned}
$$

Analytical expression for the pressure superposition derivative $\frac{d \Delta P}{d \ln \tau}$ can now be written as:

$$
\frac{d \Delta P}{d \ln \tau}=\tau \frac{d \Delta P}{d \tau}=-\left(\frac{1}{\Delta t_{D}}+1\right) \cdot\left(\Delta t_{D}\right)^{2} \cdot \frac{d \Delta P}{d \Delta t_{D}}=-\left[\Delta t_{D}+\left(\Delta t_{D}\right)^{2}\right] \cdot \frac{d \Delta P}{d \Delta t_{D}}
$$

Thus, replacing Eq. 3.4 into Eq. 3.7 provides:

$$
\begin{aligned}
& \left.\frac{d \Delta P}{d \ln \tau}=-2 m_{N} \cdot \Delta t_{D} \cdot\left[1+\left(\Delta t_{D}\right)\right] \cdot\left[\left(1+\Delta t_{D}\right)^{1 / 2}-\Delta t_{D}{ }^{1 / 2}\right)\right]= \\
& =-2 m_{N}\left[\Delta t_{D} \cdot\left(1+\Delta t_{D}\right)^{3 / 2}-\left(\Delta t_{D}\right)^{3 / 2} \cdot\left(1+\Delta t_{D}\right)\right]= \\
& =-2 m_{N}\left[\Delta t_{D} \cdot\left(1+\Delta t_{D}\right)^{3 / 2}-\left(\Delta t_{D}\right)^{3 / 2}-\left(\Delta t_{D}\right)^{5 / 2}\right]=
\end{aligned}
$$

The function contained inside the parentheses can at this point be studied for the two limiting cases, i.e. for dimensionless time $\Delta t_{D}$ less than 1 (approaching 0 ), and for dimensionless time $\Delta t_{D}$ greater than 10 (approaching infinite). Considering the binomial expansion rule (Abramowitz and Stegun, 1972), 


$$
(a+b)^{n}=\sum_{k=0}^{n} \frac{n !}{(n-k) ! k !} a^{n-k} b^{k}
$$

it is convenient to expand the group $\left(1+\Delta t_{D}\right)^{3 / 2}$ and truncating the series at the second term:

$$
\left(1+\Delta t_{D}\right)^{3 / 2} \cong 1+\frac{3}{2} \Delta t_{D}
$$

Thus, the limit for $\frac{d \Delta P}{d \ln \tau}$ as $\Delta t_{D}$ approaches 0 provides:

$$
\frac{d \Delta P}{d \ln \tau}=-2 m_{N} \cdot \Delta t_{D}
$$

Please recall Eq. 2.24, where $m_{N}$ is defined as negative parameter, so that the sign of $\frac{d \Delta P}{d \ln \tau}$ is globally positive.

Seeking now a solution for the limit for $\frac{d \Delta P}{d \ln \tau}$ as $\Delta t_{D}$ approaches infinite, it is convenient to preliminarily manipulate the group $\left(\Delta t_{D}\right) \cdot\left(1+\Delta t_{D}\right)^{3 / 2}$ as:

$$
\begin{aligned}
& \left(\Delta t_{D}\right) \cdot\left(1+\Delta t_{D}\right)^{3 / 2} \cdot \frac{\left(\Delta t_{D}\right)^{3 / 2}}{\left(\Delta t_{D}\right)^{3 / 2}}=\left(\Delta t_{D}\right)^{5 / 2} \cdot \frac{\left(1+\Delta t_{D}\right)^{3 / 2}}{\left(\Delta t_{D}\right)^{3 / 2}}=\left(\Delta t_{D}\right)^{5 / 2} \cdot\left(1+\frac{1}{\Delta t_{D}}\right)^{3 / 2} \\
& \text { Then, expanding the group }\left(1+\frac{1}{\Delta t_{D}}\right)^{3 / 2} \text { using the rule in Eq. } 3.9 \text { and truncating }
\end{aligned}
$$
the series at the second term:

$$
\left(1+\frac{1}{\Delta t_{D}}\right)^{3 / 2} \cong 1+\frac{3}{2} \frac{1}{\Delta t_{D}}
$$

Thus, replacing Eqs. 3.12 and 3.12 into Eq. 3.8, for any significantly large $\Delta t_{D}$, provides: 


$$
\begin{aligned}
& \frac{d \Delta P}{d \ln \tau}=-2 m_{N}\left[\left(\Delta t_{D}\right)^{5 / 2} \cdot\left(1+\frac{1}{\Delta t_{D}}\right)^{3 / 2}-\left(\Delta t_{D}\right)^{3 / 2}-\left(\Delta t_{D}\right)^{5 / 2}\right]= \\
& =-2 m_{N}\left[\left(\Delta t_{D}\right)^{5 / 2} \cdot\left(1+\frac{3}{2 \Delta t_{D}}\right)-\left(\Delta t_{D}\right)^{3 / 2}-\left(\Delta t_{D}\right)^{5 / 2}\right]= \\
& =-2 m_{N}\left[\left(\Delta t_{D}\right)^{5 / 2}+\frac{3}{2}\left(\Delta t_{D}\right)^{3 / 2}-\left(\Delta t_{D}\right)^{3 / 2}-\left(\Delta t_{D}\right)^{5 / 2}\right]= \\
& =-2 m_{N}\left[\left(\Delta t_{D}\right)^{5 / 2}+\frac{3}{2}\left(\Delta t_{D}\right)^{3 / 2}-\left(\Delta t_{D}\right)^{3 / 2}-\left(\Delta t_{D}\right)^{5 / 2}\right]= \\
& =-m_{N}\left(\Delta t_{D}\right)^{3 / 2}
\end{aligned}
$$

Also in this case, please recall Eq. 2.24, where $m_{N}$ is defined as negative parameter, so that the sign of $\frac{d \Delta P}{d \ln \tau}$ is globally positive.

\subsection{Analogies between the G-Function Derivative Technique and the Log-Log Diagnostic Representation for Leakoff Characterization}

In Chapter II the Barree and Mukherjee (1996) characterization for the "pressuredependent" leakoff (PDL) behavior and the "fracture height recession" leakoff behavior was introduced and described, relying on the diagnostic plot that involves construction of the "superposition" derivative $G d p_{w} / d G$ versus the G-function itself.

Xue and Ehlig-Economides (2013) showed that these complex leakoff behaviors can all be identified on the log-log diagnostic plot as well.

They observed that when the logarithmic derivative of the wellbore pressure falloff data lies above the normal leakoff $3 / 2$ slope trendline, the corresponding "superposition" derivative $G d p_{w} / d G$ exhibits the characteristic "hump" above the straight line, as typical PDL. The end of PDL corresponds to critical fissure opening pressure also in the log-log diagnostic plot representation, where the logarithmic derivative smoothly merges the elastic closure $3 / 2$ slope trendline. 
Furthermore, they observed that when the logarithmic derivative of the wellbore pressure falloff data lies below the elastic closure 3/2 slope trendline, the corresponding "superposition" derivative $G d p_{w} / d G$ exhibits the distinguishing "bottom belly" of the superposition derivative that lies below the straight line trend that connects the origin with the normal leakoff portion of the $\mathrm{BC}$ falloff data, as typical fracture height recession.

Figure 3.4 shows a FCT example from Xue and Ehlig-Economides (2013), where the wellbore pressure falloff analysis is performed with the G-function plot representation (A) and with the log-log diagnostic plot (B). They showed that the fracture closure time is identified on the G-function plot for $G_{c}=13.33$, which corresponds to closure time $=5.15 \mathrm{hr}$ and a closure pressure value of $11,313 \mathrm{psi}$; the departure from the elastic closure $3 / 2$ slope trendline provide essentially the same pressure closure characterization. Furthermore, notice the described characteristic PDL trend of the "superposition" derivative $G d p_{w} / d G$ and the logarithmic derivative.

Figure 3.5 shows another FCT example from Xue and Ehlig-Economides (2013); this time they show a fracture height regression characteristic behavior interpreted with the G-function plot representation (A) and with the log-log diagnostic plot (B). Neither the G-function nor the log-log diagnostic plot show a clear straight trendline, indicating a particularly severe fracture height regression effect. Consequently, closure pressure identification must be performed relying on a small portion of the $\mathrm{BC}$ data, indeed effectively like a tangent. 


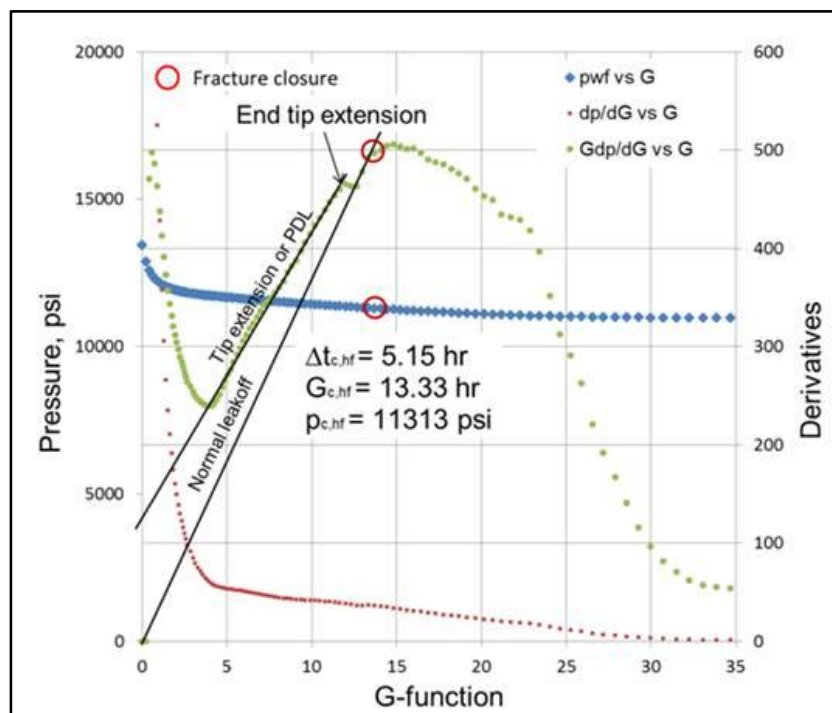

(A)

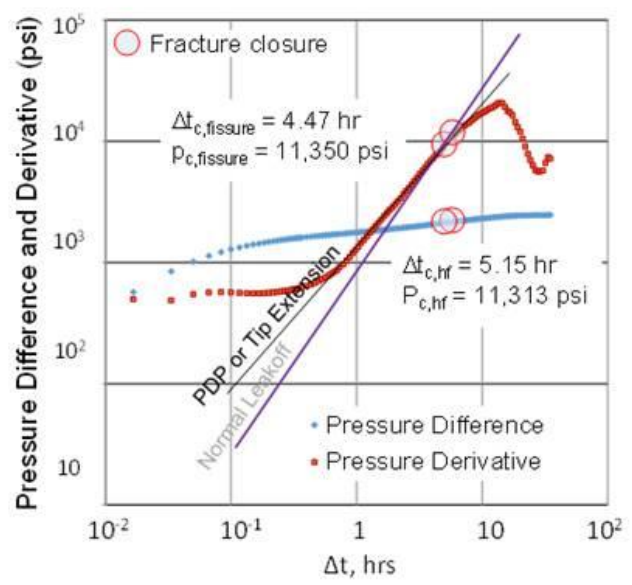

(B)

Figure 3.4 Example of PDL Behavior (from Xue and Ehlig-Economides, 2013)

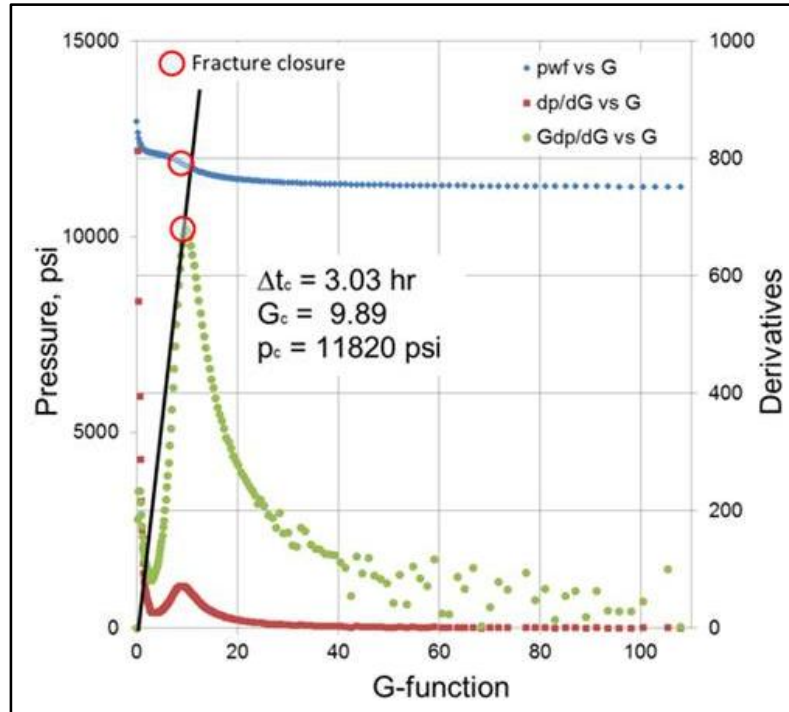

(A)

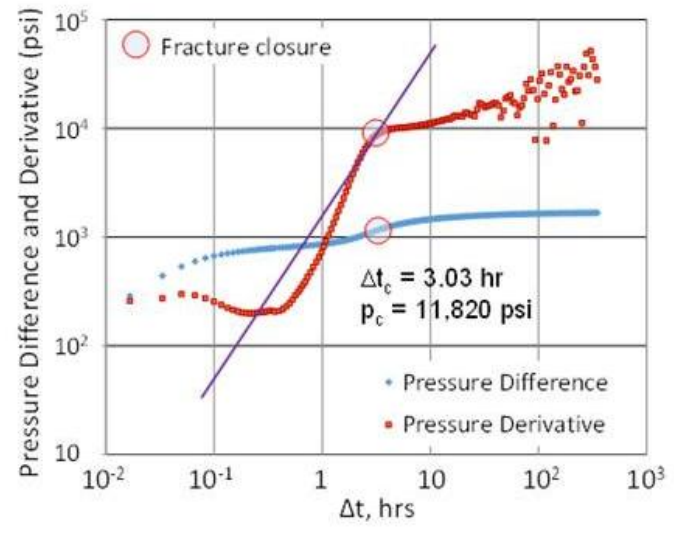

(B)

Figure 3.5 Example of Fracture Height Recession Behavior (from Xue and EhligEconomides, 2013) 
The logarithmic derivative in the log-log diagnostic plot (B) shows a steep upward trend, and closure time and pressure are being picked when the tangent to the derivative has a slope of $3 / 2$. As such, in this case the closure shut-in time is identified at $\Delta \mathrm{t}=3 \mathrm{~h}$ and the hydraulic fracture closure pressure, $\mathrm{p}_{\mathrm{c}}=11,820 \mathrm{psi}$, which are in excellent agreement with the analysis performed with the G-function plot representation (A).

\subsection{Rationale for a Piecewise Global Fracture Calibration Test}

The interest in assessing the possibility of using Bourdet et al. (1989) log-log diagnostic plot representation for visualizing the wellbore pressure falloff in FCTs, as well as developing an alternative fracture closure pressure identification technique, were the two initial motivations for the early stages of this research work.

Shortly after realizing that the Bourdet et al. (1989) log-log representation was not just possible, but actually convenient for flow regime identification and closure pressure identification (as published in Mohamed, Nasralla, Sayed, Marongiu-Porcu, and Ehlig-Economides, 2011), the research interest expanded rapidly into the posibility of generating synthetic models that can reproduce the observed $\mathrm{BC}$ and $\mathrm{AC}$ behaviors, becoming thus able to run pressure match analysis for the FCT wellbore pressure falloff, essentially mimicking the logic of all the modern commercial pressure transient analysis software packages, like Interpret ${ }^{\mathrm{TM}}$, Topaz ${ }^{\mathrm{TM}}$, Fekete ${ }^{\mathrm{TM}}$, and so on.

Apart from the Craig and Blasingame (2006) fracture injection/falloff model (previously described in Chapter I) that (questionably) accounts for fracture creation, propagation and closure as solely storage phenomena and appears to be too complex and impractical for the vast majority of the field engineers and hydraulic fracturing professionals, the industry is currently not offering a global FCT model that can be used to interpret and simulate the global $\mathrm{BC}+\mathrm{AC}$ sequence of wellbore pressure falloff.

For instance, Marongiu-Porcu (2003) presented a vast comparative assessment between two commercial hydraulic fracturing simulation packages, FracCade ${ }^{\mathrm{TM}}$ and $\mathrm{MFrac}^{\mathrm{TM}}$, where, among other findings, it was pointed out the complete absence of an 
AC model for the wellbore pressure falloff once the simulation achieved fracture closure. Figures 3.6 and 3.7, reproduced from Marongiu-Porcu (2003), show two obvious examples of this negative remark: two pressure match analyses are performed on two FCTs from high-permeability unconsolidated sandstone gas wells from offshore Adriatic Sea (East Italy), using respectively the FracCade ${ }^{\mathrm{TM}}$ and the MFrac ${ }^{\mathrm{TM}}$, and in both cases it appear obvious the abrupt truncation of the wellbore pressure falloff simulation immediately beyond the fracture closure and the absence of a simulated AC wellbore pressure falloff portion.

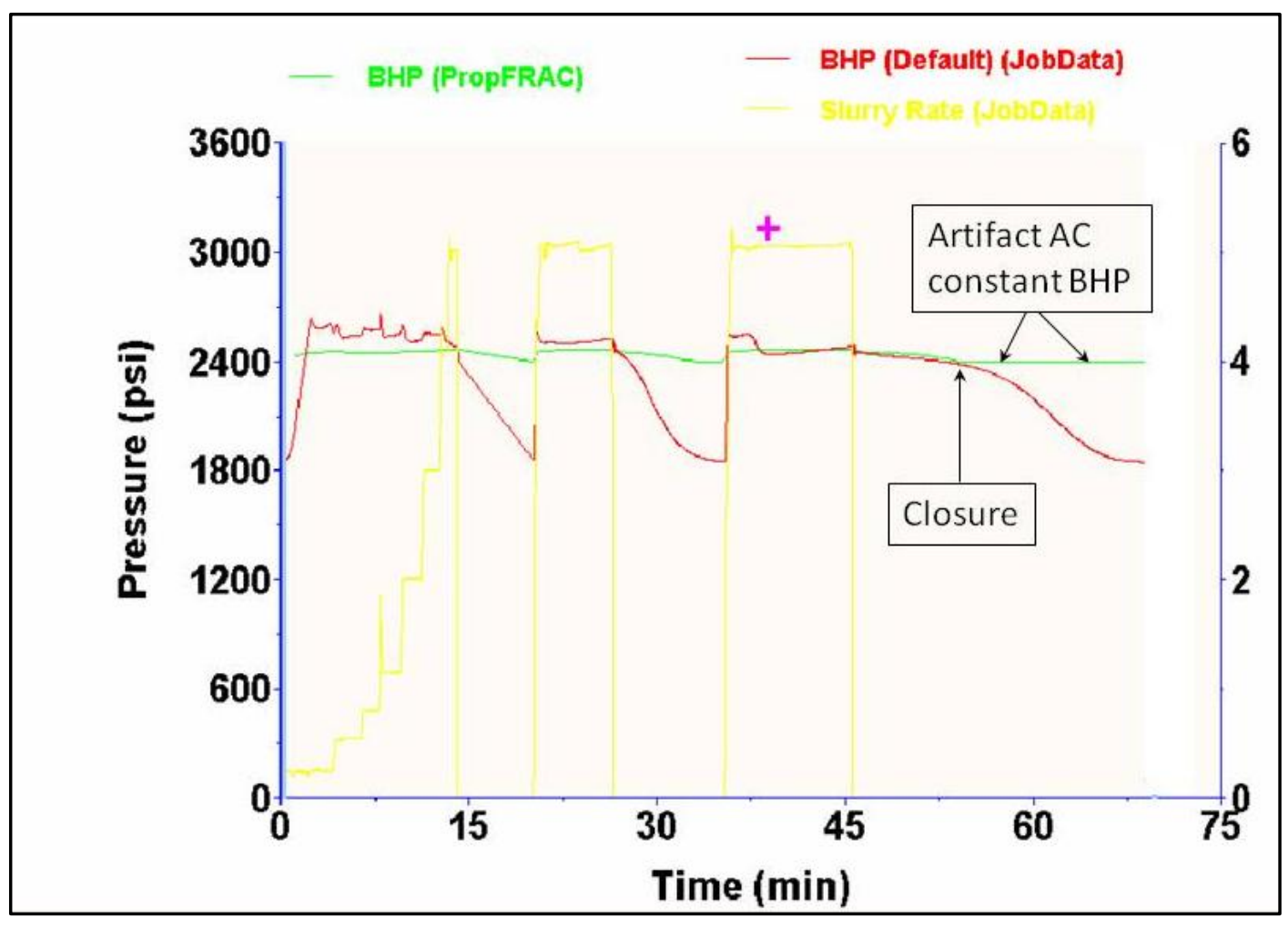

Figure 3.6 Pressure Match Analysis Performed on a FCT with the FracCade ${ }^{\mathrm{TM}}$ Hydraulic Fracturing Simulator (from Marongiu-Porcu, 2003) 


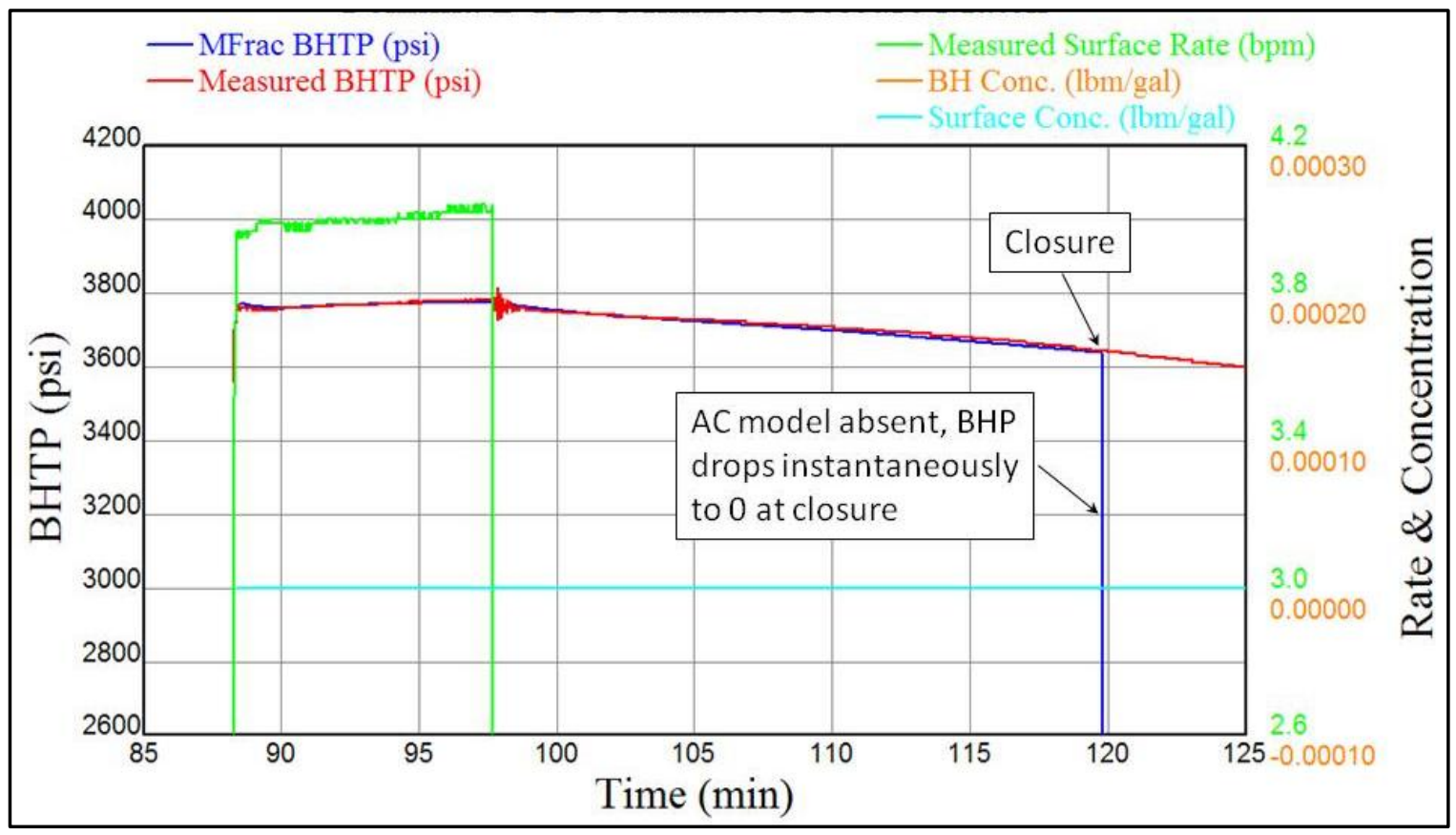

Figure 3.7 Pressure Match Analysis Performed on a FCT with the MFrac ${ }^{\text {TM }}$ Hydraulic Fracturing Simulator (from Marongiu-Porcu, 2003)

A third commercial hydraulic fracturing simulation package, FracPro $2011^{\mathrm{TM}}$ has also been assessed within this research work, and the findings are no more encouraging than the one reported in Marongiu-Porcu (2003). Figure 3.8 shows the simulation with FracPro $2011^{\mathrm{TM}}$ of a 50,000-gals injection of $30 \#$ crosslinked gel for 29.7 minutes on a 0.5 md dolomite.

At a first glance, the FCT simulation illustrated in Figure 3.8 appears to be able to generate an $\mathrm{AC}$ wellbore pressure falloff (i.e., the blue curve continues to fall off even after the yellow net pressure curve reaches zero, meaning that the simulation has achieved complete fracture closure at that moment). A more attentive look at the portion of blue curve inside the red dashed circle, reveals a major discontinuity in the transition $\mathrm{BC}$ to AC. This is clearly an artifact of the simulated wellbore pressure falloff model, since it is a well established fact that it is impossible to identify fracture closure events from simple Cartesian representations $p_{w f}$ versus shut-in time, and if it were possible to identify the fracture closure event from a simple Cartesian representation, there would be 
no need for the Nolte (1986) and Barree and Mukherjee (1996) g-function analysis methods.

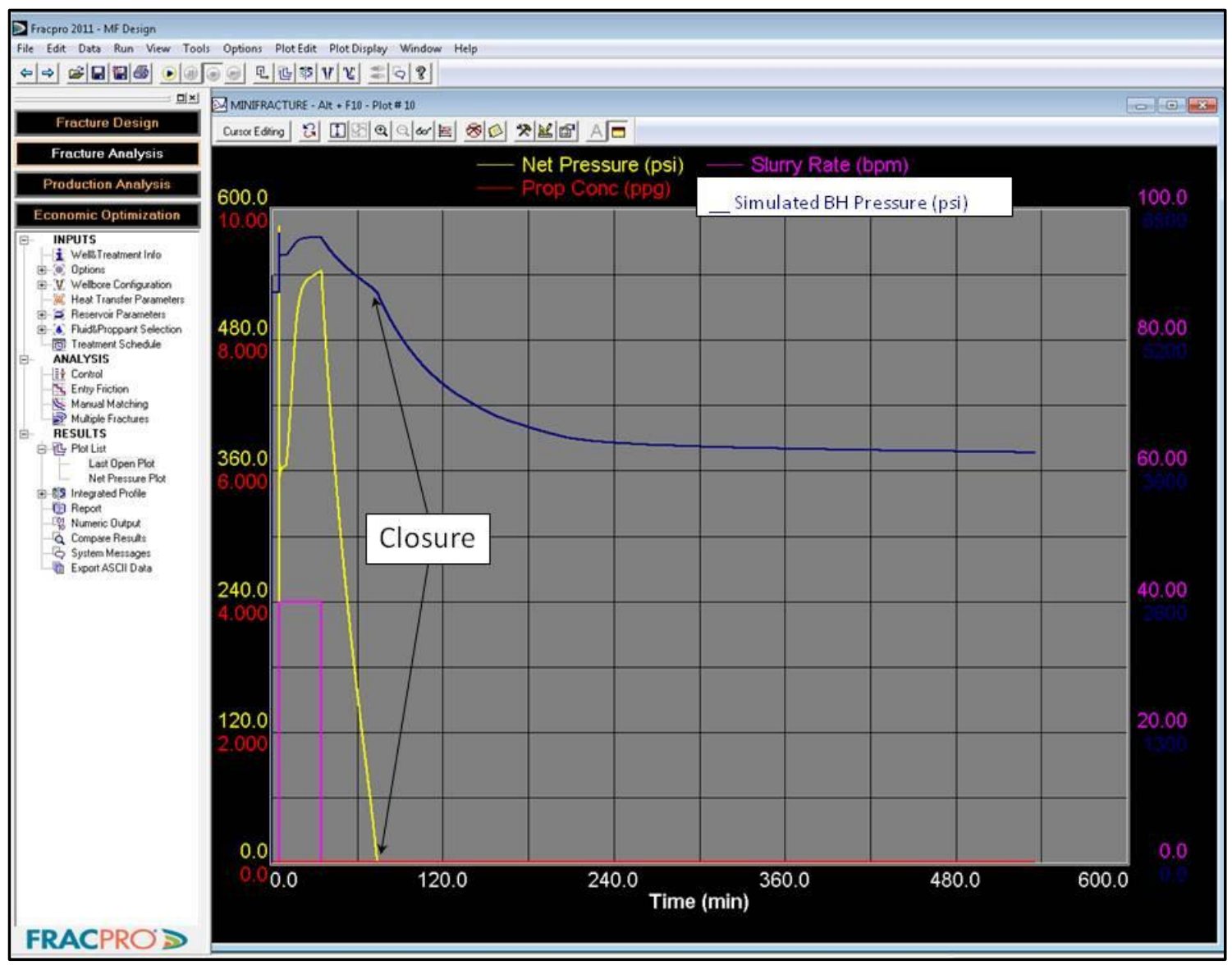

Figure 3.8 Simulation of a FCT with the FracPRO 2011 ${ }^{\text {TM }}$ Hydraulic Fracturing Simulator

The magnitude of this artifact discontinuity becomes much larger when this FracPro $2011^{\mathrm{TM}}$ simulated wellbore pressure falloff was plotted using the log-log diagnostic representation, as shown in Figure 3.9, where two abnormal "jumps" of the wellbore pressure derivative are evident. The first anomaly occurs at fracture closure, where the expected departure from the 3/2 slope trendline is not followed by a smooth transition towards a $1 / 2$ slope trendline, but instead spikes up instantaneously by almost 
an order of magnitude. This is actually a very strong indication that the AC model implemented in the FracPro $2011^{\mathrm{TM}}$ simulator is not consistent with what has been seen in actual published FCT data.

The second anomaly in Figure 3.9 occurs after 3 hours of elapsed shut-in time in the FracPro $2011^{\mathrm{TM}}$ simulated wellbore pressure, and is most likely showing the switch towards a second AC portion, speculatively representing pseudo-radial flow.

A third very relevant anomaly is the $\mathrm{BC}$ derivative trend, which does not manifest the expected 3/2 slope (in fact, it appears to be an unit slope), and consequently does not respect Nolte's $(1979 ; 1986)$ leakoff.

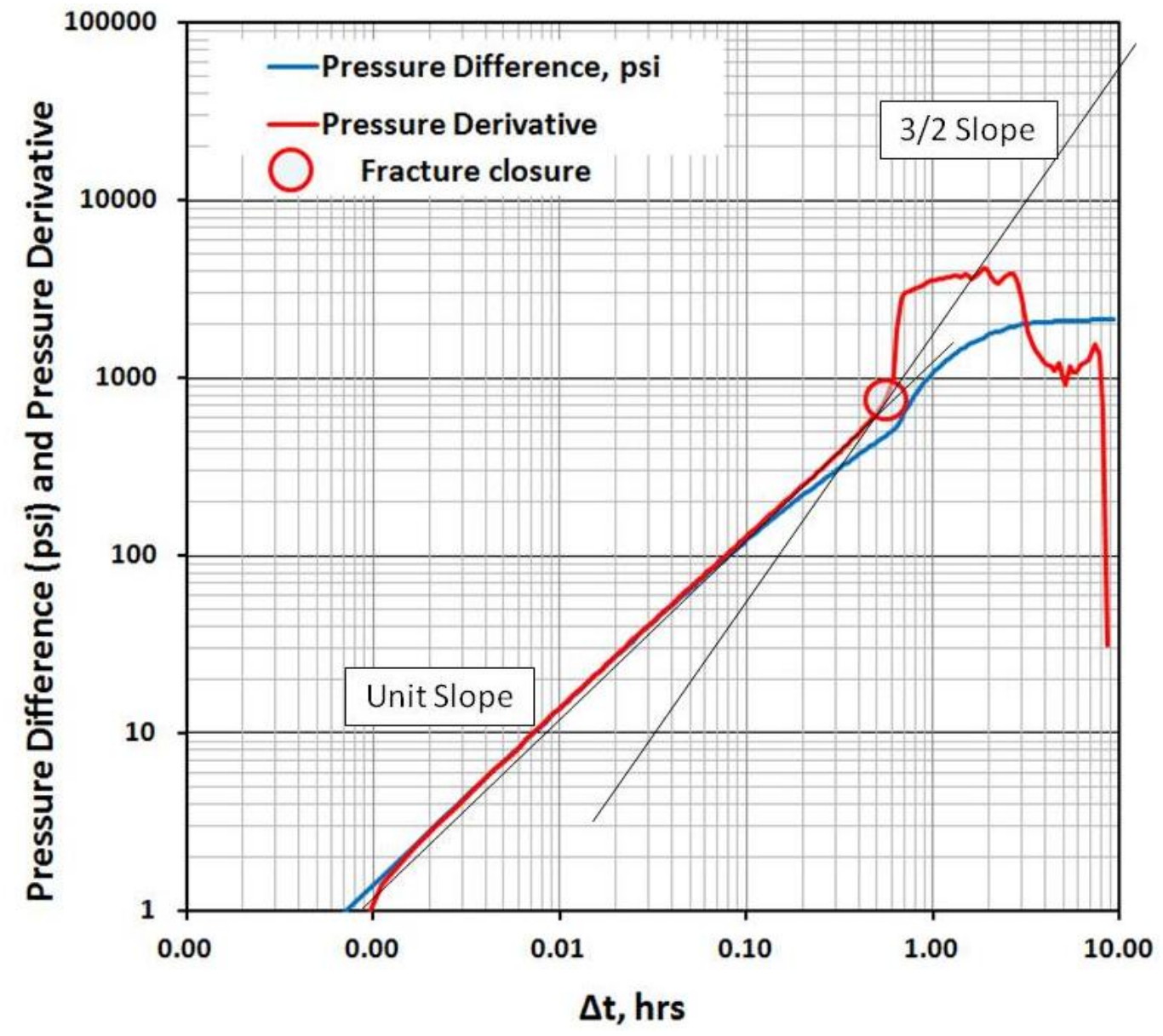

Figure 3.9 Log-Log Representation for the Simulation of a FCT with the FracPRO 2011 $^{\text {TM }}$ Hydraulic Fracturing Simulator 
Ribeiro and Horne (2013) presented a model that generates the pressure response and predicts the flow velocities throughout the reservoir during fracture creation by coupling the mass balance inside the reservoir and within the created fracture with traditional 2D fracture propagation models.

The limitation and inconsistency of this model manifest themselves when they make use of the log-log diagnostic representation shown in Figure 3.10 for validation of the fracture closure event simulation. Similar to the previous discussion regarding the FracPro $2011^{\mathrm{TM}}$ simulator, a major model artifact occurs at fracture closure, where the expected departure from the $3 / 2$ slope trendline is followed by an abrupt jump of over 1.5 orders of magnitude. Again, such behavior is not observed in actual FCT data.

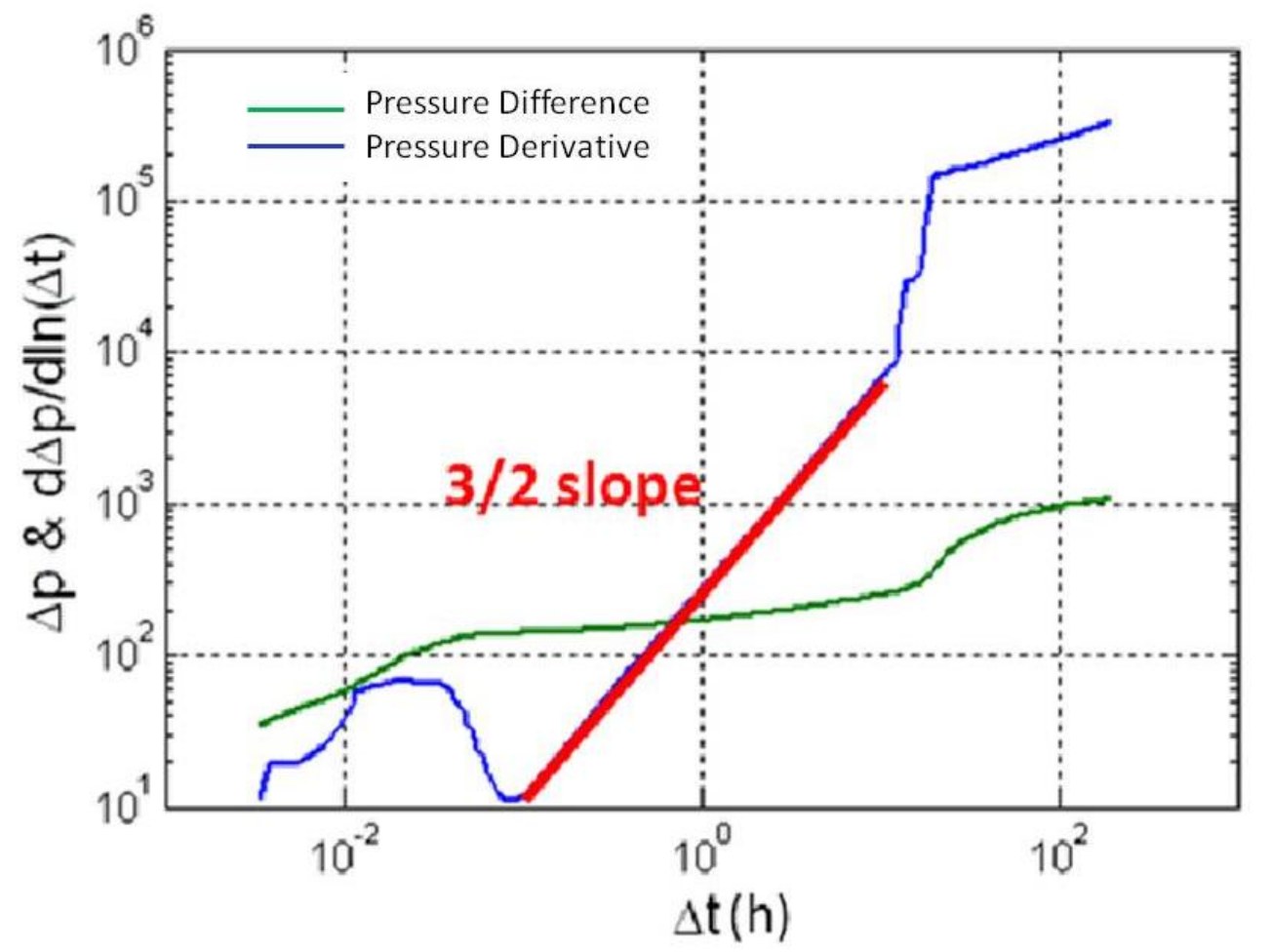

Figure 3.10 Log-Log Representation for the Simulation of a FCT Generated and Presented by Ribeiro and Horne (2013) 
On the basis of the presented critiques to the (limited) number of (inadequate) existing FCT wellbore pressure falloff models, the reader may now concur with the objectives of this research, which entails developing a global model for FCT analysis and design that is capable of simulating the complete $\mathrm{BC}$ and $\mathrm{AC}$ wellbore pressure falloff behavior following a step-rate or constant rate injection test.

Unless an approach analogous to the one presented by Craig and Blasingame (2006), solely based on storage phenomena, a more realistic description needs to necessarily consider a piecewise $\mathrm{BC}+\mathrm{AC}$ wellbore pressure falloff solution, for which three fundamental conditions must be honored:

- The entire set of input parameters must be completely consistent between the $B C$ and AC model;

- The transition between the two $\mathrm{BC}$ and $\mathrm{AC}$ wellbore pressure falloff solutions must be continuous and smooth;

- The AC wellbore pressure falloff solution can only accommodate for a infinite conductivity fracture, whose distinguishing feature is the linear flow $1 / 2$ slope trendline.

The second condition appears trivial, but in order to properly model the fracture morphology, the challenge to be faced is that the $\mathrm{BC}$ portion of the wellbore pressure falloff dominates and masks any possible reservoir response until it completely dissipates. After the closure event there may be a transition (analogous to the one appearing in wellbore storage behavior between flow strictly from the wellbore to flow strictly from the reservoir) until AC behavior is finally visible in the falloff response. In this formulation, the $\mathrm{BC}$ and $\mathrm{AC}$ portions of the wellbore pressure falloff are effectively coupled using a strategic spline methodology discussed in the next Section.

A final condition anticipated in Section 2.2 is to model the $\mathrm{AC}$ response as that of an effectively infinite conductivity fracture. Although several publications (Soliman et al., 2005; Craig and Blasingame, 2006; and Barree et al., 2009) have postulated and 
entertained the possibility of an AC bilinear flow, a careful consideration of the global nature of the FCT makes this postulate appear completely inadequate.

In a conventional drawdown or buildup transient, the flow regime of a closed and unchanging fracture draining the productive formation depends by the contrast of conductivity between the fracture $\left(k_{f} w\right)$ and the formation $\left(k x_{f}\right)$, and when the ratio of these two indicators (i.e., the dimensionless fracture conductivity, $C_{f D}$ ) is less than about 30, the fracture manifests a bilinear flow behavior.

The nature of a FCT is quite different from a conventional production drawdown condition. In this case, initially the fracture is being propagated instantaneously, and it is obviously open and empty (no proppant or any other porous material). The rate "signal" that is being applied to the reservoir under the form of leakoff process throughout the fracture walls occurs after flowing within this infinite conductivity slot (whose section is typically modeled as elliptical or rectangular, according to classic PKN and KGD models, respectively). Both Carter's (Howard and Fast, 1957) and Nolte's (1979) formulations stipulate the infinite conductivity condition during fracture propagation. Furthermore, once the injection is over and the shut-in period begins, there is uniquely a linear flow throughout the fracture walls of the fluid that has contributed the final fracture geometry that is then being ejected from the closing fracture.

Understanding these major fundamental differences between the drawdown or buildup condition of a closed propped fracture and leakoff conditions within an open empty fracture should be sufficient to confirm the impossibility of encountering finite conductivity flow AC behavior in a FCT.

\subsection{Global Fracture Calibration Test Modeling}

This section presents the detailed description of the logic and workflow that constitutes the global FCT model subject of this dissertation. A methodical reference to the fundamental equations introduced in Chapter II is used, and a distinction between analysis mode and design mode for the global FCT model is exposed. 


\subsubsection{Global Fracture Calibration Test Analysis Model}

In order to use the presented global FCT model to analyze wellbore pressure falloff field data, it is necessary to have independent measurements of the formation gross and net thickness ( $h$ and $h_{n e t}$ ), Poisson's ratio $v$, Young's modulus $E$, formation porosity $\phi$, representative formation fluid viscosity $\mu$, representative formation fluid volume factor $\left(B_{o}\right.$ or $\left.B_{g}\right)$, representative formation fluid compressibility $\left(c_{o}\right.$ or $\left.c_{g}\right)$ and total system compressibility $c_{t}$. Additionally, formation temperature, $T_{R}$, and gas gravity, $\gamma_{g}$, are needed for a gas reservoir.

Although the global FCT model is capable of providing the full description of the fracture geometry created at the immediate injection shut-down, it is recommended to gather some alternative estimate for the fracture height $h_{f}$.

As a first resort, the analysis should review the gamma-ray log to identify likely stress contrast related to formation lithology contrast. In principle, the use of temperature logs within four hours after the injection shut-down is also a valid alternative for fracture height estimation for vertical wells FCTs, but the limited timeframe available to run the wireline temperature gauge after bleeding-off the pressurized wellbore would make impossible the acquisition of the wellbore pressure falloff for extended times, which is of crucial importance for AC linear and pseudo-radial flow regimes to ensue. Therefore, when available, fracture imaging methods (microseismic, FMI or tiltmeter) can also provide an estimate of fracture height (Barree et al., 2002; Mayerhofer et al., 2011; Grae et al., 2012). Imaging methods may also be beneficial for estimating fracture half length or radius, especially for FCTs performed on horizontal wells targeting to drain tight or ultra tight formations, such as tight gas sands, shale gas and shale oil.

Generally the two appropriate choices for the fracture geometry are the PKN or the radial model. When the injected fluid volume is (relatively) small or when the stress contrast between the productive pay and adjacent layers is deemed insufficient to provide good fracture height containment, the created fracture geometry may be radial. 
When gamma-ray log-inferred lithology suggests strong fracture height containment, and with sufficient injected volume the fracture half-length considerably exceeds its height, the PKN model applies.

Once all the required input data are available, generation of a global FCT model to match with data involves 7 instruction blocks: log-log diagnostic plot construction, immediate determinations from log-log diagnostic plot, fracture height characterization and $2 \mathrm{D}$ model preliminary assumption, $\mathrm{BC}$ analysis, $\mathrm{AC}$ analysis, $\mathrm{BC}$ and $\mathrm{AC}$ model generation and piecewise model connection via spline.

\section{(1) Log-Log Diagnostic Plot Construction}

1) The ISIP is determined from the Cartesian plot of the wellbore pressure falloff data ( $p_{w}$ versus time) acquired during shut-in; this operation is generally performed with an extrapolation of the stabilized falloff trend for $\Delta P \rightarrow 0$.

2) The pressure differences $\Delta P$ for the wellbore pressure falloff data are calculated with respect to the ISIP.

$$
\Delta p(\Delta t)=I S I P-p_{w}(\Delta t)
$$

3) For the ideal case of a constant rate injection, the duration of such injection $t_{e}$ can be directly used for the calculation of the superposition time $\tau$ using Eq. 3.2, while for variable rate injections (which are not recommended) the $t_{e}$ is calculated as the total volume of injected fluid divided by the last (and hopefully longest) injection rate.

$$
\tau=\frac{t_{e}+\Delta t}{\Delta t}
$$

4) The Bourdet et al. (1989) pressure derivative is calculated with respect to the natural logarithm of the superposition time using Eq. 3.1.

$$
\Delta p^{\prime}=\frac{d p}{d \ln \tau}
$$


5) The log-log diagnostic plot of the FCT under analysis is constructed. At this point, the wellbore pressure derivative characteristic progression of flow regimes can be qualitatively identified.

In the case the FCT under analysis is for a gas reservoir below 5,000 psi of static average pressure, it is recommended to making use of the real-gas potential function $m(p)$ (Al-Hussainy et al., 1966) to generate the log-log diagnostic plot.

$$
m(p)=2 \int_{p_{0}}^{p} \frac{p}{\mu \cdot Z} d p
$$

\section{(2) Immediate Determinations from Log-Log Diagnostic Plot}

The following steps are performed without the need of making any assumption on the 2D fracture propagation model and without needing to know the fracture height.

1) The closure event is identified by the departure of the wellbore pressure derivative from the $3 / 2$ slope trend: the elapsed closure time $t_{c}$ is read directly from the corresponding abscissa of the identified closure event, while the $\Delta p_{c}$ is used to calculate the closure pressure solving Eq. 3.15 for $p_{c}$.

2) The analysis method based on the log-log diagnostic plot allows direct determination of $b_{N}$ and $m_{N}$, by virtue of the intimate correspondence between the g-function and the characteristic 3/2 slope trend that was discussed in paragraph 3.2. In fact, considering the low leakoff upper bound approximation for the gfunction (Eq. 2.15-b), substituting the definition of $\tau$ (Eq. 3.2) and rearranging, it follows:

$$
g\left(\Delta t_{D}, \alpha=1\right)=\frac{4}{3} \Delta t_{D}^{3 / 2}\left(\tau^{\frac{3}{2}}-1\right)
$$


Then, substituting Eq. 3.17 into Eq. 2.22, and taking the logarithmic derivative according to the basic derivative rule (Eq.3.7) provides:

$$
\Delta p^{\prime}=2 m_{N} \Delta t_{D}^{5 / 2} \tau\left(1-\tau^{1 / 2}\right)
$$

Solving for $m_{N}$ and rearranging Eq. 2.2 provides the final expression for our two necessary parameters $b_{N}$ and $m_{N}$ :

$$
\begin{aligned}
& m_{N}=\frac{\Delta p^{\prime}}{2 \Delta t_{D}^{5 / 2} \tau\left(1-\tau^{1 / 2}\right)} \\
& b_{N}=p_{w}-m_{N} \frac{4}{3} t_{D}^{3 / 2}\left(\tau^{3 / 2}-1\right)
\end{aligned}
$$

The closure point previously identified $\left(\Delta t, \Delta p^{\prime}\right)_{\mathrm{c}_{\mathrm{c}}}$ can be used as convenient input for Eqs. 3.19 and 3.20.

\section{(3) Fracture Height Characterization and 2D Model Preliminary Assumption}

At this point the required preliminary assumption for the $2 \mathrm{D}$ fracture propagation model is strictly related to whatever estimate is available for the fracture height $h_{f}$ as well as the lithology interpretation from gamma-ray log analysis and the expected fracture height containment within the non-target adjacent layers.

If the fracture height is known with confidence, the following steps $4 \mathrm{~A}$ and $5 \mathrm{~A}$ complete the determination of the $\mathrm{BC}$ and $\mathrm{AC}$ parameters, respectively, necessary for the construction of the global FCT model.

On the contrary, if the information relative to fracture height and lithology-based height containment are insufficient, the steps $4 \mathrm{~B}$ and $5 \mathrm{~B}$ complete the determination of the $\mathrm{AC}$ and $\mathrm{BC}$ parameters, respectively, necessary for the construction of the global FCT model. 


\section{(4) $\underline{\text { A. Before-Closure Analysis for Known Values of Fracture Height }}$}

1) Assume first the radial fracture propagation model. Then, substitute the equation for the fracture radius $R_{f}$ from Table 2.1 into Equation 2.22, obtaining the following equation from which $R_{f}$ is easily computed by noting that the factor $A_{e}$ is equal to the fracture area, $\pi R_{f}^{2} / 2$, and noting that the value for $b_{N}$ has already been quantified by Eq. 3.20:

$$
b_{N}=p_{C}+S_{f} V_{i} / A_{e}=p_{C}+\frac{3 E^{\prime} V_{i}}{8 R_{f}^{3}}
$$

2) If the resulting value for $R_{f}$ is less than the formation thickness, assume a radial fracture geometry. If $R_{f}$ is greater than the formation thickness, and if there is no strong evidence of containment, still assume a radial fracture. Otherwise assume the PKN fracture propagation model, but the expression for the fracture surface area and stiffness $S_{f}$ must now reflect the PKN model. Thus, $x_{f}$ is determined from the following equation by noting that in this case $A_{e}=h_{f} x_{f}$ :

$$
b_{N}=p_{C}+S_{f} V_{i} / A_{e}=p_{C}+\frac{2 E^{\prime} V_{i}}{\pi h_{f}^{2} x_{f}}
$$

3) Use the computed values for $m_{N}$ and $b_{N}$ to compute leakoff coefficient, fracture width, and fracture fluid efficiency from the proper set of equations reported in Table 2.2 for the indicated 2D radial or PKN fracture propagation model.

4) The fracture stiffness is calculated using the proper equation for the specific $2 \mathrm{D}$ fracture propagation model reported in Table 2.1. Then, a check on the consistency of the results can be done using the values of fracture net pressure at immediate shut-in, comparing the stiffness-based relation and the definition of fracture net pressure.

$$
p_{n e t}=\bar{w} \cdot S_{f}
$$

It is relevant to notice that even when this check fails, the FCT model analysis results are not necessarily inconsistent, since abnormally high values of net 
pressures can be due to both poroelastic backstress and formation plasticity, as observed and studied in Wang, Marongiu-Porcu and Economides (2014).

\section{(5) A. After-Closure Analysis for Known Values of Fracture Height}

1) If the pseudo-radial flow regime is observed in the late time portion of the $\mathrm{AC}$ wellbore pressure falloff and the fracture geometry is deemed as either a fully confined PKN or as un-confined (radial), the effective reservoir permeability in the exposed reservoir region is determined for an oil or a gas reservoir, respectively as (Lee et al., 2003):

$$
\begin{aligned}
& k_{o}=\frac{70.6 q B_{o} \mu_{o}}{m^{\prime} h} \\
& k_{g}=\frac{711 q T}{m^{\prime} h}
\end{aligned}
$$

where all parameters are expressed in field units, the reservoir temperature $T$ is in Rankin degrees, and the reported value of the constant logarithmic derivative level related to the pseudo-radial flow regime $m$ ' is picked from the log-log diagnostic plot ( $\Delta p$ ' for oil, or $\Delta m(p)$ 'for gas). For a radial fracture use $h=2 R_{f}$.

The reference rate $q$ is the last injection rate recorded at the surface (equivalent to $q_{i(T O T)}$ when the injection is performed at constant rate); if the FCT under analysis is for a gas reservoir, this reference injection rate is converted to the units of $\mathrm{MSCF} / \mathrm{d}$, assuming piston-like displacement of the gas by the injected fluid.

2) If the pseudo-radial flow regime is not observed (which is a very common occurrence in tight gas sandstones and shales FCTs, due to the impractical required shut-in times), the effective reservoir permeability in the exposed reservoir region is determined in the next AC modeling instruction block as input matching parameter to obtain a best-fitting curve (pressure match) of the recorded AC shut-in pressure wellbore data. Nevertheless, a guess initial value 
could be estimated if linear flow is observed in the $\mathrm{AC}$ response using the following equations for an oil or a gas reservoir, respectively (Lee et al., 2003):

$$
\begin{aligned}
& k_{o}=\left(\frac{4.064 q B_{o}}{2 \Delta p^{\prime} h \cdot x_{f}}\right)^{2}\left(\frac{\mu \Delta t}{\phi c_{t}}\right) \\
& k_{g}=\left(\frac{41.046 q T_{R}}{2 \Delta m(p)^{\prime} h \cdot x_{f}}\right)^{2}\left(\frac{\Delta t}{\phi \mu_{g} c_{g}}\right)
\end{aligned}
$$

where the flow rate is as before and for a point $\left(\Delta t, \Delta \mathrm{p}^{\prime}\right)$ in the pressure derivative interval that exhibits a $1 / 2$ slope, and the values for $h$ and $x_{f}$ depend on the fracture geometry.

For radial fracture with $2 R_{f}<$ the formation thickness $h, x_{f}=R_{f}$ and $h=2 R_{f}$.

For radial fracture with $2 R_{f}>$ the formation thickness $h, x_{f}=R_{f}$ and $h=$ formation height.

For a PKN fracture $h$ is the formation thickness and $x_{f}$ is fracture half-length.

The AC portion of the global FCT model generated with this value for $k$ will need to be adjusted to get an accurate fit with the log-log derivative of the wellbore pressure falloff data.

3) The initial reservoir pressure, $p_{i}$, is estimated using a point selected from the portion of the pressure change response corresponding to radial flow (level derivative) with the following equation (Lee et al., 2003):

$$
p^{*} \sim p_{i}=-m^{\prime} \ln \left(\frac{e_{e} \Delta t_{\text {slope }=0}}{\Delta t_{\text {slope }=0}}\right)-\Delta p\left(\Delta t_{\text {slope }=0}\right)+I S I P
$$

Alternatively, the $p_{i}$ is estimated by extrapolating the late-time straight trend seen on a Horner plot of the injection falloff pressure data.

The average reservoir pressure cannot be estimated without the radial flow response. The Nolte (1997) approach using linear flow behavior from the $\mathrm{AC}$ response is not valid because it assumes that extrapolation of the linear flow 
to infinite shut in time will give reservoir pressure. This is not correct because the finite fracture dimension implies that the final flow regime that can be extrapolated to initial pressure will be radial flow, and not linear.

A reasonable guess for the initial reservoir pressure can be acquired if pore pressure gradient wireline (or bottomhole gauges) measurements are available. Alternatively, the definition of minimum horizontal absolute stress derived from the Poisson's uniaxial strain translation (Valkó and Economides, 1995) can be rearranged a solved for the initial reservoir pressure:

$$
p_{i}=\frac{\sigma_{\min }-\left(\frac{v}{1-v}\right) \sigma_{V}}{\alpha\left(\frac{1-2 v}{1-v}\right)}
$$

where $\sigma_{\min }$ is the minimum horizontal stress (whose value can be effectively approximated with the field derived fracture closure stress), $\sigma_{V}$ is the overburden stress, $v$ is the Poisson's ratio, and $\alpha$ is the (poroelasticity) Biot's parameter.

Equation 3.23 does not consider any possible additional tectonic-induced stress term, since (if present) this effect would be already affecting the magnitude of the field derived fracture closure stress.

Alternatively, Xue and Ehlig-Economides (2013) suggested using the inherent relationship between permeability and initial reservoir pressure. The permeability estimate provides the slope for the Horner plot of the wellbore pressure falloff data. On the Horner plot extrapolate a line with slope $2.303 \mathrm{~m}$ ' from the last measured pressure to the Horner time value of 1 for an estimate of the initial reservoir pressure that is consistent with the permeability estimate. A better estimate can be found by extrapolating the global model matching the existing data to radial flow, and then using the modeled radial flow to estimate the reservoir pressure.

If neither linear nor radial flow appears in the $\mathrm{AC}$ response, then the relationship between permeability and initial reservoir pressure indicated by Xue 
and Ehlig-Economides (2013) can be used to estimate paired estimates for permeability and initial reservoir pressure, but no unique estimate for both is possible.

\section{(4) B. After-Closure Analysis for Unknown Values of Fracture Height}

When fracture height is not known, the $\mathrm{BC}$ analysis cannot provide a value for $R_{f}$ or $x_{f}$. In this case, the interpretation requires that the data end with radial flow or that a permeability (and hence a radial flow derivative level) is assumed for the model generation. An independent estimate for the formation pressure can help to pin down the formation permeability in the absence of radial flow in the AC response.

1) If the pseudo-radial flow regime is observed in the late time portion of the $\mathrm{AC}$ wellbore pressure falloff and the fracture geometry is deemed as either a fully confined PKN or as un-confined (radial), the effective reservoir permeability in the exposed reservoir region is determined for an oil or a gas reservoir, respectively as (Lee et al., 2003):

$$
\begin{aligned}
& k_{o}=\frac{70.6 q B_{o} \mu_{o}}{m^{\prime} h} \\
& k_{g}=\frac{711 q T}{m^{\prime} h}
\end{aligned}
$$

where all parameters are expressed in field units, the reservoir temperature $T$ is in Rankin, and the reported value of the constant logarithmic derivative level related to the pseudo-radial flow regime $m$ ' is picked from the log-log diagnostic plot ( $\Delta p^{\prime}$ for oil, or $\Delta m(p)$ 'for gas).

The reference rate $q$ is the last injection rate recorded at the surface (equivalent to $q_{i(T O T)}$ when the injection is performed at constant rate); if the FCT under analysis is for a gas reservoir, this reference injection rate is converted to the units of $\mathrm{MSCF} / \mathrm{d}$, assuming piston-like displacement of the gas by the injected fluid. 
2) The initial reservoir pressure, $p_{i}$, is estimated using a point selected from the portion of the pressure change response corresponding to radial flow (level derivative) with the following equation (Lee et al., 2003):

$$
p^{*} \sim p_{i}=-m^{\prime} \ln \left(\frac{t_{e}+\Delta t_{\text {slope }=0}}{\Delta t_{\text {slope }=0}}\right)-\Delta p\left(\Delta t_{\text {slope }=0}\right)+I S I P
$$

Alternatively, the $p_{i}$ is estimated by extrapolating the late-time straight trend seen on a Horner plot of the injection falloff pressure data.

3) If linear flow also appears as a $1 / 2$ slope derivative trend before the radial flow, the fracture half length can be estimated using Eq. 3.24 rearranged for $x_{f}$. As in instruction block $5 \mathrm{~A}$, use of this flow-regime equation would provide a result (fracture half length) that represents a guess initial value to be used to generate the best-fitting curve (pressure match) of the recorded AC shut-in pressure wellbore data. This estimate needs to be refined by finding a match for the pressure change and logarithmic derivative using the global FCT model.

If the initial estimate provides $x_{f}<h / 2$, the radial fracture propagation model can be assumed, and in that case the fracture radius is estimated as

$$
R_{f}=\sqrt{\frac{2 h x_{f}}{\pi}}
$$

so that the fracture leakoff area is preserved; in this case also the effective reservoir permeability in the exposed reservoir region must be recomputed using $h=2 R_{f}$ in Eq. 3.23.

If the estimate for $x_{f}$ is greater than $h / 2$, then either radial or PKN geometry could be assumed.

4) If radial flow is not seen, if at least linear flow appears, then it is available only an estimate for the product of permeability and the "flowing fracture area" as in Eq. 3.24. In either case, the created radial or PKN fracture height, $h_{f}$, may be greater than the formation height, $h$. In this case a reasonable approach would be 
to start with an assumed maximum possible permeability value consistent with assuming the departure from linear flow occurs right after the end of the existing falloff response. In turn, this assumed permeability can be used to estimate a consistent fracture half-length. The likelihood is that even using the global FCT model, the final model match will not be unique.

Analogous considerations to the ones exposed in point 3 of instruction block 5A apply with regard of possible alternative and independent estimations for the initial reservoir pressure.

\section{(5) B. Before-Closure Analysis for Unknown Values of Fracture Height}

1) According to the fracture propagation model assumed in instruction block $4 \mathrm{~B}$, the proper equation from Table 2.2 is used to calculate the fracture height $h_{f}$ (PKN) or to validate the value of $R_{f}$ (Radial) determined from the AC analysis in instruction block 4B.

2) Use the computed values for $h_{f}$ (or $\left.R_{f}\right), m_{N}$ and $b_{N}$ to compute leakoff coefficient, fracture width, and fracture fluid efficiency from the proper set of equations for the specific 2D fracture propagation model reported in Table 2.2.

3) The fracture stiffness is calculated using the proper equation for the specific $2 \mathrm{D}$ fracture propagation model reported in Table 2.1. Then, a check on the consistency of the results can be done using the values of fracture net pressure at immediate shut-in, comparing the stiffness-based relation and the definition of fracture net pressure. $\quad p_{n e t}=\bar{w} \cdot S_{f}$

\section{(6) Before-Closure and After-Closure Model Generation}

Table 3.1 recaps the complete set of parameters that have either been calculated or used as inputs within instruction blocks 1 to 5 . The final instruction block 
describing $\mathrm{BC}$ and $\mathrm{AC}$ model generation follows here. The reader may note that this table includes the KGD fracture propagation geometry, which has not been addressed up to now in the analysis description. While this geometry might occur for relevant volumes of injected fluid, which appears more likely for actual fracture treatment, into formation that exhibit scarce fracture height containment, this fracture geometry for the FCTs it is not anticipated. This holds particularly true for the tight formations, where limited volumes of injected fluids are injected with the crucial target of characterizing the AC pressure falloff behavior.

Therefore, while the global model can be generated for all three fracture geometries, including KGD, we anticipate its use for the KGD model will be rare.

Table 3.1 Complete Set of Parameters Needed for the Generation of the Global FCT Model

\begin{tabular}{|c|c|}
\hline \multicolumn{2}{|c|}{ Formation Data } \\
\hline Initial pressure (pi) & psi \\
\hline Formation Temperature & ${ }^{\circ} \mathrm{F}$ \\
\hline Permeability & md \\
\hline Porosity & fraction \\
\hline Net thickness & $\mathrm{ft}$ \\
\hline Wellbore radius & $\mathrm{ft}$ \\
\hline \multicolumn{2}{|l|}{ Fluid Data } \\
\hline \multicolumn{2}{|l|}{ Specific gravity } \\
\hline Total compressibility & $1 / \mathrm{psi}$ \\
\hline Reservoir fluid viscosity & ср \\
\hline Gas FVF & $\mathrm{cu} \mathrm{ft} / \mathrm{MSCF}$ \\
\hline \multicolumn{2}{|l|}{ Rock Data } \\
\hline Young's Modulus & psi \\
\hline \multicolumn{2}{|l|}{ Poisson's Ratio (v) } \\
\hline \multicolumn{2}{|c|}{ Fracture Data } \\
\hline Injection rate & bpm \\
\hline Injection fluid FVF & bbl/stB \\
\hline Closure pressure & psi \\
\hline Closure time & hours \\
\hline Rf, $x f$ & $\mathrm{ft}$ \\
\hline Leak-off coefficient (CL) & $\mathrm{ft} /$ minute $\mathrm{e}^{0.5}$ \\
\hline Fracture height (PKN/KGD) & $\mathrm{ft}$ \\
\hline
\end{tabular}


1) Nolte's BC fracture pressure falloff is generated using Eq. 2.21 or Eq. 2.22.

2) The pressure differences $\Delta P$ for the simulated $\mathrm{BC}$ wellbore pressure falloff are calculated with respect to the ISIP. Then, the same procedure followed in points 3-4-5 of instruction block 1 is used to construct the Bourdet et al. (1989) logarithmic derivative of the simulated $\mathrm{AC}$ wellbore pressure falloff with respect to the natural logarithm of the superposition time using Eq. 3.1.

3) The value of the g-function at shut-in time $g_{0}\left(\Delta t_{D}=0, \alpha\right)$ and closure time $g_{c}\left(\Delta t_{D, c}, \alpha\right)$ (where and $\Delta t_{D}$ is calculated using Eq. 2.11 at closure time $t_{c}$ ) are calculated using Eq. 2.13, where the proper value of $\alpha$ is picked accordingly to the $2 \mathrm{D}$ fracture propagation model selected.

4) The fracture fluid efficiency is calculated using the fundamental equation presented by Nolte (1986).

$$
\eta=1-\frac{g_{0}\left(\Delta t_{D}=0, \alpha\right)}{g_{c}\left(\Delta t_{D, c}, \alpha\right)}
$$

5) Consistently with Nolte's $(1979 ; 1986)$ notation introduced in Chapter II, where $V_{i}$ is the volume of fluid injected into one fracture wing (i.e., half of the total injected fluid volume), $V_{F}$ is the volume obtained at the end of the injection for one fracture wing and $V_{L}$ is the leakoff fluid volume throughout one fracture wing during injection, the values of $V_{F}$ and $V_{L}$ for the calculated fracture fluid efficiency are calculated as follow.

$$
\begin{aligned}
& V_{L}=V_{i} \cdot(1-\eta) \\
& V_{F}=V_{i} \cdot \eta
\end{aligned}
$$

6) The values of the average total leakoff rate during the FCT injection and during the shut-in are calculated as follow, respectively. 


$$
\begin{aligned}
& q_{L(T O T)}=\frac{2 \cdot V_{i} \cdot(1-\eta)}{t_{e}} \\
& q_{F(T O T)}=\frac{2 \cdot V_{i} \cdot \eta}{\Delta t_{c}}
\end{aligned}
$$

7) The effective reservoir permeability in the productive reservoir region and the hydraulic fracture half length are the two required matching inputs for the generation of the $\mathrm{AC}$ dimensionless pressure versus dimensionless time solution with the calculation scheme presented in Chapter II, Eqs. 2.25-2.29. In fact, these two (plus the reservoir pressure) are the key input matching parameters to obtain a best-fitting curve (pressure match) of the recorded AC shut-in pressure wellbore data. The presence of the infinite conductivity fracture is accounted for by using Prats (1961) relation already shown as Eq. 2.29.

8) Numerical solution with the Stehfest (1970) algorithm of Van Everdingen and Hurst (1949) cylindrical-source well solution under constant rate drawdown in an infinite-acting reservoir (Eq. 2.25) in the Laplace domain and numerical inversion to the time domain is set up. Eqs. 2.26 and 2.27 are used as definitions for dimensionless pressure and time, respectively.

$$
\bar{p}_{w D}=\frac{K_{0}\left(r_{D} \sqrt{s}\right)}{s^{3 / 2} K_{1}(\sqrt{s})}+\frac{S}{s}
$$

9) It is reasonable and realistic to expect that at a far enough distance from the wellbore and after the fracture has completely closed, the perceived pressure signal corresponds to the transient response induced by the leakoff process during injection and shut-in fracture closure. The evolution of the leakoff process through the varying fracture faces surface during injection is not realistically available, but it can be conveniently discretized and approximated (as in Valkó and Economides, 1999) as the two leakoff rates injection (as in Eqs. 3.31 and 
3.32) followed by a zero-rate section during the shut-in, where the first rate is the total leakoff rate during the FCT injection period (Eq. 3.31), and the second rate is the total average leakoff rate calculated between shut-in and fracture closure (Eq. 3.32). Superposition in time (Lee et al., 2003) is used to model this leakoff rate history.

$$
\begin{aligned}
& p_{w D}(\sup )=\frac{q_{L(T O T)}}{q_{i(T O T)}} \cdot p_{w D(i n j)}[0 \rightarrow t]-\frac{q_{L(T O T)}}{q_{i(T O T)}} \cdot p_{w D(i n j)}\left[t_{e} \rightarrow t\right] \\
& +\frac{q_{F(T O T)}}{q_{i(T O T)}} \cdot p_{w D(s . i)}\left[t_{e} \rightarrow t\right]-\frac{q_{F(T O T)}}{q_{i(T O T)}} \cdot p_{w D(s . i)}\left[t_{c}+t_{e} \rightarrow t\right]
\end{aligned}
$$

The square parenthesis in the four terms show the corresponding time domains (i.e., $t_{e}$ defines the end of injection, $t_{c}$ defines the closure time calculated with respect to the end of injection $t_{e}$ and $t$ refers to a generic time step involved in the solution of Eq. 2.27 in the Laplace domain and numerical inversion. Furthermore, and very important, the ratio of rates for each term are required to "normalize" the time domain solution (after numerical inversion from the Laplace domain) and make it consistent with the reference rate used for the construction of the log-log diagnostic plot.

10) The final superposition dimensionless pressure values for each term in Eq. (3.33) obtained from numerical inversion from the Laplace domain solution are converted into actual $p$ and $t$ using the following equation, where the reference rates and fluid propertied are defined with the proper units, according to the nature of the reservoir fluid (liquid or gas).

$$
p_{w(A C)}(t)=p_{i}+\frac{141.2 \cdot q \cdot B \cdot \mu \cdot p_{w D}}{k \cdot h}
$$


11) The pressure differences $\Delta P$ for the simulated $A C$ wellbore pressure falloff are calculated with respect to the ISIP. Then, the same procedure followed in points 3-4-5 of instruction block 1 is used to construct the Bourdet et al. (1989) logarithmic derivative of the simulated AC wellbore pressure falloff with respect to the natural logarithm of the superposition time using Eq. 3.1.

Finally it is necessary to connect the $\mathrm{BC}$ and $\mathrm{AC}$ functions in both $\Delta \mathrm{p}$ and the logarithmic Bourdet derivative. The next section explains how this is done.

\section{(7) Piecewise FCT Model Connection via Spline}

Once the $\mathrm{BC}$ and $\mathrm{AC}$ models have been generated consistently, a spline algorithm is used to connect these two solutions and provide a continuous smooth matching model for the falloff pressure change and the logarithmic derivatives. The selected approach utilizes third order polynomials in the form of

$$
\log \Delta p^{\prime}=a_{0}+a_{1} \Delta x+a_{2} \Delta x^{2}+a_{3} \Delta x^{3}
$$

where $\Delta x$ is a generic elapsed time within the spline domain of definition. The four coefficients $a_{0}, a_{1}, a_{2}$ and $a_{3}$ are unknown, to be determined applying four boundary conditions: the two end-point and start-point for the $\mathrm{BC}$ and $\mathrm{AC}$ solutions $\log -\log$ derivatives, respectively, and the two first derivative of the loglog pressure derivatives, which provide a smooth continuous transition between the two consistent models and the spline section.

In most cases the $\mathrm{AC}$ and $\mathrm{BC}$ solutions are very well aligned, and it has been determined with confidence that an interval of 0.25 logarithmic cycles between the closure event and the beginning of the $\mathrm{AC}$ solution, starting from the closure point, is the default spline domain which provides a continuous and smooth junction. The more irregular cases may require increasing slightly the spline time domain, although it is never necessary to exceed half a logarithmic cycle as spline time domain between the closure event and the beginning of the $\mathrm{AC}$ solution. 


\subsubsection{Global Fracture Calibration Test Design Model}

The main objective of the global FCT design model is to provide a forward model for the FCT behavior that can be used to design a sufficiently short closure duration followed by recognizable AC linear and pseudo-radial flow regimes within a practical falloff duration.

Just as for the analysis mode, the global $\mathrm{BC}$ and $\mathrm{AC}$ piecewise model uses the same consistent fracture geometry, in terms of fracture radius and width for a radial fracture geometry, or fracture width, height and half-length if other 2D fracture geometry models (PKN or KGD) are selected.

The same reservoir fluid and rock inputs parameters listed in Table 3.1 are necessary also to run the global FCT model in design mode. These parameters are the formation gross and net thickness $\left(h\right.$ and $h_{n e t}$ ), Poisson's ratio $v$, Young's modulus $E$, formation porosity $\phi$, representative formation fluid viscosity $\mu\left(\mu_{o}\right.$ or $\left.\mu_{g}\right)$, representative formation fluid volume factor $\left(B_{o}\right.$ or $\left.B_{g}\right)$, representative formation fluid compressibility ( $c_{o}$ or $c_{g}$ ), total system compressibility $c_{t}$, as well as formation temperature $T_{R}$ and gas gravity $\gamma_{g}$ in the case the FCT design is for a gas reservoir.

Additionally, also the set of parameters related to the leakoff process throughout the fracture walls become required input parameters for the design mode. These parameters are the surface injection rate, the leakoff coefficient $C_{L}$, the fracture closure pressure, the fracture closure time, and the equivalent surface area of one face of one fracture wing $A_{e}$.

The effective reservoir permeability in the exposed reservoir region and the reservoir pressure are the remaining required input parameters for the global FCT design model. Since these are not actually known, the model allows the user to run convenient and fast parametric studies to evaluate the falloff duration required to reach AC radial flow or, at least, AC linear flow.

In design mode it is of even more strategic importance to gather some estimate for the fracture height $h_{f}$ (from any of the techniques already mentioned in Section 3.5.1), so that the surface area $A_{e}$ can be expressed in terms of such inferred fracture 
height $h_{f}$ and the fracture half length $x_{f}$, other sensitive variable to be used to run convenient and fast parametric studies.

For a specified closure time, estimated closure pressure, and proposed fracture geometry, Eqs. 3.19 to 3.22 enable calculation of the injection fluid volume. The resulting volume must be sufficient to ensure fracture creation considering the wellbore volume. Then the global FCT design model can be generated to confirm the falloff duration long enough to see $\mathrm{AC}$ radial flow.

This becomes of instrumental importance for tight sand and shale formations, where the challenge is to find an injection volume sufficient to create a fracture of enough areal extension to guarantee realistic description of the leakoff process throughout the surface area $A_{e}$, and concurrently minimizing the fracture closure time and the time required to observe the $\mathrm{AC}$ transient features that are used for estimation of formation pressure and permeability. For very low permeability, conventional buildup tests cannot be performed because the formation will not flow without creating a hydraulic fracture, and the FCT becomes a timely way to get permeability and formation pressure estimates essential for a main fracture treatment design that maximizes well productivity. For mild to higher permeability formations, the model enables estimation of the total test time including $\mathrm{AC}$ pseudo-radial flow from which estimates of formation pressure and permeability are straightforwardly determined without the need for a pretreatment pressure buildup test.

The outputs provided by the global FCT model are the total injection fluid volume and injection time along with values for the fracture fluid efficiency, the average fracture width and net pressure at the moment of pumps shut-down. The simulated FCT design provides a neat visual diagnostic output that can be used to run parametric cases of specific interest. The global FCT model also allows running proper parametric studies to identify the optimal injection rate, expected to provide enough injectivity into the created fracture in logistically convenient and executable injection times.

It is important to highlight that with so many independent variables related to the leakoff process throughout the fracture walls (i.e., the surface injection rate, the leakoff 
coefficient $C_{L}$, the fracture closure pressure, the fracture closure time $t_{c}$, and the equivalent surface area of one face of one fracture wing $A_{e}$ ), the risk of generating unrealistic FCT designs is considerable.

A realistic combination for the selected input parameters should be checked with the specific values of resulting fracture fluid efficiency. This is particularly recommended for doubtful input values of leakoff coefficient and fracture closure time; in this circumstance, a check on the consistency of the final output should also be done by comparing the value of fracture net pressure at immediate shut-in calculated with the stiffness-based relation with the one calculated according to the definition of fracture net pressure at shut-in.

\subsection{Chapter Summary}

This chapter has introduced and defined the global FCT model construction. It has been presented a detailed analysis of the main assumptions and hypothesis upon which it is formulated, and the main algorithms that have been constructed for the use of this model in field data interpretation mode as well as design mode have been shown.

Field data are used in Chapter IV to show examples of applications for the global FCT analysis model, as well as validate it and demonstrate its added value over current interpretation methods. Different ranges of reservoir permeability are intentionally selected for these examples, in order to show applicability and issues within different reservoir conditions.

The conclusive part of Chapter IV shows the main features and implications relative to the use of the presented global FCT design model. 


\section{CHAPTER IV}

\section{FIELD DATA ANALYSIS CASES*}

Chapter III illustrated the main workflow and algorithms that have been constructed for the use of the global FCT model for field data interpretation mode as well as design mode.

This chapter presents three analyses and interpretations performed on three FCTs for three different formations: the Taylor sand interval in the Cotton Valley formation, the Haynesville shale and the Mesaverde sand. Subsequently, these same three field cases are used as base cases to illustrate the capabilities of the global FCT design model and how to generate optimized FCT designs.

These field cases have been originally presented in Mohamed, Nasralla, Sayed, Marongiu-Porcu, and Ehlig-Economides (2011) ${ }^{*}$, Marongiu-Porcu et al. (2011) ${ }^{*}$, and Marongiu-Porcu et al. (2014)*.

\footnotetext{
"Reproduced with permission of SPE from "Evaluation of After-Closure Analysis Techniques for Tight and Shale Gas Formations" by Mohamed, I.M., Nasralla, R.A., Sayed, M.A., Marongiu-Porcu, M., and Ehlig-Economides, C.A., 2011. SPE-140136-MS presented at the Hydraulic Fracturing Technology Conference, The Woodlands, Texas. Copyright 2011, Society of Petroleum Engineers. Further reproduction prohibited without permission.

"Reproduced with permission of SPE from "Global Model for Fracture Falloff Analysis" by Marongiu-Porcu, M., Ehlig-Economides, C.A., and Economides, M.J., 2011. SPE144028-MS presented at the North American Unconventional Gas Conference and Exhibition, The Woodlands, Texas. Copyright 2011, Society of Petroleum Engineers. Further reproduction prohibited without permission.

*Reproduced with permission of SPE from "Comprehensive Fracture Calibration Test Design" by Marongiu-Porcu, M., Ehlig-Economides, C.A., Retnanto, A., and Economides, M.J., 2014. SPE-168634-MS. presented at the Hydraulic Fracturing Technology Conference, The Woodlands, Texas. Copyright 2014, Society of Petroleum Engineers. Further reproduction prohibited without permission.
} 


\subsection{Cotton Valley Tight Gas Well}

The Cotton Valley tight gas formation is located in East Texas above the Haynesville Shale (McCain et al., 1993). The Cotton Valley trend can also be found in Northwest Louisiana; Figure 4.1 (reproduced from Thompson et al., 2010) shows the main variation in the stratigraphic column for the two states.

The formation rock contains shale, sandstone, and clay deposits that produce natural gas. The Cotton Valley formation is typified by low porosities (5 to $10 \%$ ) and permeability values in the micro-Darcy range, and may generally be described as medium-hard, gray sandstone. The Cotton Valley formation can be found at depths between 7,500 and 11,000 feet.

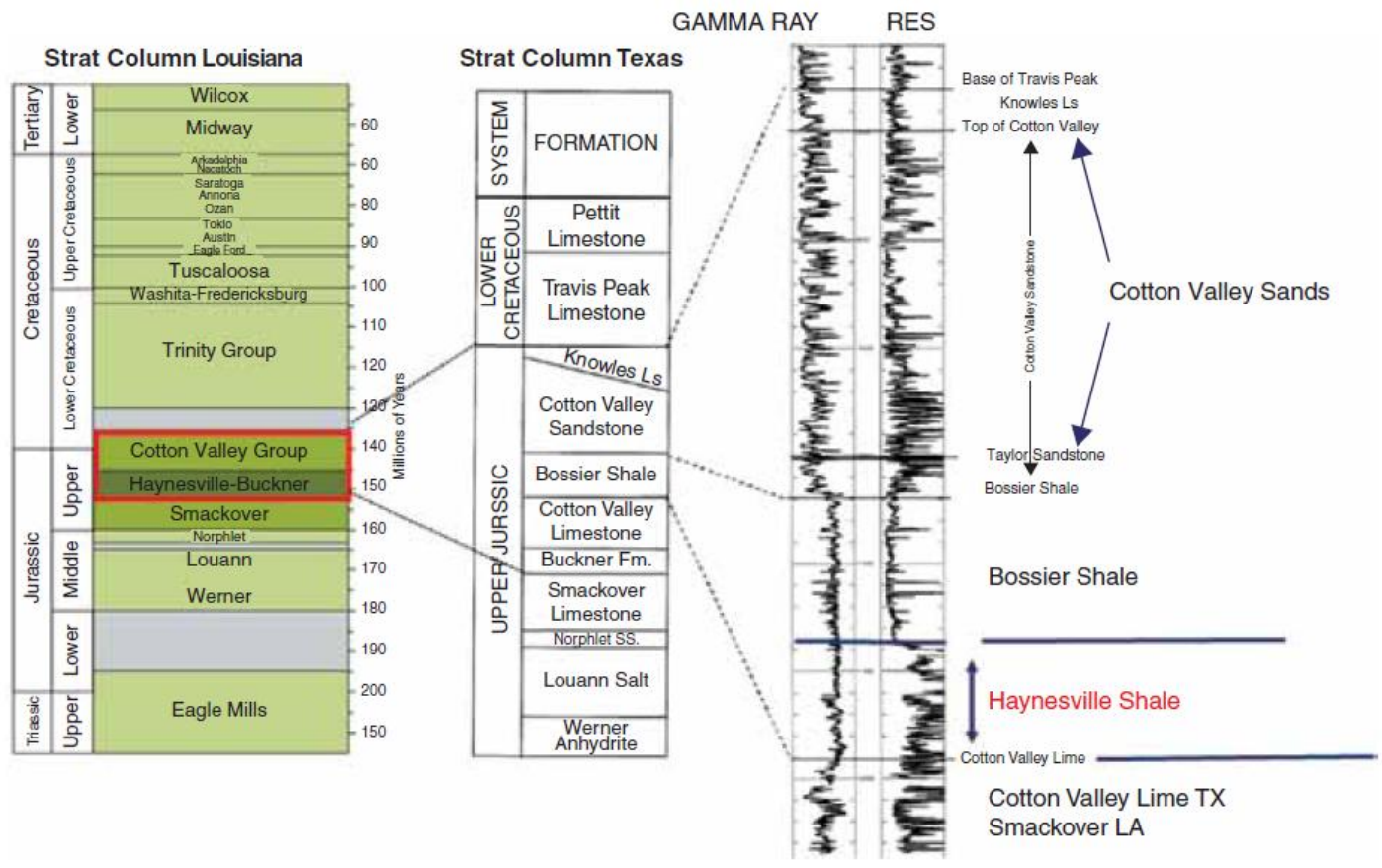

Figure 4.1 East Texas and Northwest Louisiana Stratigraphic Columns (from Thompson et al., 2010) 
An FCT test was performed in a vertical gas well completed in the Taylor sand interval in the Cotton Valley formation. The entire gross pay interval of $32 \mathrm{ft}(10,270$ 10,302 $\mathrm{ft}$ TVD) was perforated, but the petrophysical analysis performed by the operator indicated a net pay thickness of only $15 \mathrm{ft}$.

The test was conducted by pumping 36.25 bbls $(1,552 \mathrm{gal})$ of $3 \% \mathrm{KCl}$ water in a total of 19 minutes. The bottomhole pressure falloff was monitored for 6 days before retrieving the downhole gauges. Figure 4.2 illustrates the first four hours of this sequence of events.

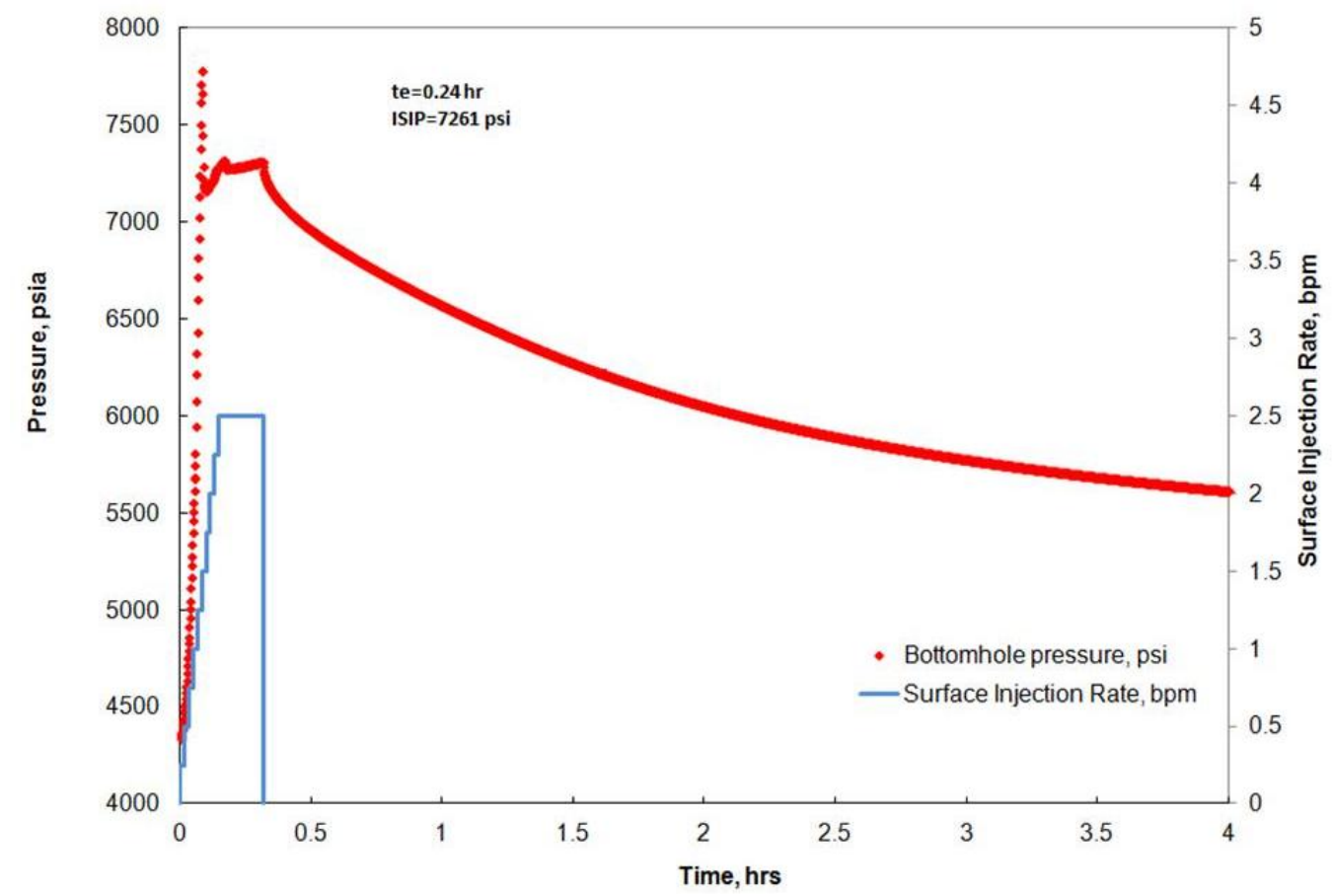

Figure 4.2 Bottomhole Pressure and Injection Profile for the Cotton Valley FCT

For this FCT the operator did not employ any fracture imaging method for fracture height estimation, but common experience on the specific field as well as their lithology and petrophysics characterization of the Cotton Valley/Taylor sands suggests 
that hydraulic fractures are contained by the bounding shale formations. This justifies use of the PKN fracture geometry model.

A representative open hole gamma-ray log was found in the U.S. Securities and Exchange Commission (2007) website, reproduced in Figure 4.3.

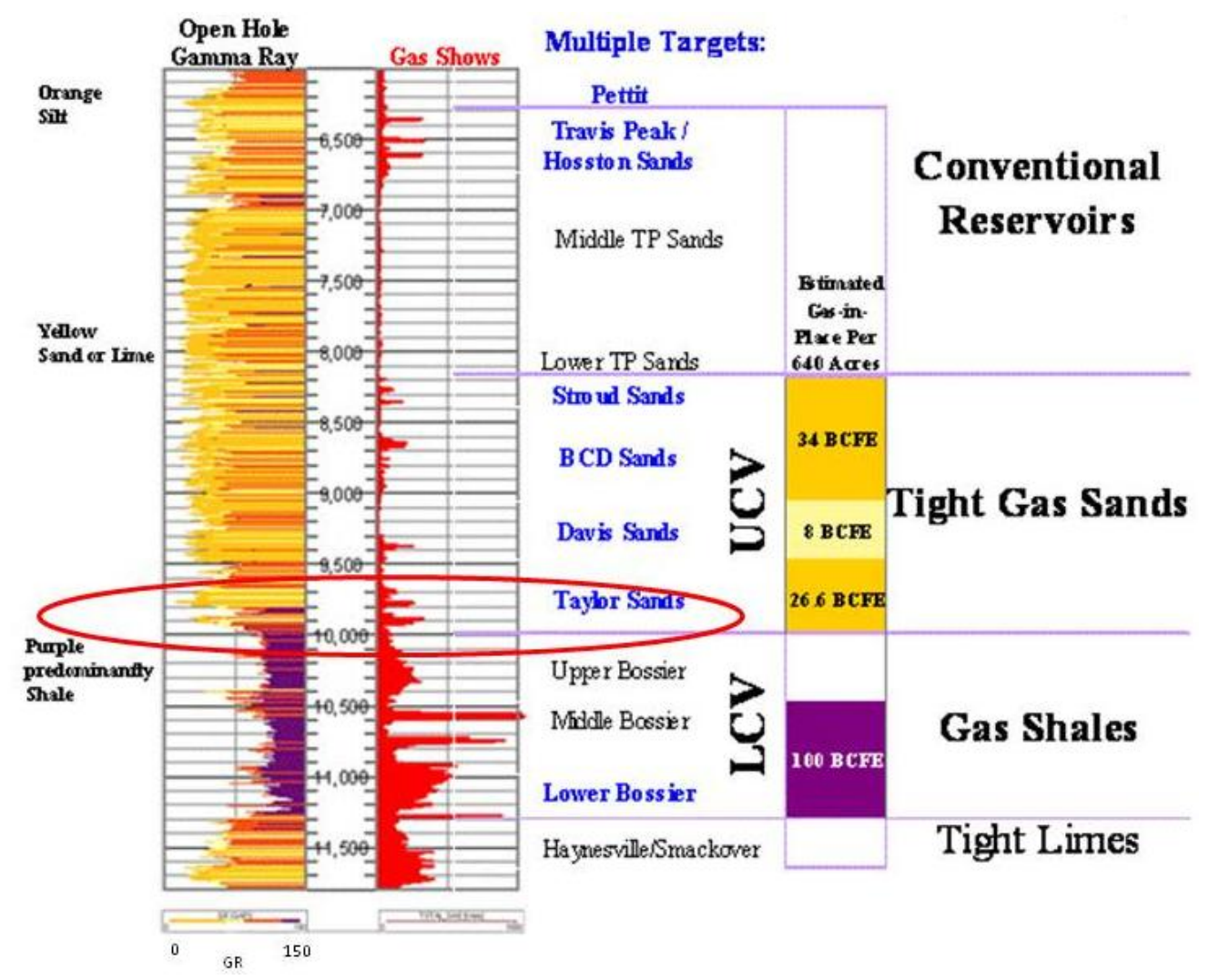

Figure 4.3 Gamma-Ray Log for the Cotton Valley Formation (from U.S. SEC website, 2007)

The Taylor sand (red circle) seems in fact laying in top of a thick high-stress shale (the purple colored upper Bossier Shale), while a thin shale bed is shown as potential upper confinement layer. Nevertheless, Figure 4.3 seems to suggest a larger gross pay than the some $30 \mathrm{ft}$ reported by the operator for the Taylor sand, strictly related to the uncertainties and vertical resolution of the gamma-ray log acquisition and 
processing systems. Table 4.1 provides reservoir and fluid properties used for the analysis.

Table 4.1 Input Parameters for the Cotton Valley FCT Analysis

\begin{tabular}{|c|c|}
\hline$B_{g}($ Res bbl/MSCF) & 0.0043 \\
\hline$\mu_{g}(\mathrm{cp})$ & 0.0223 \\
\hline$\gamma_{g}$ & 0.7 \\
\hline$c_{t}\left(10^{-5} \mathrm{psi}^{-1}\right)$ & 8.6 \\
\hline$E^{\prime}\left(10^{6} \mathrm{psi}\right)$ & 6 \\
\hline ISIP (psi) & 7,260 \\
\hline$\phi(\%)$ & 6.5 \\
\hline$S_{w}(\%)$ & 45 \\
\hline$h_{\text {gross }}(\mathrm{ft})$ & 32 \\
\hline$h_{n e t}(\mathrm{ft})$ & 15 \\
\hline$r_{w}(\mathrm{ft})$ & 0.354 \\
\hline $\begin{array}{c}\text { Formation } \\
\text { Temperature }\left({ }^{\circ} \mathrm{F}\right)\end{array}$ & 270 \\
\hline
\end{tabular}

Figure 4.4 shows the $\log -\log$ diagnostic plot for the recorded wellbore pressure falloff data in terms of the real-gas potential function $m(p)$, for an ISIP of 7,261 psi.

All the anticipated features are easily identifiable from this figure. The $3 / 2$ slope trend is visible for almost an entire logarithmic cycle, and a clear departure from this trend is identified at $\Delta t_{c}=1 \mathrm{hr}$ and $\Delta m(p)_{c}{ }^{\prime}=1.3510^{9} \mathrm{psi}^{2} / \mathrm{cp}\left(\Delta p_{c}{ }^{\prime}=2,977 \mathrm{psi} ; \Delta p_{c}=\right.$ 893 psi), giving a closure pressure of 6,368 psi.

Using the values for $\Delta t_{c}, \Delta p_{c}$, and $\Delta p_{c}$, Eqs. 3.19 and 3.20 are then used to calculate the parameters $m_{N}$ and $b_{N}$, respectively -299 and 7,660 psi.

Since information relative to fracture height and lithology-based height containment are not available, the instruction blocks $4 \mathrm{~B}$ and $5 \mathrm{~B}$ illustrated in Section 
3.5.1 are used to complete the determination of the $\mathrm{AC}$ and $\mathrm{BC}$ parameters necessary for the construction of the global FCT model.

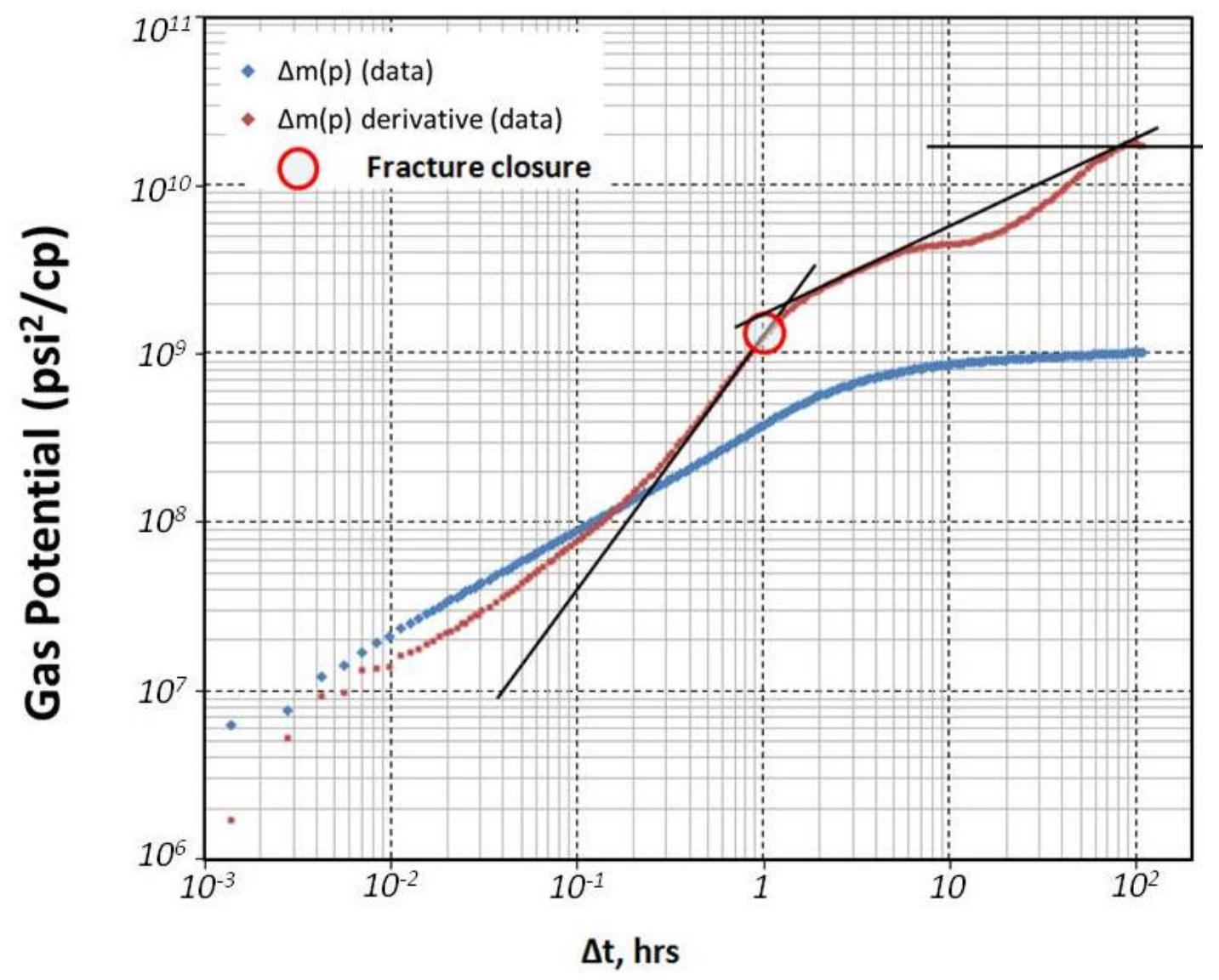

Figure 4.4 Log-Log Diagnostic Plot for the Recorded Wellbore Pressure Falloff Data of the Cotton Valley FCT

The late time portion of the wellbore pressure falloff data represented in Figure 4.4 is reasonably indicating pseudo-radial flow, with the flat derivative level at $1.8510^{10}$ $\mathrm{psi}^{2} / \mathrm{cp}\left(\Delta p^{\prime}=42,000 \mathrm{psi}\right)$. The effective reservoir permeability in the exposed reservoir region is then calculated using Eq. 3.23, providing a value of $0.0095 \mathrm{md}$, which is in excellent agreement with operator's common experience on the specific formation. 
The reservoir pressure is then calculated using Eq. 3.25, providing a value of as 4,804 psi.

A guess initial value for the fracture half length has then been calculated using Eq. 3.24 rearranged for $x_{f}$; in fact, since linear flow appears as a $1 / 2$ slope derivative trend before the radial flow, using the point $\Delta t=3.38 \mathrm{hr}$ and $\Delta m^{\prime}(p)=3 \cdot 10^{9} \mathrm{psi}^{2} / \mathrm{cp}$-cycle, a value of $80 \mathrm{ft}$ is obtained for the fracture half length.

The values of $g_{c}\left(\Delta t_{D, c}, \alpha\right)$ and fracture fluid efficiency $\eta$ are determined using Eqs. 2.13 and 3.28, for the known value of $\Delta t_{c}$, obtaining respectively 4.4 and $67.5 \%$.

Then, the values of the average total leakoff rate during the FCT injection and during the shut-in are calculated using Eqs. 3.31 and 3.32, obtaining respectively 0.815 bpm and 0.405 bpm.

The remaining procedure described in instruction block 6 of Section 3.5.1 is then used to generate the best-fitting curve (pressure match) of the wellbore pressure falloff data recorded during the shut-in, starting from the guess initial value for the fracture half length of $80 \mathrm{ft}$. Figure 4.5 shows the final global model match for both pressure change and logarithmic derivative generated for the Cotton Valley FCT. This match is based on a final refined value of $50 \mathrm{ft}$ for the fracture half-length. Using this value in the proper set of equations reported in Table 2.2 for the indicated 2D PKN fracture propagation model, it is then obtained a fracture height $h_{f}=77 \mathrm{ft}$, leakoff coefficient $C_{L}=0.00079$ $\mathrm{ft} / \mathrm{min}^{0.5}$, and average fracture width $\bar{w}_{e}=0.212$ inches.

The value of fracture height reported above falls well within the realistic range that can be expected from the gamma-ray characterization presented in Figure 4.3.

Furthermore, a check on the consistency of the results is performed for the fracture fluid efficiency, which is re-calculated with the specific equation in Table 2.2, obtaining an excellent confirmation of $\eta_{e}=67 \%$. A second check is done using the values of fracture net pressure at immediate shut-in, comparing the stiffness-based relation (Eq. 2.18) and the definition of fracture net pressure; this check also provides a robust validation of the results, obtaining respectively 868 psi and 893 psi, thus also 
validating the linear elastic rock behavior assumption and excluding the possibility of poroelastic and plastic rock constitutive behavior.

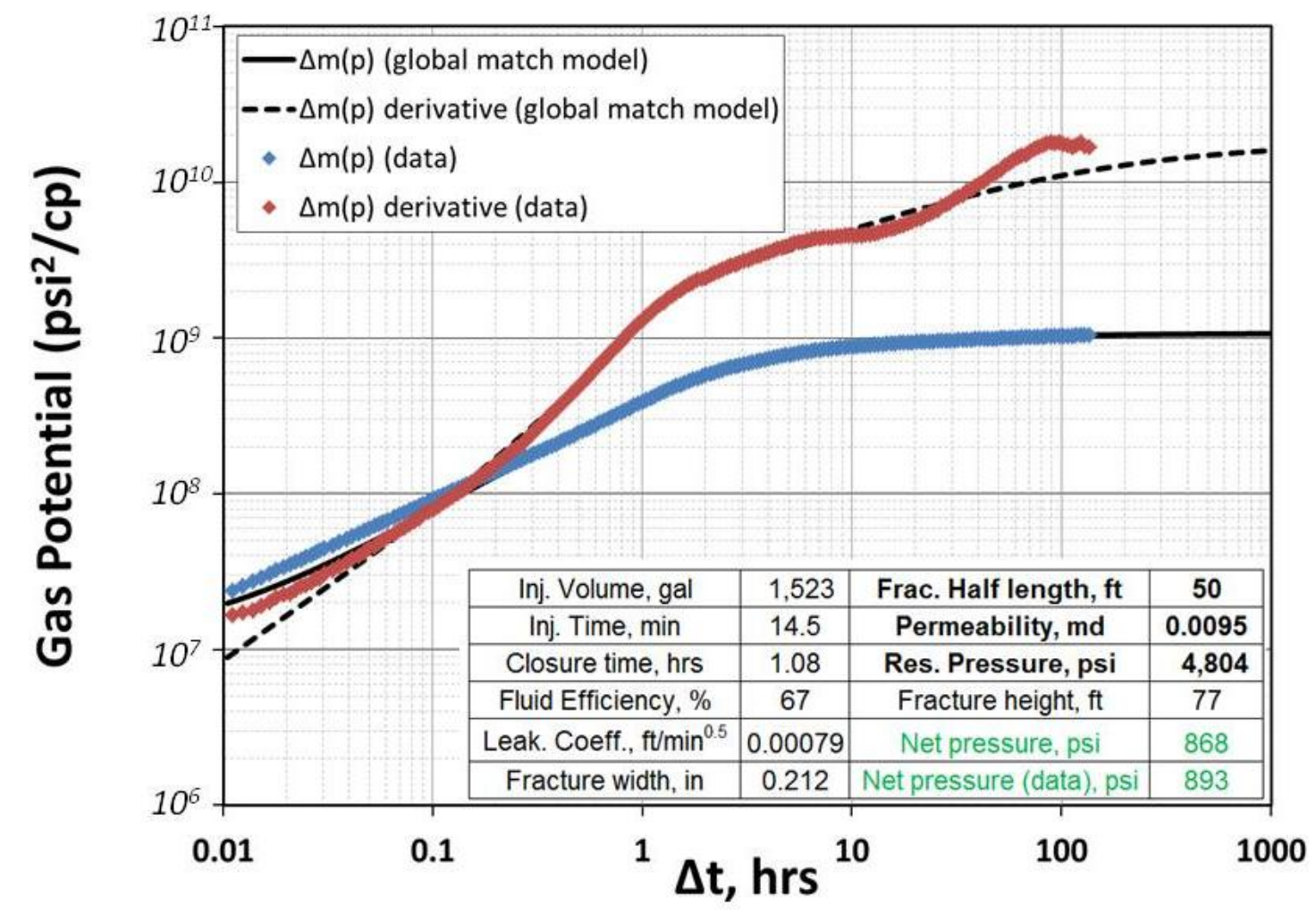

Figure 4.5 Final Global Model Match for the Cotton Valley FCT

The $\mathrm{BC}$ portion of the global match in Figure 4.5 looks excellent, as well as does the first part of the AC portion. However, after about 5 hours of shut-in time the data show a more complex behavior than that exhibited by the model itself, and arrives earlier at the level of the derivative interpreted as pseudo-radial flow.

A last relevant comment is due, in regards of the noticeable difference between the guess initial value for the fracture half length of $80 \mathrm{ft}$ calculated using linear-flow regime equation (Eq.3.24) and the final global model analysis output of $50 \mathrm{ft}$. This issue with the flow regime-based analysis for the AC linear flow was firstly illustrated in 
Marongiu-Porcu et al. (2014). They pointed out that drawdown models for the linear flow regime, when used for FCT modeling tend to overestimate the value of fracture length because of superposition distortion in the falloff transient. In turn the global FCT model presented in this dissertation accounts for superposition using the actual leakoff injection history.

\subsection{Haynesville Shale Gas Well}

The Haynesville shale gas formation is located in Northwest Louisiana, East Texas, and extends into Arkansas. Recalling Figure 4.1 (which shows the main variation in the stratigraphic column for East Texas and Louisiana), it arises that the Haynesville hale is overlain by the Bossier Shale, which in turn is overlain by the Cotton Valley Sandstone. In turn, The Haynesville shale lays above the Cotton Valley limestone in Texas and the Smackover limestone in Louisiana (Thompson et al., 2010).

The Haynesville shale is a very promising formation due to its abnormal high pressure (pore pressure gradients reported up to $0.95 \mathrm{psi} / \mathrm{ft}$ ) and large thickness (gross thickness reported between 75 and $400 \mathrm{ft}$ ); it can generally be found at depths between 11,000 and 13,000 feet, with formation temperature greater than $300{ }^{\circ} \mathrm{F}$, average formation porosity of $7 \%$ and water saturation of approximately $30 \%$.

The FCT considered in this analysis has been previously studied and presented by Xue and Ehlig-Economides (2013); the test was conducted on a single cluster located at the toe of a cased-hole horizontal well (at an average true vertical depth of $12,500 \mathrm{ft}$ ) by pumping $20 \mathrm{bbl}(840 \mathrm{gal})$ of $1 \% \mathrm{KCl}$ water at an average rate of $2.2 \mathrm{bpm}$ for 9 minutes. The surface pressure was monitored for 355 hours, and the bottomhole pressure was converted from the surface pressure values by adding a hydraulic pressure along the vertical depth of $12,500 \mathrm{ft}$ using a well fluid gradient of $0.433 \mathrm{psi} / \mathrm{ft}$. Figure 4.6 illustrates the first two hours of this sequence of events. 
For this FCT the operator did not provide a fracture height estimation via fracture imaging methods, and as a further complication the FCT was performed from a horizontal wellbore.

The extensive reported gross thickness for the Haynesville shale suggests use of the radial fracture geometry model; Table 4.2 provides reservoir and fluid properties used for the analysis.

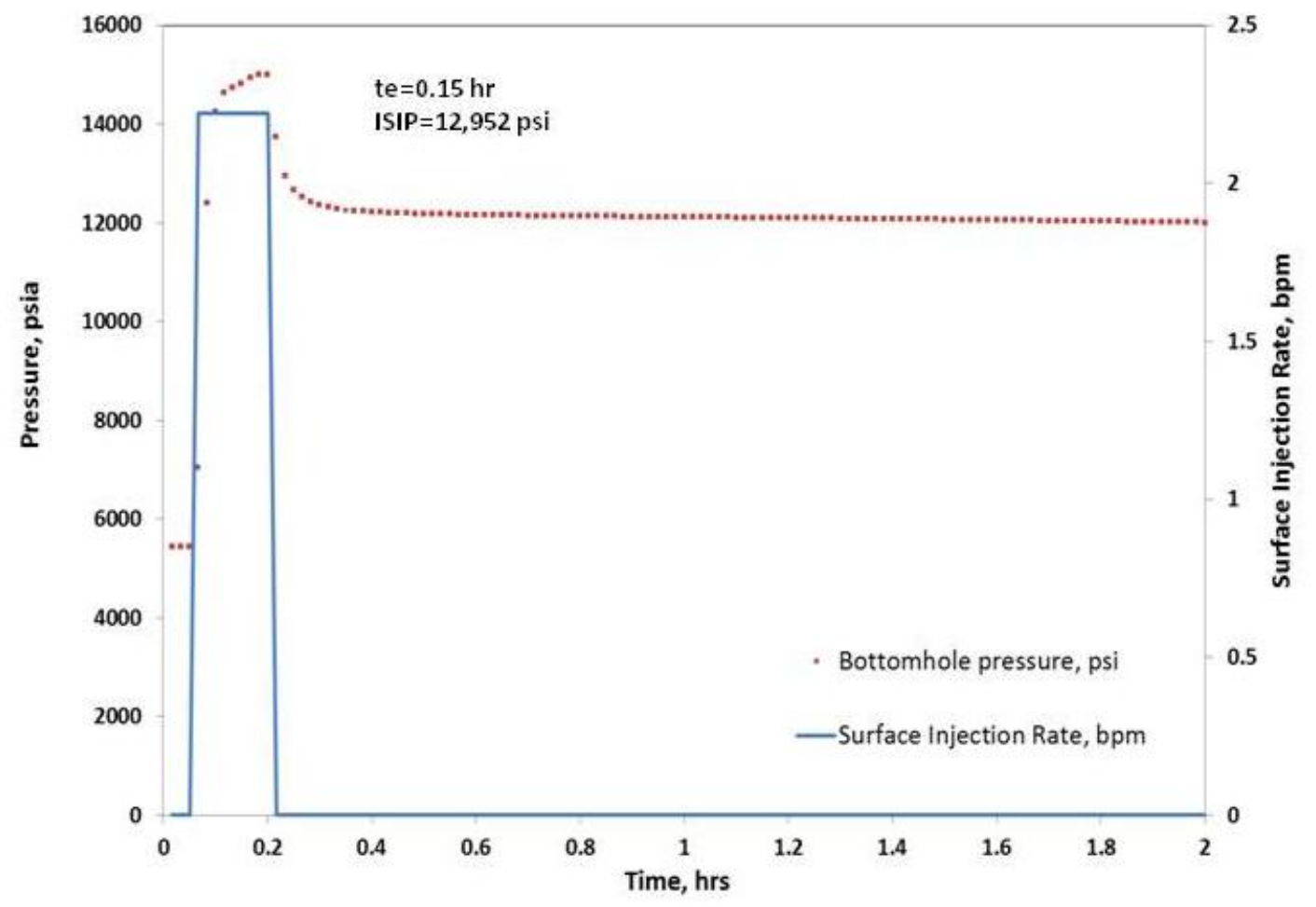

Figure 4.6 Bottomhole Pressure and Injection Profile for the Haynesville FCT

A representative open hole gamma-ray log was provided by Hammes et al. (2011), reproduced in Figure 4.7; the Haynesville shale gas formation is bounded within the green segments), confirming the indications of a thick gross interval on the order of $150 \mathrm{ft}$. 
Table 4.2 Input Parameters for the Haynesville FCT Analysis

\begin{tabular}{|c|c|}
\hline$B_{g}$ (Res bbl/MSCF) & 0.0032 \\
\hline$\mu_{g}(\mathrm{cp})$ & 0.038 \\
\hline$\gamma_{g}$ & 0.7 \\
\hline$c_{t}\left(10^{-5} \mathrm{psi}^{-1}\right)$ & 2.98 \\
\hline$E^{\prime}\left(10^{6} \mathrm{psi}\right)$ & 6 \\
\hline ISIP (psi) & 12,952 \\
\hline$\phi(\%)$ & 7 \\
\hline$S_{w}(\%)$ & 30 \\
\hline$h_{\text {gross }}(\mathrm{ft})$ & 150 \\
\hline$h_{n e t}(\mathrm{ft})$ & 150 \\
\hline$r_{w}(\mathrm{ft})$ & 0.354 \\
\hline $\begin{array}{c}\text { Formation } \\
\text { Temperature }\left({ }^{\circ} \mathrm{F}\right)\end{array}$ & 360 \\
\hline
\end{tabular}

Figure 4.8 shows the log-log diagnostic plot for the recorded wellbore pressure falloff data in terms of the real-gas potential function $m(p)$, for an ISIP of 12,952 psi.

Interestingly, this diagnostic plot presents some departure from the ideal anticipated features. First, the obvious deviation from the early BC behavior $3 / 2$ slope (i.e., between 0.1 and $1 \mathrm{hr}$ ) is an indication of what Barree and Mukherjee (1996) introduced and defined as "fracture-height recession", as also reported by Xue and Ehlig-Economides (2013), who showed how abnormal leakoff behavior appears on the log-log diagnostic plot and observed that fracture-height recession would result in a derivative falling below the $3 / 2$ slope derivative trend.

This specific FCT log-log diagnostic plot has already been shown in Figure 3.5 (reproduced from Xue and Ehlig-Economides, 2013), in order to illustrate the logarithmic derivative steep upward trend, and the closure time and pressure are being picked when the tangent to the derivative has a slope of $3 / 2$. 


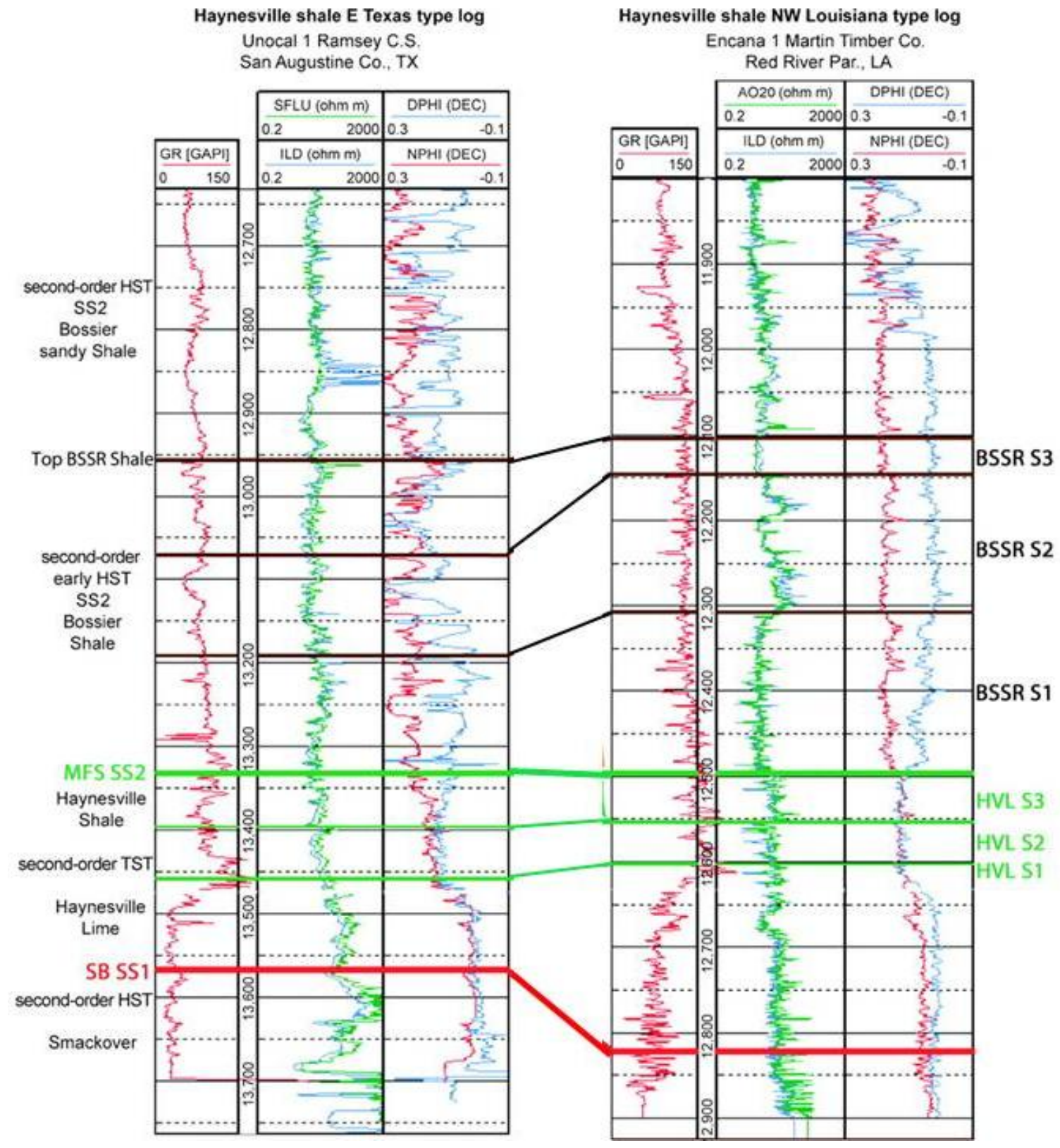

Figure 4.7 Gamma-Ray Log for the Haynesville Shale Formation (from Hammes et al., 2011) 


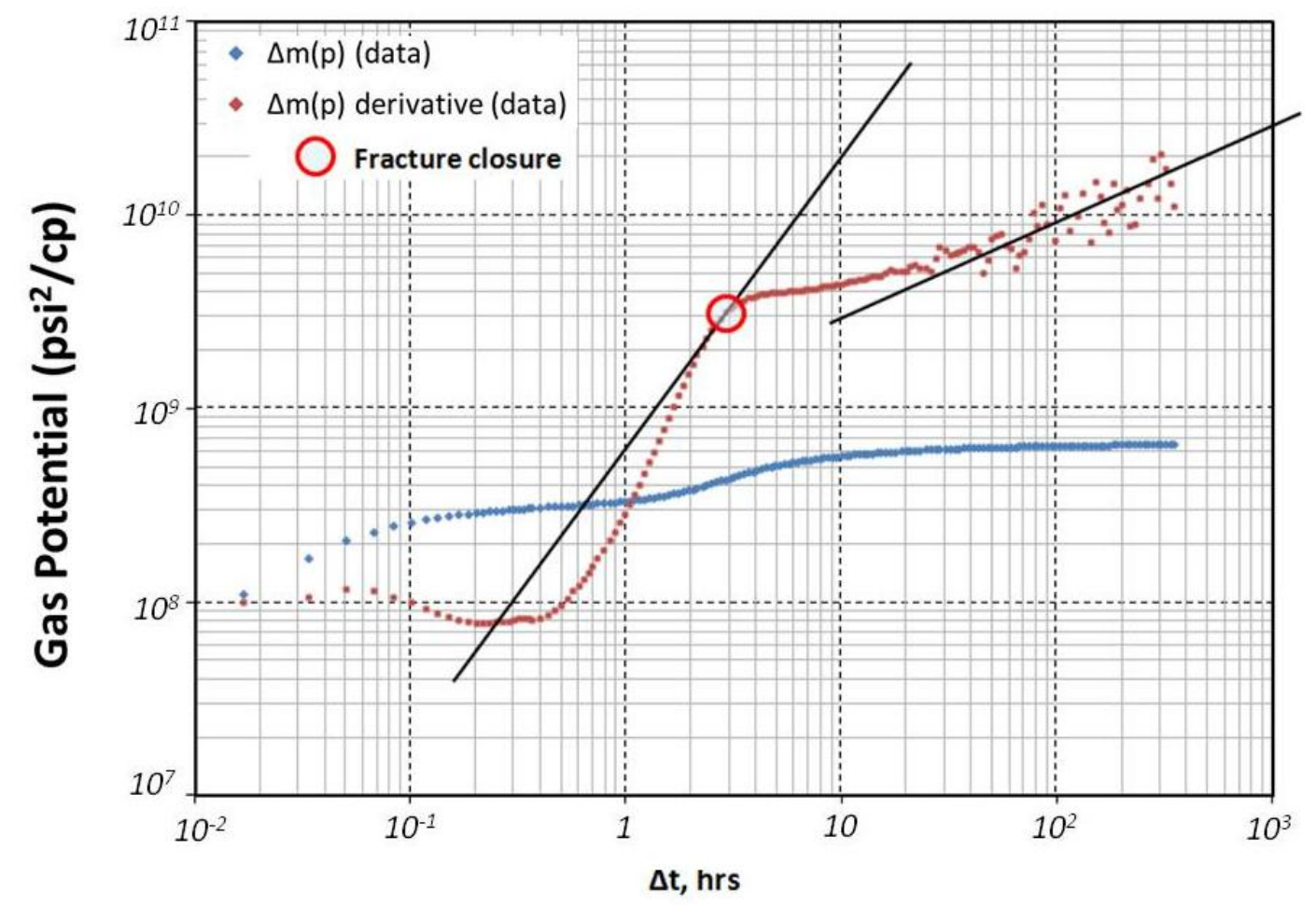

Figure 4.8 Log-Log Diagnostic Plot for the Recorded Wellbore Pressure Falloff Data of the Haynesville FCT

A clear departure from the $3 / 2$ slope is identified at $\Delta t_{c}=3 \mathrm{hr}$ and $\Delta m(p)_{c}{ }^{\prime}=$ $3.29 \cdot 10^{9} \mathrm{psi}^{2} / \mathrm{cp}\left(\Delta p_{c}{ }^{\prime}=8,335 \mathrm{psi} ; \Delta p_{c}=1,132 \mathrm{psi}\right)$, giving a closure pressure of 11,820 psi.

Using the values for $\Delta t_{c}, \Delta p_{c}$, and $\Delta p_{c}$, Eqs. 3.19 and 3.20 are then used to calculate the parameters $m_{N}$ and $b_{N}$, respectively -88.5 and 12,625 psi.

Since information relative to fracture height and lithology-based height containment are not available, the instruction blocks 4B and 5B illustrated in Section 3.5.1 are used to complete the determination of the $\mathrm{AC}$ and $\mathrm{BC}$ parameters necessary for the construction of the global FCT model.

For this FCT the absence of the pseudo-radial flow regime prevents direct estimation of the effective reservoir permeability in the exposed reservoir region. Xue and Ehlig-Economides (2013) provided three different estimates based on three different 
$\mathrm{AC}$ techniques; and general information of the reported ranges of effective reservoir permeability for the Haynesville shale gas formation (Younes et al., 2010; MarongiuPorcu et al., 2011; Song et al., 2011) suggests adopting their largest value, $k=680$ nd.The reservoir pressure is then estimated by extrapolating the late-time straight trend seen on a Horner plot of the injection falloff pressure data, providing a value of as 11,256 psi.

A guess initial value for the fracture radius has then been calculated using Eq. 3.21 rearranged for $R_{f}$, obtaining a value of $68 \mathrm{ft}$.

The values of $g_{c}\left(\Delta t_{D, c}, \alpha\right)$ and fracture fluid efficiency $\eta$ are determined using Eqs. 2.13 and 3.28, for the known value of $\Delta t_{c}$, obtaining respectively 9.1 and $86 \%$.

Then, the values of the average total leakoff rate during the FCT injection and during the shut-in are calculated using Eqs. 3.31 and 3.32, obtaining respectively 0.336 bpm and $0.093 \mathrm{bpm}$.

The remaining procedure described in instruction block 6 of Section 3.5.1 is then used to generate the best-fitting curve (pressure match) of the wellbore pressure falloff data recorded during the shut-in, starting from the guess initial value for the fracture radius of $68 \mathrm{ft}$.

Figure 4.9 shows the final global model match for both pressure change and logarithmic derivative generated for the Haynesville FCT. This match is based on a final refined value of $58 \mathrm{ft}$ for the fracture radius. Using this value in the proper set of equations reported in Table 2.2 for the indicated 2D radial fracture propagation model, it is then obtained a leakoff coefficient $C_{L}=0.00025 \mathrm{ft} / \mathrm{min}^{0.5}$, and average fracture width $\bar{w}_{e}=0.103$ inches.

A check on the consistency of these results is performed for the fracture fluid efficiency, which is re-calculated with the specific equation in Table 2.2, obtaining an excellent confirmation of $\eta_{e}=85 \%$.

The corresponding value of fracture height $\left(h_{f}=2 R_{f}=116 \mathrm{ft}\right.$ ) falls well within the realistic range that can be expected from the gamma-ray characterization presented in Figure 4.7, confirming as well the fracture propagation $2 \mathrm{D}$ radial model assumption. 


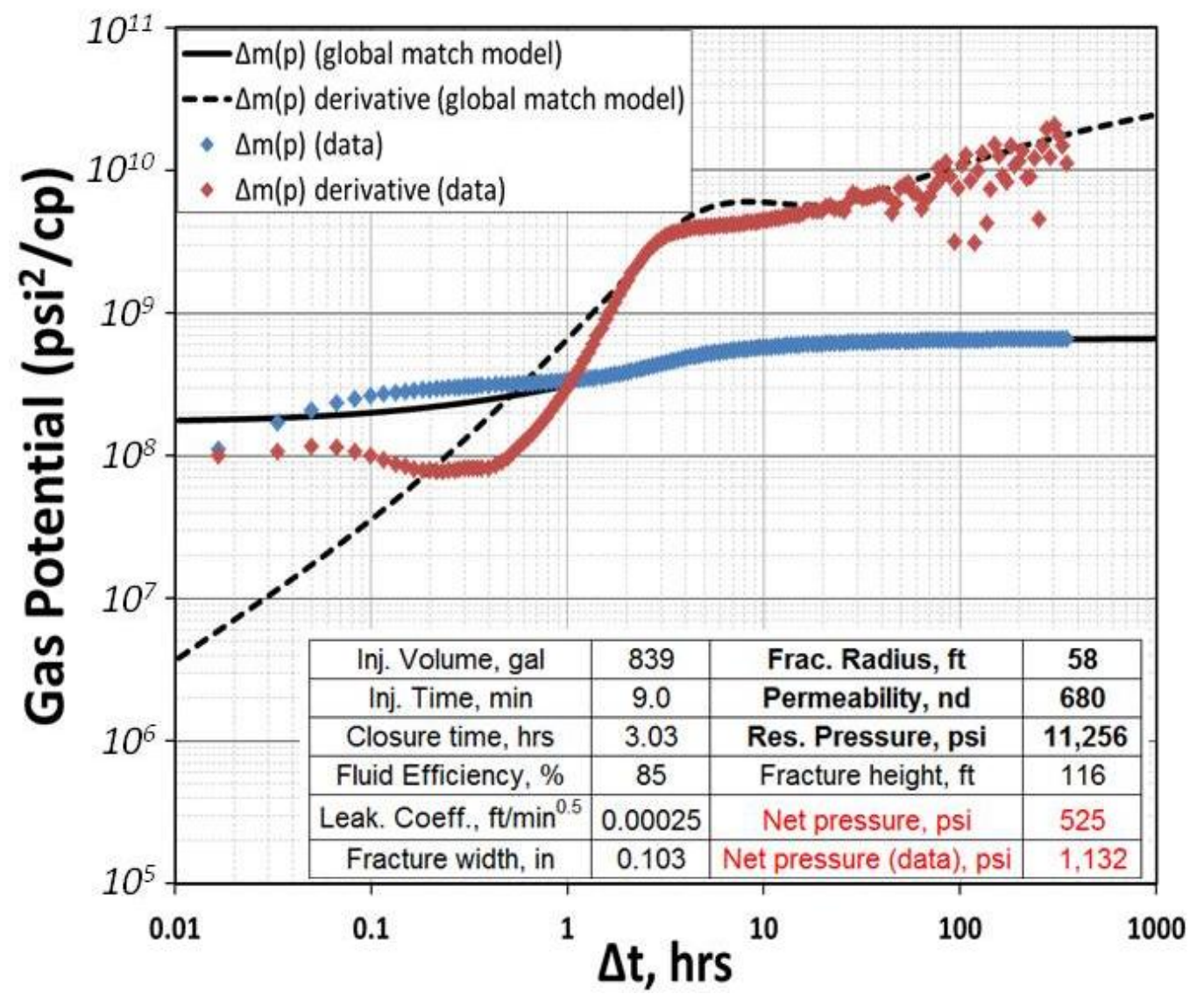

Figure 4.9 Final Global Model Match for the Haynesville FCT

Nevertheless, when the check on the values of fracture net pressure at immediate shut-in is performed comparing the stiffness-based relation (Eq. 2.18) and the definition of fracture net pressure, an apparent inconsistency arises, obtaining respectively $525 \mathrm{psi}$ and 1,132 psi. This inconsistency is due to the concurrent adverse impact of:

- lack of pseudo-radial flow regime (i.e., effective reservoir permeability cannot be determined, and thus the matching fracture radius is not unique);

- high likelihood of plastic rock constitutive behavior (i.e., abnormally high measured fracture net-pressure, typical of shales with high clays content);

- severe fracture-height recession that causes deviation from the early $\mathrm{BC}$ behavior $3 / 2$ slope and prevent to obtain a satisfactory $\mathrm{BC}$ match. 
The value of fracture radius that would provide an average fracture width $\bar{w}_{e}=$ 0.179 inches (corresponding to a stiffness-based value of net pressure that matches the 1,132 psi calculated from its definition) is $46.5 \mathrm{ft}$. In turn, the value of fracture radius that would fully honor Nolte's BC closure has been already calculated using Eq. 3.21 rearranged for $R_{f}$, as $68 \mathrm{ft}$. Neither one of these inferred fracture radii would provide a satisfactory global match for the Haynesville FCT.

In fact, the final global match based on the refined value of $58 \mathrm{ft}$ for the fracture radius, reveals the strength of this approach. Combining fundamental modeling elements from $\mathrm{BC}$ and $\mathrm{AC}$ observed events and trends, it has been possible to generate a consistent comprehensive global match for this convoluted Haynesville shale FCT, based on a fracture geometry that represents a reasonable and realistic tradeoff among several concurrent elements of departure from an ideal $\mathrm{BC}$ behavior as well as notelastic (plastic) rock constitutive behavior.

\subsection{Mesaverde Tight Gas Well}

The Mesaverde formation occurs in various structural basins in the western United States such as Piceance Basin, Powder River Basin, Uintah Basin, Washakie Basin, and Wind River Basin. Pierce (1997) described the Mesaverde formation as "interbedded light gray sandstone and gray shale in upper part; lower part massive, lightbuff, ledge-forming sandstone containing thin lenticular coal beds".The Mesaverde sand formation is typified by low porosities ( 7 to $12 \%$ ) and permeability values in the microDarcy range, and can be found at depths between 4,500 and 5,500 feet.

A maturity study from the Dolan Integration Group (2014) website shows the stratigraphic column of interest for the Mesaverde formation, reproduced in Figure 4.10.

Craig and Blasingame (2006) were the first to present this FCT on the tight gas vertical well 543-33, which targets 20 low-permeability Mesaverde sands in Piceance Basin at 4,954 ft of depth, with a reported net pay thickness of $12 \mathrm{ft}$. 


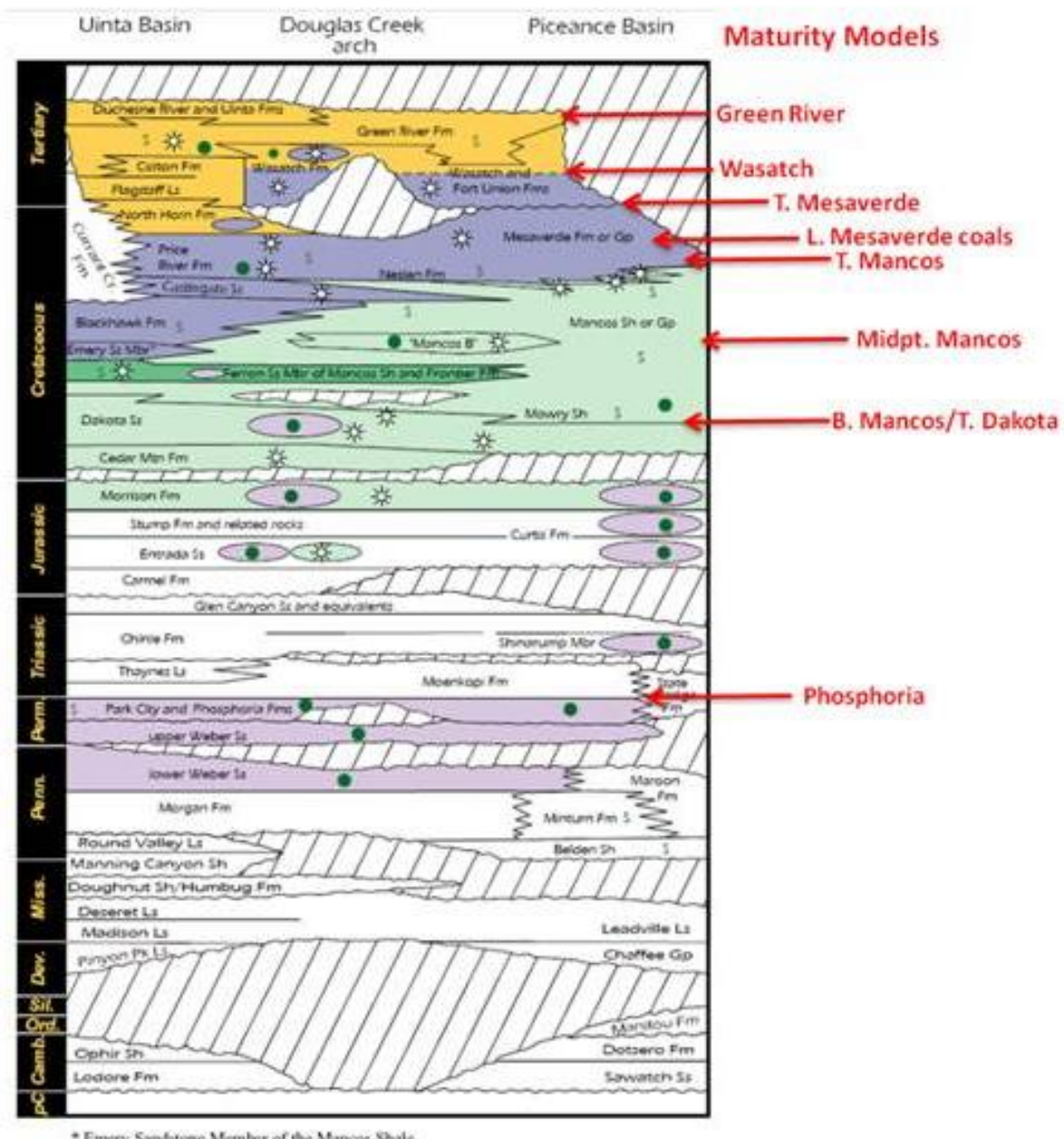

Figure 4.10 Stratigraphic Column Showing the Mesaverde Sandstone (from Dolan Integration Group Website, 2014)

The test was conducted by pumping $17.69 \mathrm{bbl}(738 \mathrm{gal})$ of $1 \% \mathrm{KCl}$ treated water at an average injection rate of $3.3 \mathrm{bbl} / \mathrm{min}$ for 5.3 minutes. The bottomhole pressure falloff was monitored for $16.2 \mathrm{hr}$ before retrieving the downhole gauges. Figure 4.11 illustrates the first four hours of this sequence of events, while Table 4.3 provides reservoir and fluid properties used for the analysis. 


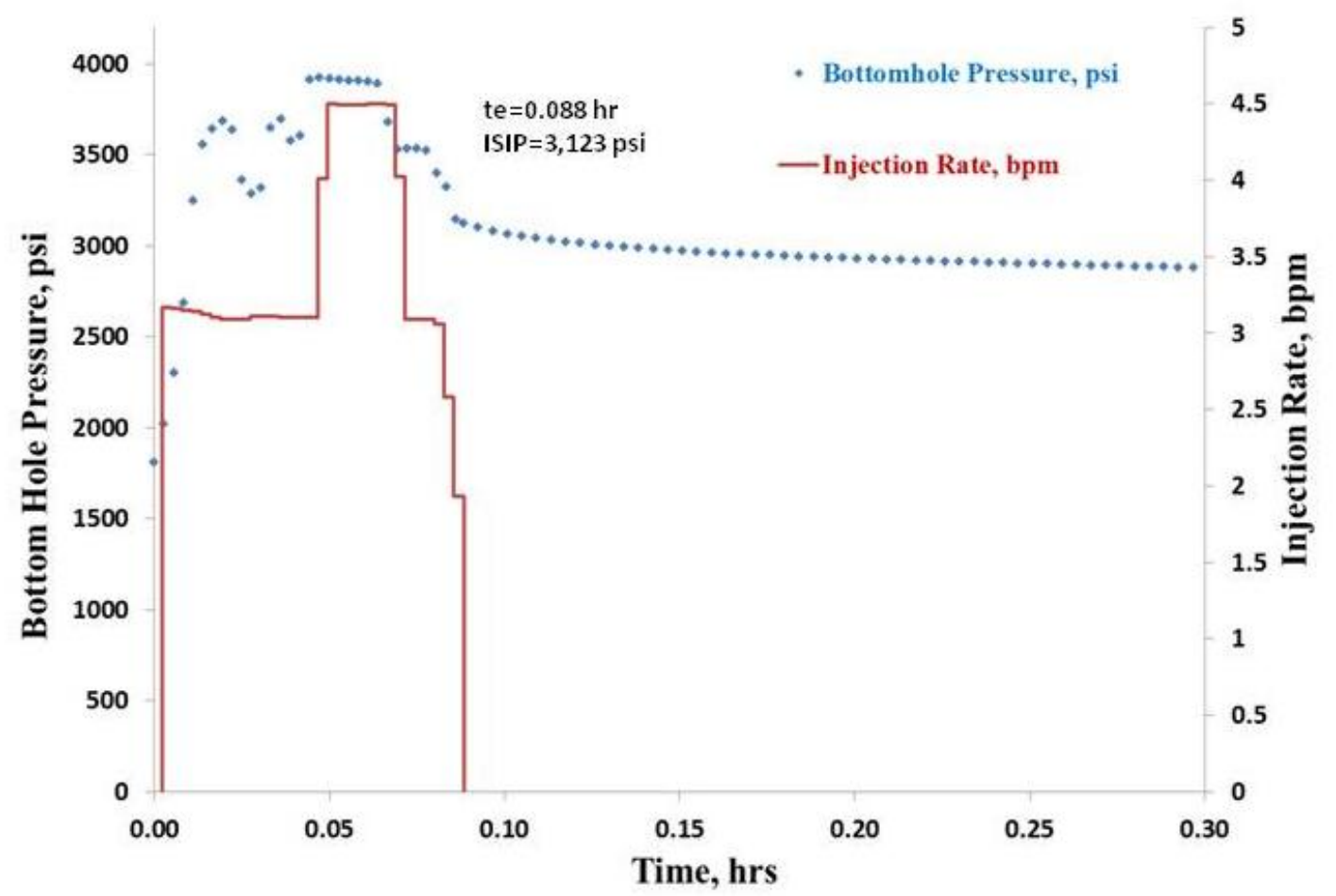

Figure 4.11 Bottomhole Pressure and Injection Profile for the Mesaverde FCT

Table 4.3 Input Parameters for the Mesaverde FCT Analysis

\begin{tabular}{|c|c|}
\hline $\boldsymbol{B}_{g}($ Res bbl/MSCF) & 0.0064 \\
\hline $\boldsymbol{\mu}_{g}(\mathbf{c p})$ & 0.017 \\
\hline$\gamma_{g}$ & 0.63 \\
\hline $\boldsymbol{c}_{\boldsymbol{t}}\left(\mathbf{1 0}^{-4} \mathbf{p s i}^{-1}\right)$ & 2.12 \\
\hline $\boldsymbol{E}^{\prime}\left(\mathbf{1 0 ^ { 6 }} \mathbf{p s i}\right)$ & 5.7 \\
\hline $\mathbf{I S I P}(\mathbf{p s i})$ & 3,123 \\
\hline $\boldsymbol{\phi}(\%)$ & 10 \\
\hline $\boldsymbol{S}_{w}(\%)$ & 50 \\
\hline $\boldsymbol{h}_{\text {gross }}(\mathbf{f t})$ & 14 \\
\hline $\boldsymbol{h}_{\text {net }}(\mathbf{f t})$ & 12 \\
\hline $\boldsymbol{r}_{w}(\mathrm{ft})$ & 0.354 \\
\hline $\begin{array}{c}\text { Formation } \\
\text { Temperature }\left({ }^{\circ} \mathrm{F}\right)\end{array}$ & 160 \\
\hline
\end{tabular}


Immediately following the FCT shut-in, the well was flowed at $100 \mathrm{Mscf} / \mathrm{D}$ for $141.7 \mathrm{hrs}$, then lowered at $98 \mathrm{Mscf} / \mathrm{D}$ for the next $24.3 \mathrm{hrs}$, then lowered at $60 \mathrm{Mscf} / \mathrm{D}$ for the next $0.6 \mathrm{hrs}$ and finally lowered at $50 \mathrm{Mscf} / \mathrm{D}$ for the final $0.1 \mathrm{hrs}$ before shutting the well in for a pressure buildup test lasting 14.95 days.

Craig and Blasingame (2006) used their type-curve method to match the post treatment buildup and provided a reservoir permeability of $0.012 \mathrm{md}$, a reservoir pressure of 2,402 psi, fracture half-length of $121 \mathrm{ft}$ and a fracture conductivity of 18 md ft.

Mohamed, Nasralla, Sayed, Marongiu-Porcu, and Ehlig-Economides (2011) provided an interpretation of the same buildup using the commerical software Saphir ${ }^{\mathrm{TM}}$ to perform a classical Bourdet et al. (1989) log-log diagnostic plot analysis. Their final match and numerical results are reproduced in Figure 4.12, from which the obvious conclusion is that, as common in low permeability reservoirs, the buildup was not long enough to reveal pseudo-radial flow and its flat level of logarithmic superposition derivative that provides a direct measure for the effective reservoir permeability. In fact, the derivative level used for the buildup match in Figure 4.12 (dashed line), that reflects Craig and Blasingame (2006) reservoir permeability of $0.012 \mathrm{md}$, is well above any of the data available for the analysis.

Use of any fracture imaging method for fracture height estimation was reported, but Craig and Blasingame (2006) supported the claim of a good fracture vertical confinement; this suggests use of the PKN fracture geometry model, due to the expected fracture height containment between the confining shales.

A representative gamma-ray log was provided by the University of Kansas Center for Research, Inc. (2009), reproduced in Figure 4.13; the lower 15-ft bed (red circle) appears as just a part of the total formation pay extension (green circle), so it will be of high importance to verify the assumptions made on the expected vertical fracture containment and the PKN fracture geometry model. 


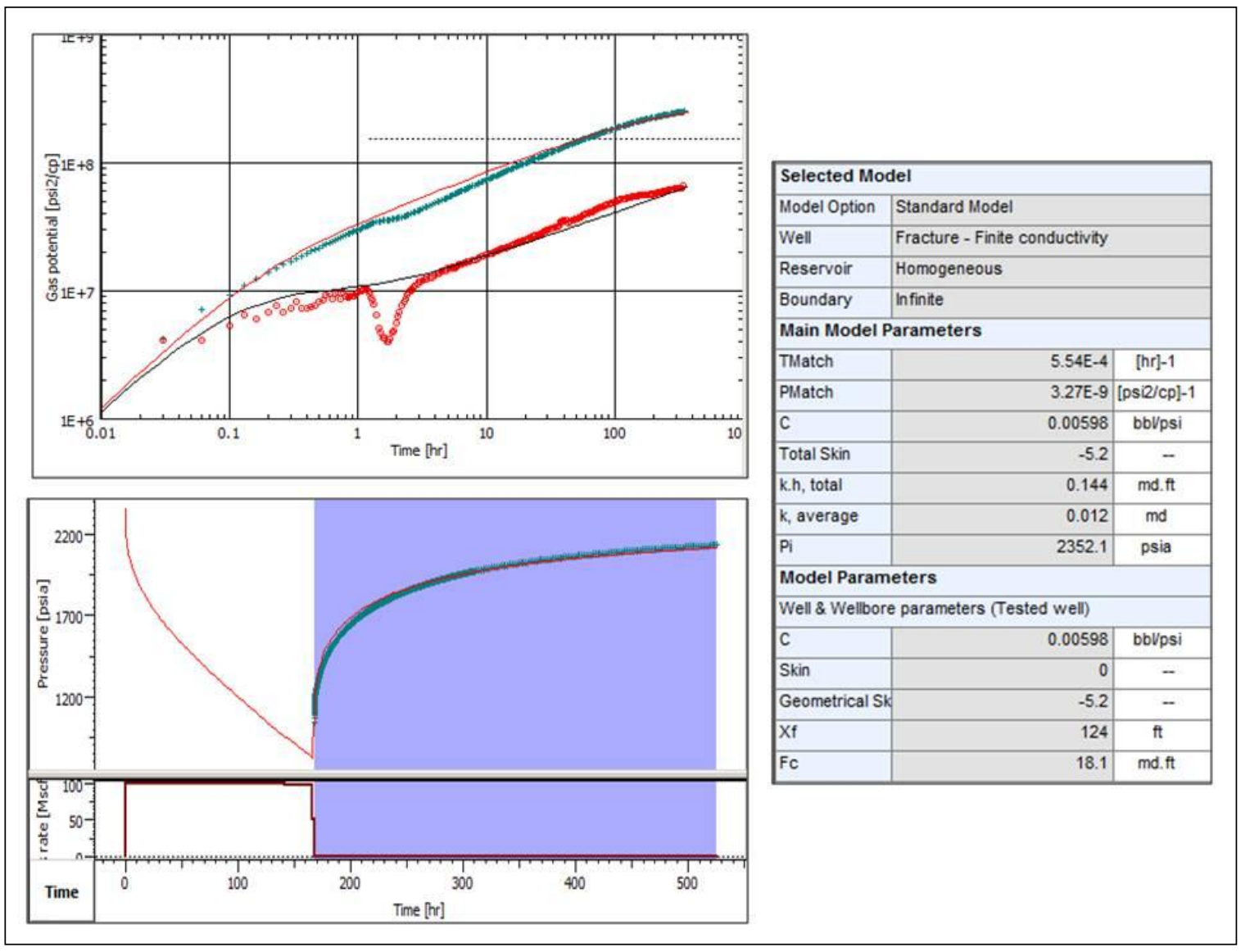

Figure 4.12 Interpretation of the Post-FCT Buildup Performed with Saphir ${ }^{\mathrm{TM}}$ for the Mesaverde Well (from Mohamed, Nasralla, Sayed, Marongiu-Porcu, and EhligEconomides, 2011)

In fact, the University of Kansas Center for Research, Inc. (2009) reported reservoir thicknesses in excess of $50 \mathrm{ft}$, while Knutson (1976) reported reservoir thicknesses ranging from $30 \mathrm{ft}$ to $50 \mathrm{ft}$.

Figure 4.14 shows the log-log diagnostic plot for the recorded wellbore pressure falloff data in terms of the real-gas potential function $m(p)$, for an ISIP of 3,123 psi. This diagnostic plot presents a departure from the ideal anticipated features.

The deviation from the early $\mathrm{BC}$ behavior $3 / 2$ slope at very early shut-in time (i.e., between $10^{-2}$ and $10^{-1} \mathrm{hrs}$ ) is an indication of what Barree and Mukherjee (1996) introduced and defined as "pressure dependent leakoff from fissure opening", as also 
reported by Xue and Ehlig-Economides (2013), who noted that the logarithmic derivative appears above the $3 / 2$ slope trend expected for normal leakoff behavior during pressure dependent leakoff.

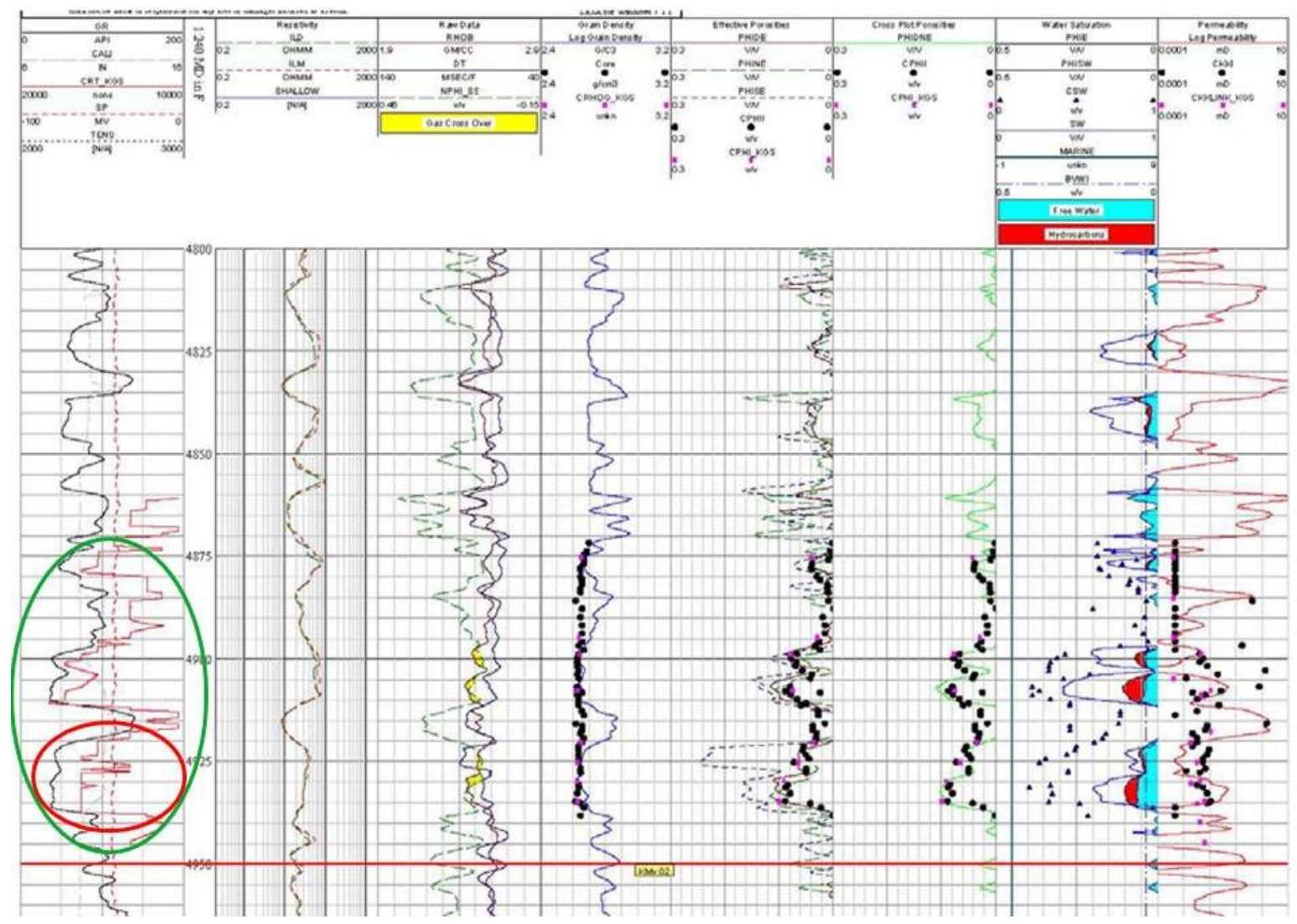

Figure 4.13 Gamma-Ray Log and Petrophysics Interpretation for the Mesaverde
Sandstone (from University of Kansas Center for Research, Inc., 2009)

Interestingly, Mohamed, Nasralla, Sayed, Marongiu-Porcu, and EhligEconomides (2011) presented a comparative log-log diagnostic plot for the FCT and the previously mentioned buildup data combined (reproduced in Figure 4.15). 


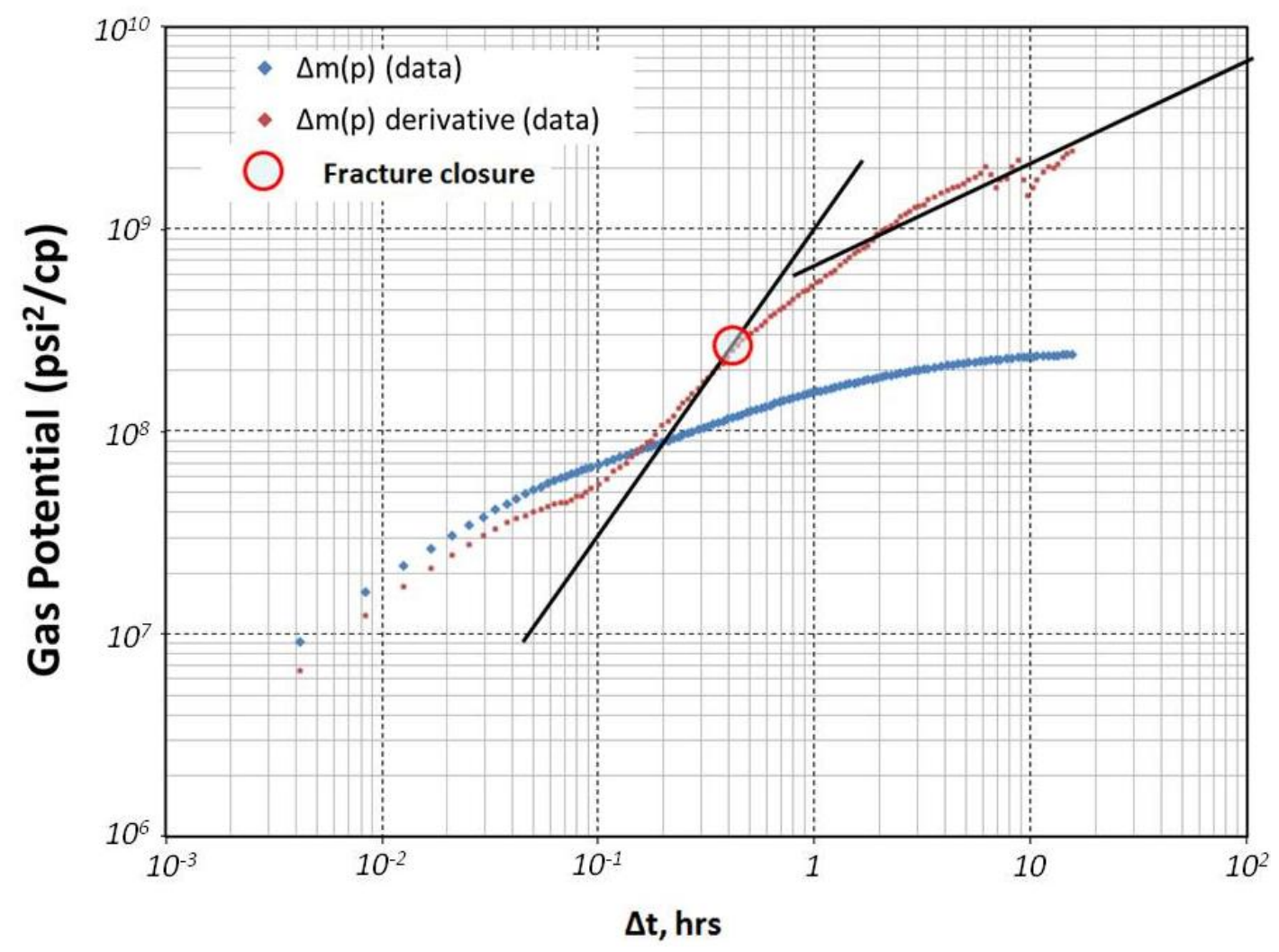

Figure 4.14 Log-Log Diagnostic Plot for the Recorded Wellbore Pressure Falloff Data of the Mesaverde FCT

The element of extreme interest in this combined representation is that once the FCT logarithmic derivative achieves its AC pseudo-linear flow, it lays reasonably close to the buildup logarithmic derivative, just slightly on the left-hand side, suggesting a somewhat shorter perceived fracture extension respect to the buildup. This provided an important empirical validation of the validity of the presented FCT analysis methodology presented in this dissertation.

A clear departure from the $3 / 2$ slope is identified at $\Delta t_{c}=0.46 \mathrm{hrs}$ and $\Delta m(p)_{c}{ }^{\prime}=$ $2.85 \cdot 10^{8} \mathrm{psi}^{2} / \mathrm{cp}\left(\Delta p_{c}{ }^{\prime}=790 \mathrm{psi} ; \Delta p_{c}=330 \mathrm{psi}\right)$, giving a closure pressure of $2,792 \mathrm{psi}$.

Using the values for $\Delta t_{c}, \Delta p_{c}$, and $\Delta p_{c}$, Eqs. 3.19 and 3.20 are then used to calculate the parameters $m_{N}$ and $b_{N}$, respectively -58.6 and 3,072 psi. 


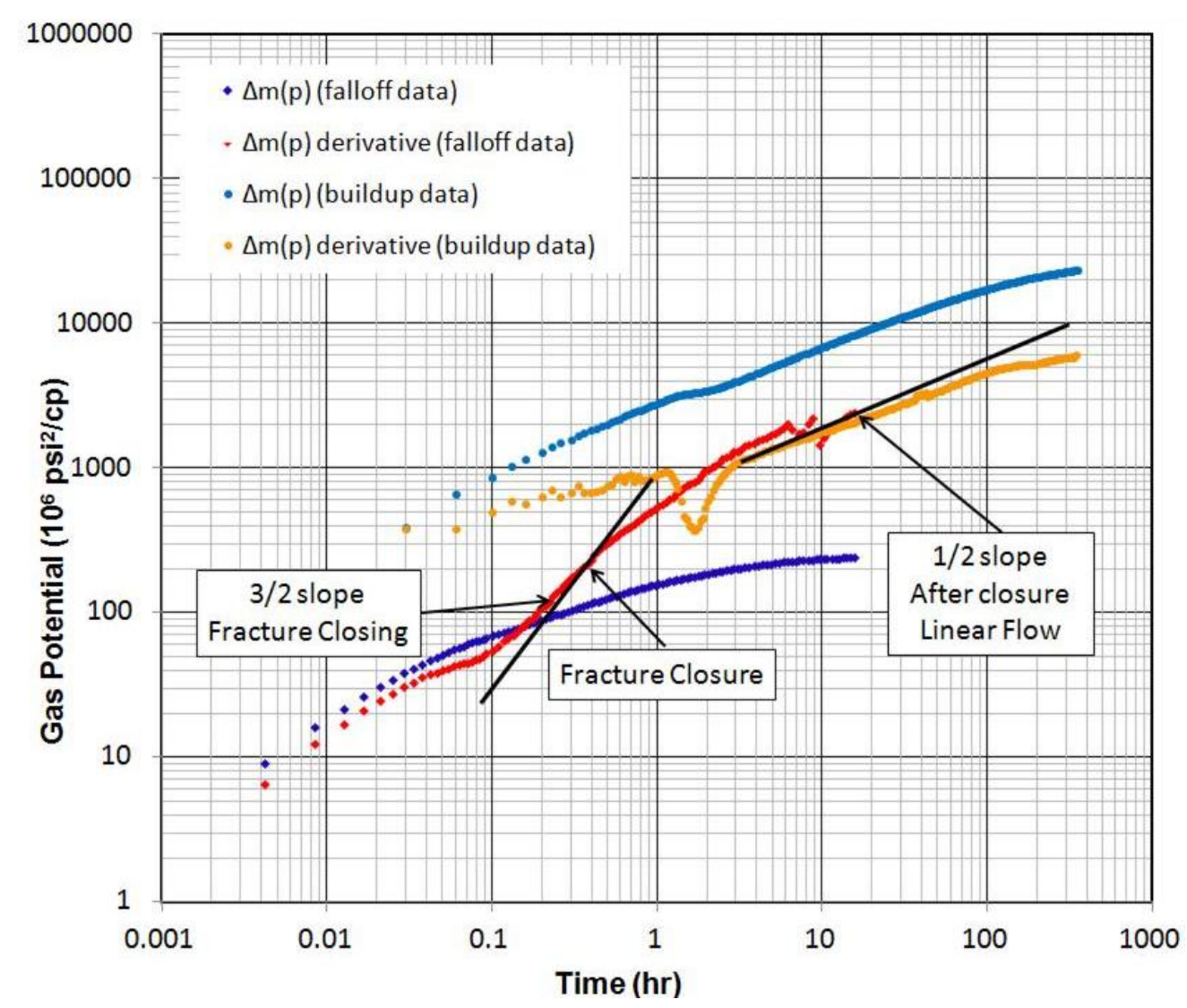

Figure 4.15 Log-Log Diagnostic Plot for the Combined Recorded Wellbore Pressure Falloff Data of the Mesaverde FCT and the Subsequent Buildup

Since information relative to fracture height and lithology-based height containment are not available, the instruction blocks 4B and 5B illustrated in Section 3.5.1 are used to complete the determination of the $\mathrm{AC}$ and $\mathrm{BC}$ parameters necessary for the construction of the global FCT model.

For this FCT the absence of pseudo-radial flow regime prevents direct estimation of the effective reservoir permeability in the exposed reservoir region; thus, the global FCT model will be constructed using the effective reservoir permeability provided by Craig and Blasingame (2006), $k=0.012 \mathrm{md}$. 
The reservoir pressure is then estimated by extrapolating the late-time straight trend seen on a Horner plot of the injection falloff pressure data, providing a value of as 2,403 psi.

A guess initial value for the fracture half length has then been calculated using Eq. 3.24 rearranged for $x_{f}$; in fact, since linear flow appears as a $1 / 2$ slope derivative trend before the radial flow, using the point $\Delta t=8.5 \mathrm{hrs}$ and $\Delta m^{\prime}(p)=2 \cdot 10^{9} \mathrm{psi}^{2} / \mathrm{cp}$-cycle, a value of $94 \mathrm{ft}$ is obtained for the fracture half length. A remarkably close value ( $91 \mathrm{ft}$ ) can also be determined using Eq. 3.21 rearranged for $R_{f}$, if $2 \mathrm{D}$ radial propagation model is considered.

The values of $g_{c}\left(\Delta t_{D, c}, \alpha\right)$ and fracture fluid efficiency $\eta$ are determined using Eqs. 2.13 and 3.28, for the known value of $\Delta t_{c}$, obtaining respectively 4.8 and $72 \%$.

Then, the values of the average total leakoff rate during the FCT injection and during the shut-in are calculated using Eqs. 3.31 and 3.32, obtaining respectively 0.975 bpm and $0.448 \mathrm{bpm}$.

The remaining procedure described in instruction block 6 of Section 3.5.1 is then used to generate the best-fitting curve (pressure match) of the wellbore pressure falloff data recorded during the shut-in, starting from the guess initial value for the fracture radius of $94 \mathrm{ft}$. Figure 4.16 shows the final global model match for both pressure change and logarithmic derivative generated for the Mesaverde FCT.

This match is based on a final refined value of $75 \mathrm{ft}$ for the fracture half length; using this value in the proper set of equations reported in Table 2.2 for the indicated 2D PKN fracture propagation model, it is then obtained a fracture height $h_{f}=92 \mathrm{ft}$, leakoff coefficient $C_{L}=0.00032 \mathrm{ft} / \mathrm{min}^{0.5}$, and average fracture width $\bar{w}_{e}=0.06$ inches.

The high value of fracture height reported above suggests quite poor fracture height containment within the Mesaverde formation, as hypothesized during the previous discussion of Figure 4.13, and also anticipated using Eq. 3.21. 


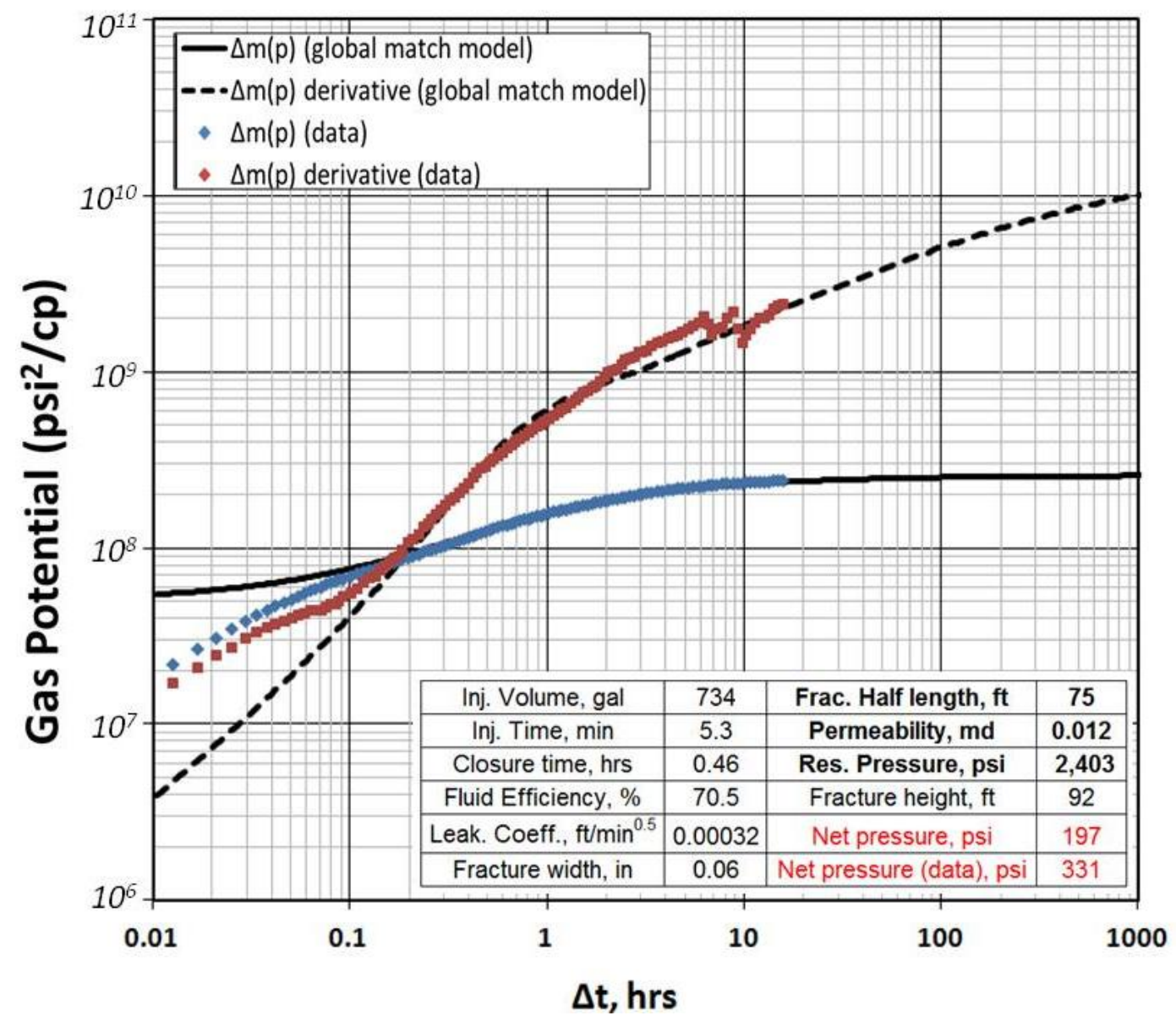

Figure 4.16 Global Model Match for the Mesaverde FCT with 2D PKN Propagation Model

Furthermore, a check on the consistency of the results is performed for the fracture fluid efficiency, which is re-calculated with the specific equation in Table 2.2, obtaining an good confirmation of $\eta_{e}=70.5 \%$.

When the check on the values of fracture net pressure at immediate shut-in is performed comparing the stiffness-based relation (Eq. 2.18) and the definition of fracture net pressure, an apparent inconsistency arises, obtaining respectively 197 psi and 331 psi. The two main reasons for this apparent FCT analysis inconsistency are the lack of pseudo-radial flow regime (and the consequently assumed value of effective reservoir 
permeability) and the questionable suggestions provided by Craig and Blasingame (2006) of using the 2D PKN fracture propagation model with a gross pay thickness of 14 $\mathrm{ft}$. In turn, there is no indication of severe plastic rock constitutive behavior for the Mesaverde sand that would provide abnormally high measured fracture net-pressure.

An alternative global model match for both pressure change and logarithmic derivative generated for the Haynesville FCT is presented in Figure 4.17, where now 2D radial propagation model is considered, and assuming the same effective reservoir permeability of $0.012 \mathrm{md}$.

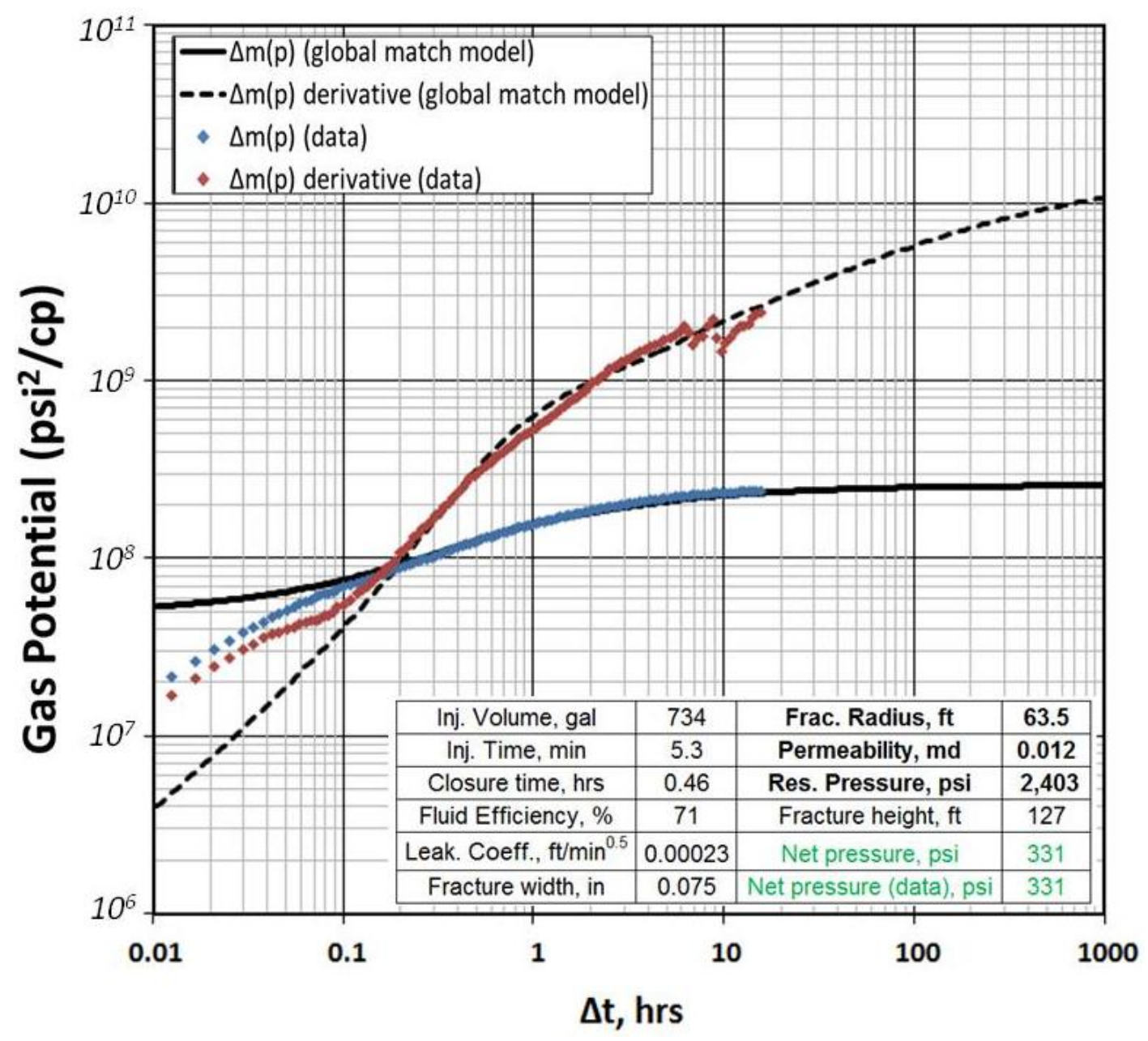

Figure 4.17 Global Model Match for the Mesaverde FCT with 2D Radial Propagation Model 
This match is based on a final refined value of $63.5 \mathrm{ft}$ for the fracture radius; using this value in the proper set of equations reported in Table 2.2 for the indicated 2D radial fracture propagation model, it is then obtained a leakoff coefficient $C_{L}=0.00023$ $\mathrm{ft} / \min ^{0.5}$, an average fracture width $\bar{w}_{e}=0.075$ inches and a satisfactory check on fluid efficiency, $\eta_{e}=71 \%$.

Performing again the check on the values of fracture net pressure at immediate shut-in is performed comparing the stiffness-based relation (Eq. 2.18) and the definition of fracture net pressure, a quite compelling agreement is found, obtaining the same value of 331 psi for both.

The corresponding value of fracture height $\left(h_{f}=2 R_{f}=127 \mathrm{ft}\right)$ still falls within the realistic range that can be expected from the gamma-ray characterization presented in Figure 4.13, confirming as well the fracture propagation 2D radial model assumption.

\subsection{Optimized Fracture Calibration Test Designs}

This section will show the main features relative to the use and implications of the presented FCT design model, all based on the actual field data and demonstrating the potential use of the FCT not just for estimation of fracture closure stress and the leakoff coefficient, but also the formation pressure and permeability, in the course of a realistic and viable amount of time.

\subsubsection{Parametric Studies with the Global Fracture Calibration Test Design Model Based on the Mesaverde Tight Gas Well Example}

Having widely addressed the interpretation and modeling for the Mesaverde tight gas sand FCT in the previous section, the same input data set (refer to Table 4.3) and model results (refer to Figure 4.16) are now being used as base case to illustrate sensitivities to various model inputs. 
Figure 4.18 shows sensitivity to reservoir permeability for a simulated injection of $734 \mathrm{gal}$ of fluid with a fracture fluid efficiency of $70 \%$. The rest of required input data values for $p_{i}, x_{f}, C_{L}, t_{c}$, and $p_{c}$ are the ones calculated as outputs in the previously presented analysis (refer to Figure 4.16), and kept constant for the three permeability values.

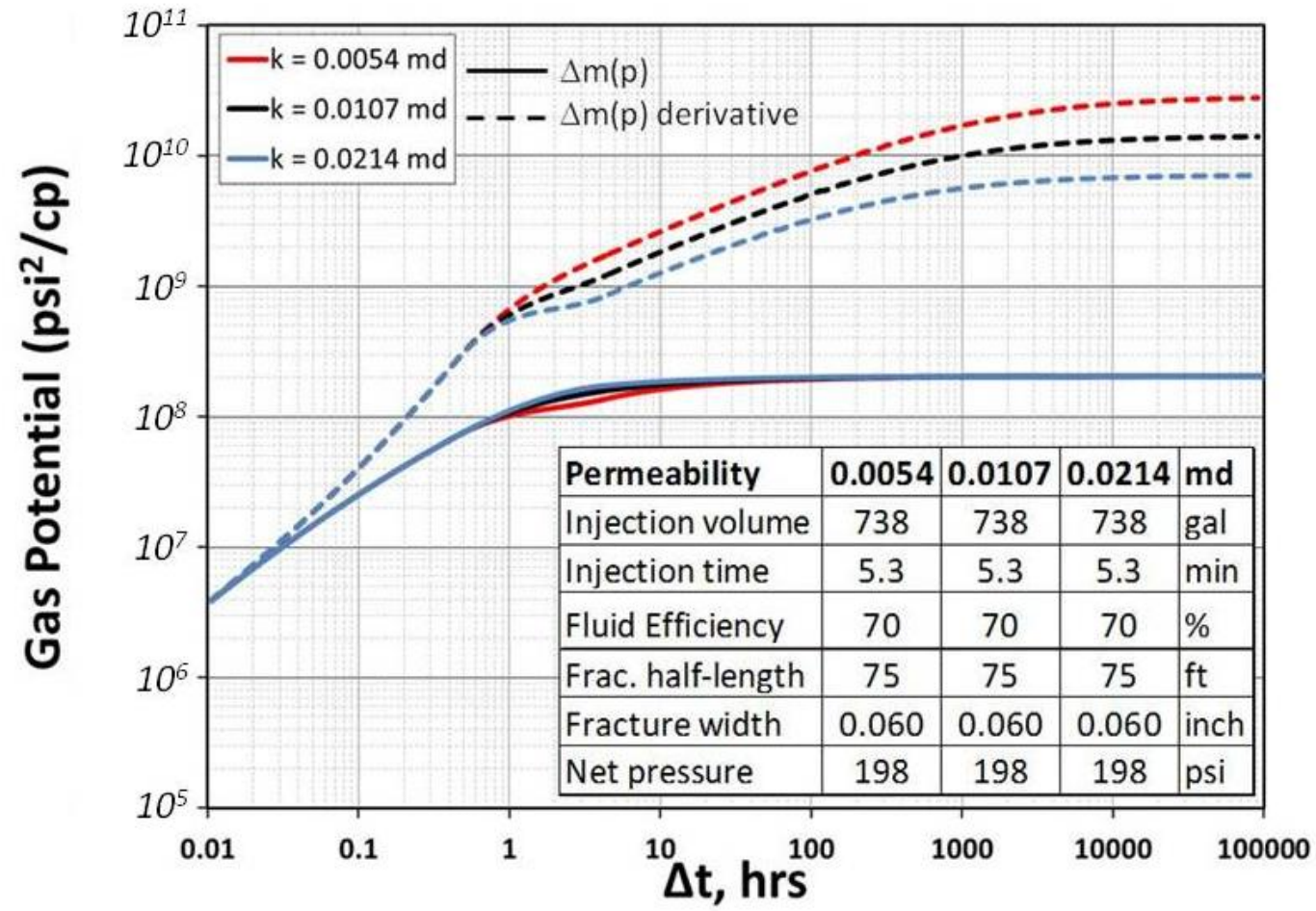

Figure 4.18 Series of FCT Designs Based on the Mesaverde FCT for Different
Values of Reservoir Permeability

The dashed curves represent the logarithmic derivative of the changes of $m(p)$, while the solid curves represent the changes in the $m(p)$, for a range of reservoir permeabilities between $0.0054 \mathrm{md}$ and $0.021 \mathrm{md}$. The black set of curves, in particular, refers to the base case model that mimics the actual final FCT global model match presented in Figure 4.16. As expected, the effective reservoir permeability does not 
impact the BC part of the global model (i.e., until $0.46 \mathrm{hrs}$ ). Establishment of pseudoradial flow requires unacceptably large times that increase with decreasing permeability.

Even for a relatively small injection as the one considered (738 gal) the earliest onset of radial flow for the $0.021 \mathrm{md}$ permeability begins after more than one year. The case at $0.0054 \mathrm{md}$ would achieve pseudo-radial flow in some 50,000 hours (almost 6 years). This clearly makes unrealistic and unacceptable any possibility of running the pressure falloff long enough to observe pseudo-radial flow.

The only way to reduce the time to achieve pseudo-radial flow is by reduction of the desired fracture extension, which corresponds, in turn, to reducing the injected volume of fracturing fluid (for the same fluid-rock interaction and/or leakoff rates). Figure 4.19 shows a sensitivity based on the original Mesaverde FCT (i.e., same $p_{i}, k$, $C_{L}, t_{c}, p_{c}$ ) for different possible values of injected volumes (225 gal, 738 gal and 2599 gal) that reflect different values of fracture half length for the PKN model being used (24 $\mathrm{ft}, 75 \mathrm{ft}, 237 \mathrm{ft}$, respectively).

Clearly, the 2599-gal injection would not be recommended if the main objective of the designed FCT were reservoir permeability determination; such case would achieve pseudo-radial flow in excess of 100,000 hours (over 11 years).

On the other hand, the 225-gal simulated FCT would achieve pseudo-radial flow in some 1,000 hours (41 days). This falloff timeframe would probably still be considered unpractical for many operators, nevertheless is certainly more realistic, and probably should be accepted in absence of other viable ways to determine a reliable value for the reservoir permeability.

It is important to realize that there are physical limits on the injection volume.

First, the created fracture should guarantee a certain vertical coverage such that the fluid-rock interaction and the leakoff phenomena are representative. Conventional wisdom would suggest that it is not recommended to design a radial fracture with radius only a fraction of the productive pay zone. This obviously poses a challenge in thick formations (i.e., more than $100 \mathrm{ft}$ ), where a radial fracture properly designed in order to cover the entire pay would most likely require a large volume of fracturing fluid. 


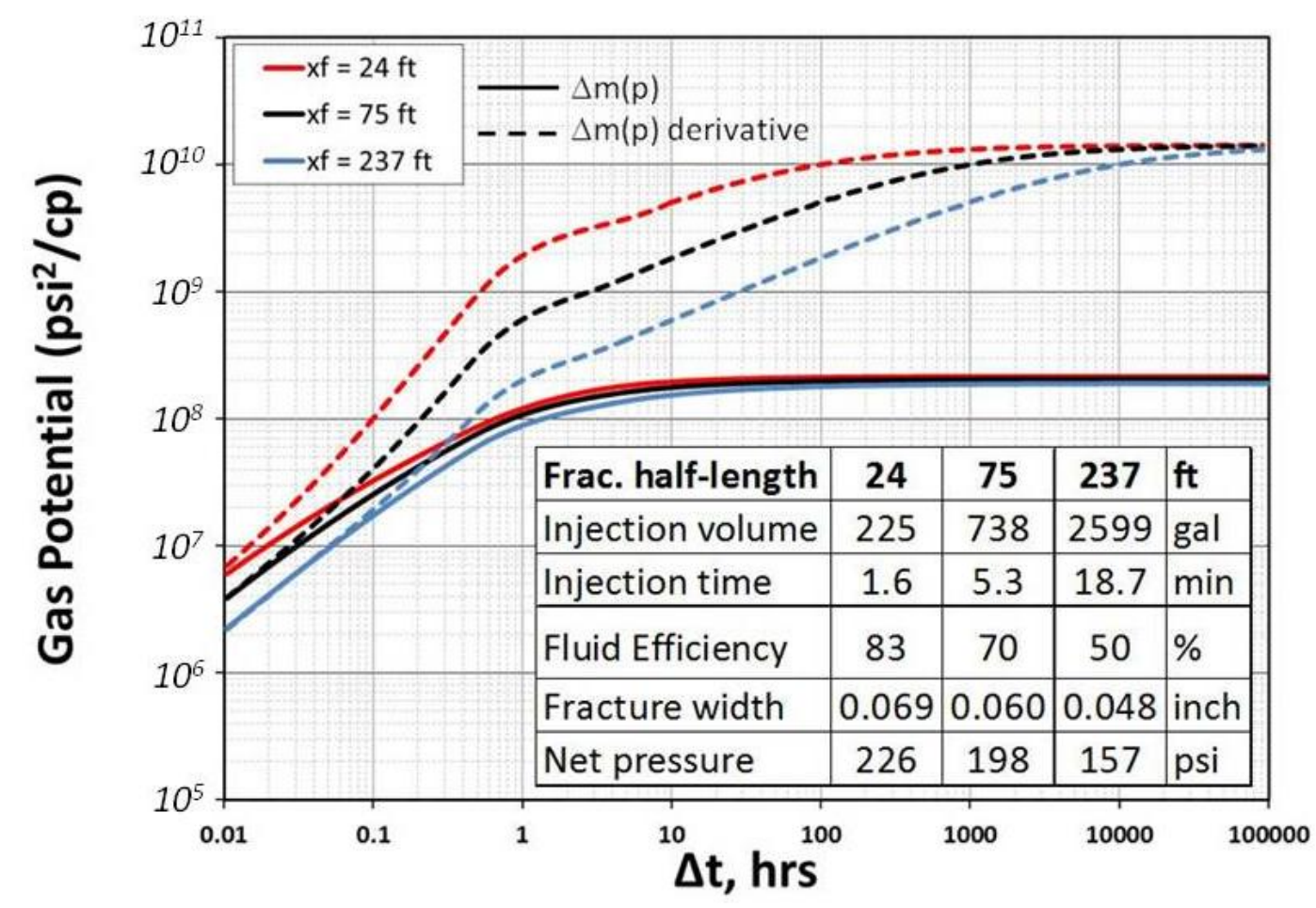

Figure 4.19 Series of FCT Designs Based on the Mesaverde FCT for Different Values of Time to Achieve Pseudo-radial Flow

In such cases not only would the resulting time to achieve pseudo-radial flow be unpractical, but as well the time to closure may be very large.

In addition, an acceptable compromise between accuracy and realistic execution of FCT can be achieved if some of the several techniques suggested in the literature for determination of an upper limit of reservoir permeability are applied, such as the relationship presented in Gringarten et al. (1975) and Earlougher (1977), given by

$$
k \leq \frac{(0.215)(141.2) q B \mu}{h \Delta p}
$$

where $\Delta p$ is the observed pressure change at the moment of departure from the $1 / 2$ slope towards the pseudo-radial flow flat logarithmic derivative. This approach would certainly cut considerably falloff times (i.e., for the cases illustrated in Figure 4.19 it 
would only take $10 \mathrm{hr}, 100 \mathrm{hrs}$ and $400 \mathrm{hrs}$ respectively for the 225 gal, 738 gal and 2,599 gal cases). If the falloff ends still in the $1 / 2$ slope trend with no downward departure, this equation provides an estimate for the upper limit for the effective reservoir permeability, which may still be considerably larger than the actual one that could be determined in presence of the pseudo-radial flow regime.

Second, the injection time resulting from a severe reduction in the injected fluid volume in a FCT could be too short and/or impossible to sustain. For instance, in Figure 4.19 the case at 225 gal injected (at a rate of $3.3 \mathrm{bbl} / \mathrm{min}$ ) corresponds to an injection time of only $1.6 \mathrm{~min}$. This might be impractical or impossible depending on several factors such injection string volume (and top-bottom time), pumping equipment specifications and pumping operators skills, formation injectivity contrast (before and after fracture breakdown achievement), presence or not of a preexisting fracture at the moment of pumping start-up. As a general rule of thumb, any FCT design resulting in injection time lasting less than a minute should be discarded, and this threshold should be furthermore adjusted (increased) if any of the above mentioned factors creates additional setbacks.

Figures 4.20 and 4.21 show two other sets of FCT designs performed with the presented global design model and based on the original Mesaverde FCT (i.e., same $p_{i}$, $\left.k, x_{f}, p_{c}\right)$ for different possible values of leakoff coefficients $\left(0.0000645 \mathrm{ft} / \mathrm{min}^{0.5}\right.$, $\left.0.00032 \mathrm{ft} / \mathrm{min}^{0.5}, 0.000645 \mathrm{ft} / \mathrm{min}^{0.5}\right)$ and closure times $(0.25 \mathrm{hrs}, 0.46 \mathrm{hrs}, 4.6 \mathrm{hrs}, 36.7$ hrs), respectively.

As expected, in Figure 4.20 the leakoff coefficient does not impact the AC part of our global model (i.e., after $0.46 \mathrm{hrs}$ ). On the other hand, larger and larger values of leakoff coefficient imply larger required fluid injection volumes, which in turn impact the required injection time and fracture width. Furthermore, in this case the FCT design model was run allowing the fracture fluid efficiency to decrease with the increasing leakoff coefficients. It will be illustrated in the next sections that constraining fracture extension, leakoff coefficient and fracture fluid efficiency simultaneously results in more or less realistic values of resulting fracture width and net pressure. 


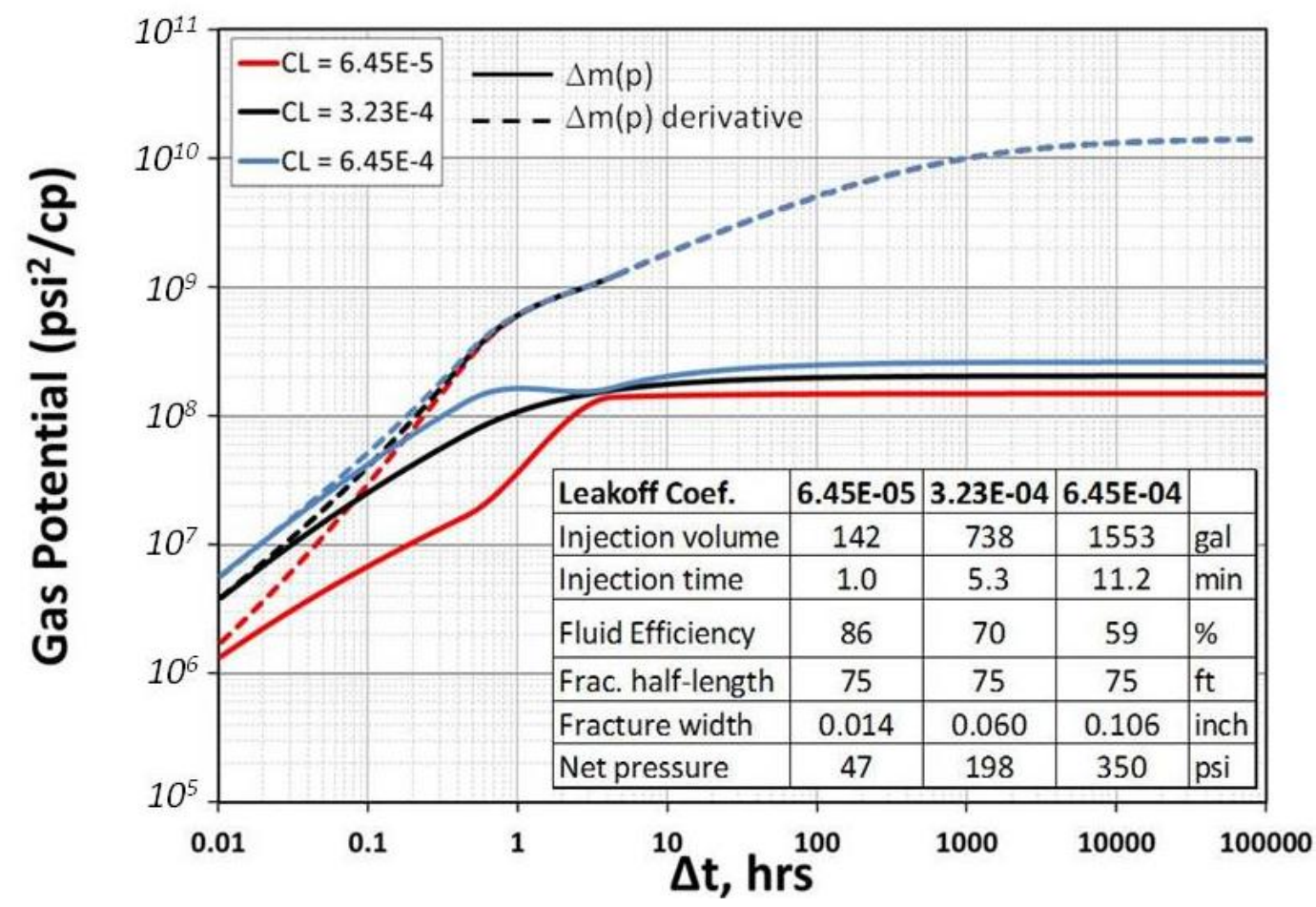

Figure 4.20 Series of FCT Designs Based on the Mesaverde FCT for Different Values of Leakoff Coefficient

From Figure 4.21, in turn, different FCT designs for different closure times may present very irregular transitions between $\mathrm{BC}$ and $\mathrm{AC}$ parts of our global model. The extreme bumps illustrated for the largest closure times considered in Figure 4.21 (corresponding to the largest fluid injection volumes and fracture widths) are actually not fully surprising and unexpected, especially in the very low permeability shale gas FCT. This behavior is probably more clear recalling that the $\mathrm{BC}$ elastic closure behavior dominates all transient responses perceived at the wellbore until the fracture completely closes (i.e., end of the 3/2 slope flow regime), thereafter allowing the $\mathrm{AC}$ flow regime(s) to be finally perceived at the wellbore. This is similar to the effect of wellbore storage in a conventional buildup test.

In the next sections the closure time will be used as one of the possible effective tuning parameters for optimized FCT designs. 


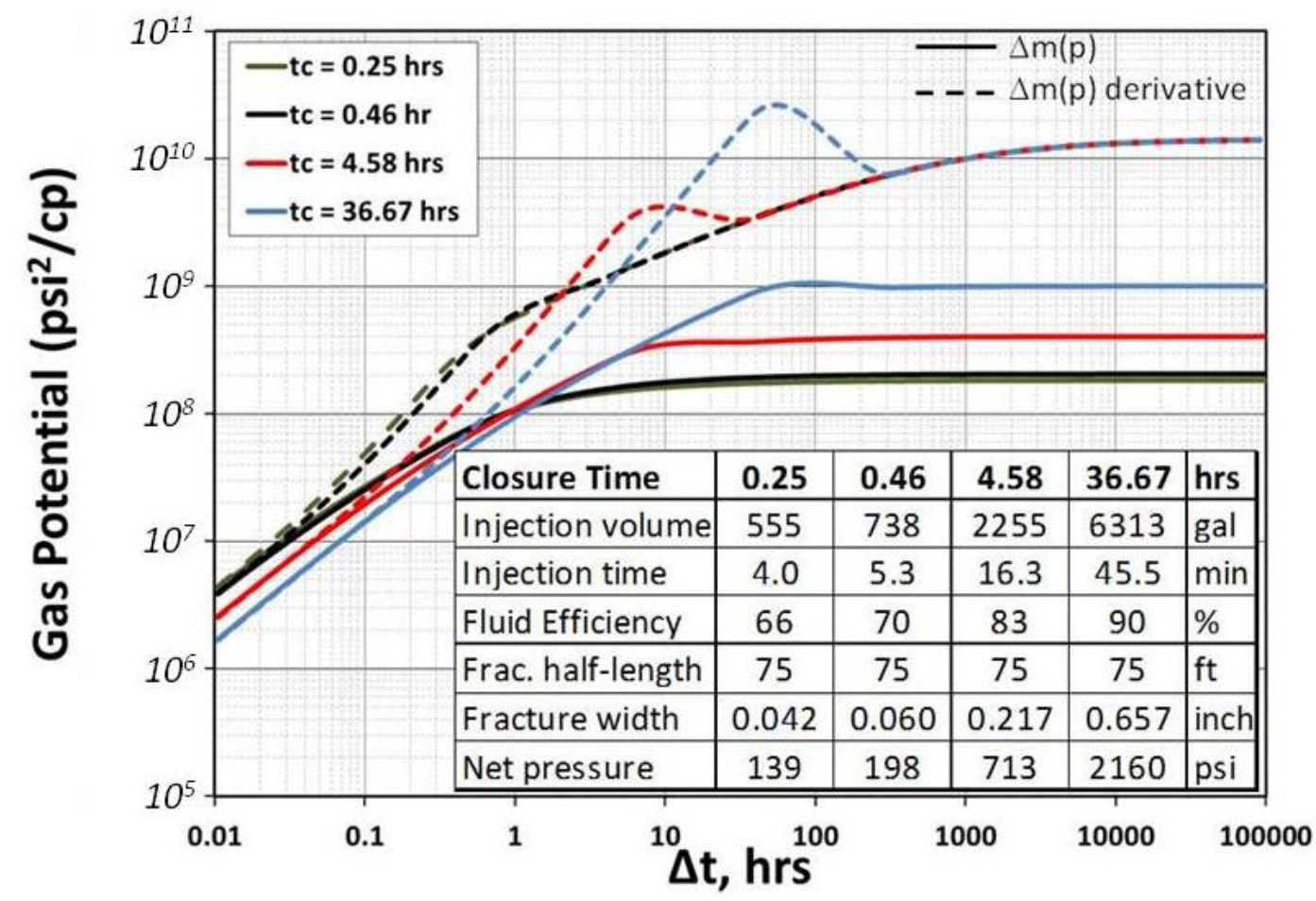

Figure 4.21 Series of FCT Designs Based on the Mesaverde FCT for Different Values of Closure Time

\subsubsection{Optimized Fracture Calibration Test Design Based on the Cotton Valley Gas Well and the Haynesville Shale Gas Well Examples}

Having widely addressed the interpretation and modeling for the Cotton Valley tight gas sand FCT in Section 4.1, the same input data set (refer to Table 4.1) and model results (refer to Figure 4.5) are now being used as base case to shows an alternative FCT design, using the following modifications from the actual Cotton Valley FCT, which still resulted in the same fracture fluid efficiency of $67 \%$ :

- Radial fracture propagation model instead of PKN,

- fracture radius of $30 \mathrm{ft}$ instead of an $x_{f}$ of $50 \mathrm{ft}$,

- closure time of $0.1 \mathrm{hr}$ instead of $1 \mathrm{hr}$. 
The design output is visually presented in Figure 4.22, characterized by the following output:

- fluid injected volume of $177 \mathrm{gal}$ instead of $1523 \mathrm{gal}$,

- injection time of $1.7 \mathrm{~min}$ instead of $14.5 \mathrm{~min}$,

- fracture width of 0.066 inches instead of 0.212 inches.

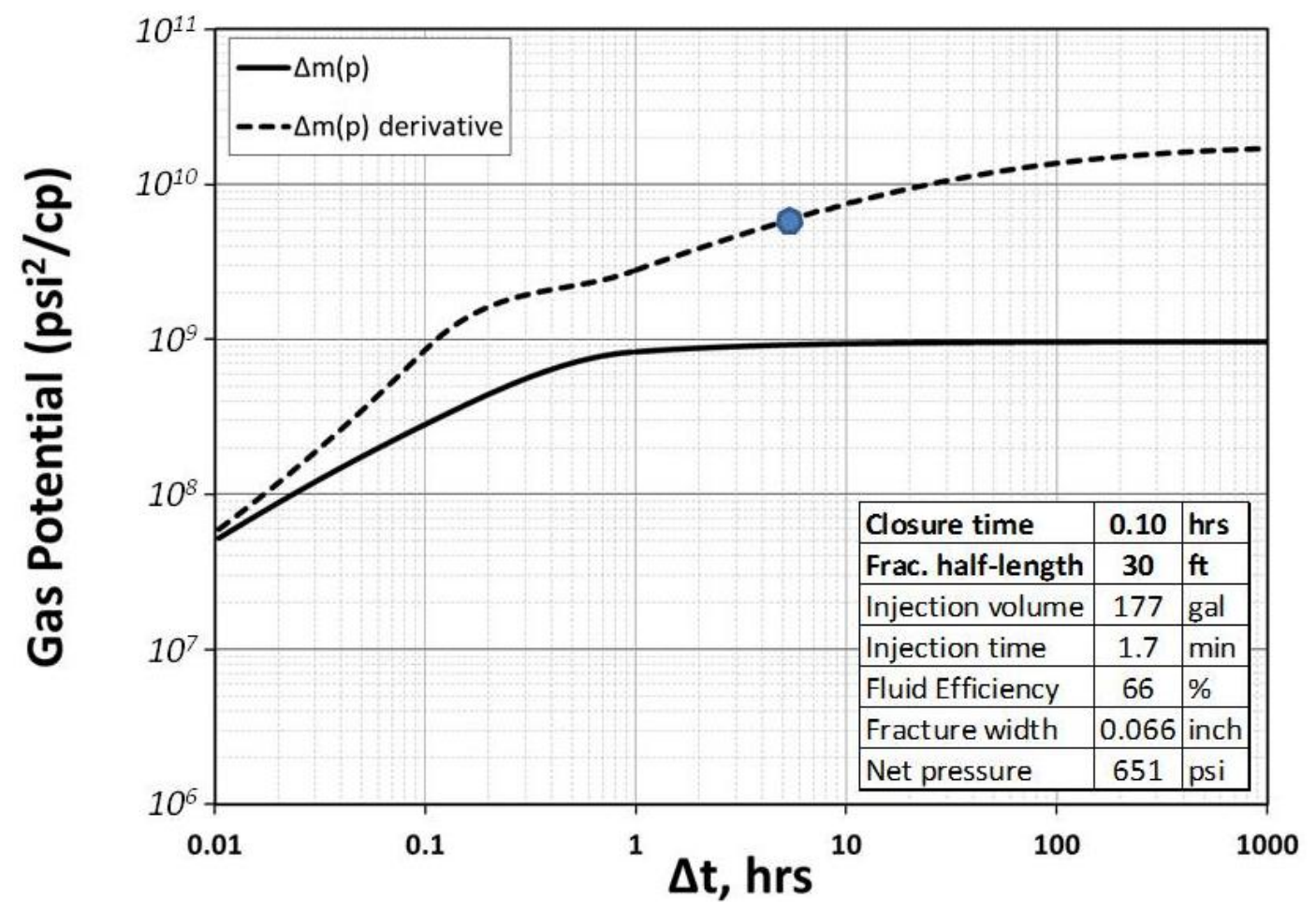

Figure 4.22 Alternative Optimized FCT Design for the Cotton Valley Gas Well Example

While the actual Cotton Valley FCT global match interpretation achieves fully developed pseudo-radial flow in over 1,000 hours (over 40 days, with some discrepancy from what shown by the actual field data), the proposed FCT would achieve pseudoradial flow in some 400 hours (17 days). 
It is not recommend a further reduction in target fracture extension (with consequent reduced injected fluid volume and injection time), for the same physical considerations brought up for the Mesaverde FCT sensitivity studies.

Nevertheless, in case this reduced falloff timeframe is still considered unpractical, the pressure falloff acquisition could be stopped once departure from $1 / 2$ slope towards the pseudo-radial flow flat logarithmic derivative has been observed, and the relationship presented in Gringarten et al. (1975) and Earlougher (1977) for the estimation of the upper limit for the effective reservoir permeability (Eq. 4.1) could be used. For the specific improved FCT design presented in Figure 4.22, the blue dot in the logarithmic derivative indicates this departure from the $1 / 2$ slope, happening after $5 \mathrm{hrs}$ of shut-in time, against the corresponding over $24 \mathrm{hrs}$ for the actual Cotton Valley FCT data.

Considering now the interpretation and modeling for the Haynesville shale gas FCT in Section 4.2, the same input data set (refer to Table 4.2) and model results (refer to Figure 4.9) are now being used as base case to shows alternative FCT designs.

The top-left plot in Figure 4.23 is the same FCT global match presented in Figure 4.9, while the top-right plot shows the same FCT global match reproduced with the FCT design model, and is the starting point for the two "improved" FCT designs presented in the bottom-left and bottom-right of Figure 4.23, still based on the same fracture fluid efficiency of $88 \%$. These two "improved" FCT designs were also generated using the radial fracture geometry.

The variation in fracture radius, closure time, resulting fluid injected volume, resulting injection time and resulting fracture width can be studied from the legends in the corners of each case in Figure 4.23. While the actual global model interpretation for the Haynesville FCT achieves fully developed pseudo-radial flow in over 40,000 hrs (over 4.5 years), the proposed FCT would achieve pseudo-radial flow in 10,000 hrs (over a year) and 5,000 hrs (about half year), respectively. 

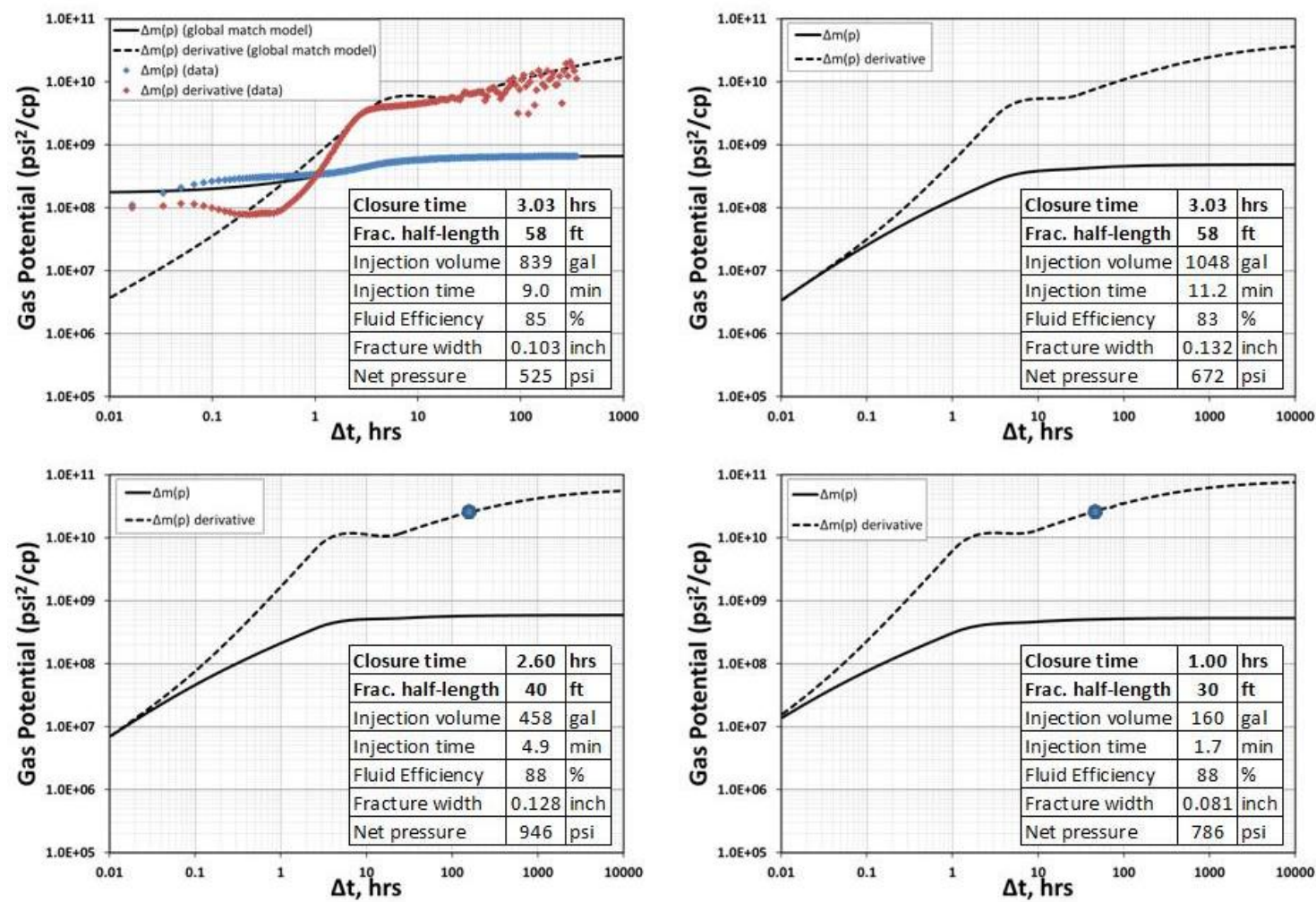

\section{Figure 4.23 Set of Log-log Diagnostic Plots Showing a Global Model Match for the Haynesville FCT and Alternative FCT Designs}

The bottom-right FCT design in Figure 4.23, with an injected fluid volume of $160 \mathrm{gal}$ in $1.7 \mathrm{~min}$ is the limit below which it is not recommended any further reduction in target fracture radius (as well as injection time and injected fluid volume), for the same physical considerations brought up previously.

However, in case this drastic reduction in falloff timeframe is still considered unpractical, the pressure falloff acquisition could be stopped once departure from $1 / 2$ slope towards the pseudo-radial flow flat logarithmic derivative has been observed, and the relationship presented in Gringarten et al. (1975) and Earlougher (1977) for the estimation of the upper limit for the effective reservoir permeability (Eq. 4.1) could be used. 
For the specific improved FCT designs presented in Figure 4.22, the blue dot in the logarithmic derivative indicates this departure from the $1 / 2$ slope, happening after about 5 days for the bottom-left FCT design and after only 2 days for the bottom-right FCT design. 


\section{CHAPTER V}

\section{SUMMARY, CONCLUSIONS AND RECOMMENDATIONS}

\subsection{Summary and Conclusions}

The objective of the research presented in this dissertation was to develop a novel global model for FCT analysis, capable of simulating the complete sequence of BC and $\mathrm{AC}$ events in a wellbore pressure falloff, following a step-rate or constant rate injection test, and representing it using a single log-log diagnostic plot, as common practice within the pressure transient analysis literature.

Achieving this target required development of a novel theoretical approach, incorporating existing theory into a novel complex workflow for FCT analysis and design.

The main contributions and conclusions from this study are summarized as follows.

- The global FCT model enables rigorously matching the complete recorded wellbore pressure falloff data, which in turn allows quantification of all the key fracture parameters (closure pressure, closure time, fracture fluid efficiency, leakoff coefficient and estimate of the induced fracture geometry), as well as reservoir permeability and formation pressure, provided that enough time is allowed for the falloff to reach the pseudo-radial flow regime.

- Field data examples have been used to show the capabilities of the global FCT model, particularly addressing tight gas sands and shale gas formations applications, being the ones that benefit the most from the use of the proposed model, for both analysis and design purposes.

- This model can be used to optimize the FCT design in order to allow determination of all the involved parameters, including reservoir permeability, 
within reasonable shut-in times as well as within certain operational and physical constraints. In fact, the optimal injection rate, fluid injected volume and injection time become now the desired output for the FCT design procedure.

\subsection{Recommendations for Future Research}

The novel theoretical approach presented in this dissertation provides numerous opportunities for additional research, some of which are as follows.

- It is not uncommon to observe wellbore pressure falloffs that exhibit multiple closure events. This phenomenon is of even higher occurrence in shale formations, where the brittle rock failure mechanism adds additional complexity to both fracture propagation and post-injection pressure falloff behavior. The global FCT model would certainly benefit of a multiple closure modeling algorithm.

- Early time BC deviations from normal leakoff behavior (i.e., pressure-dependant leakoff, fracture height recession and fracture tip-extension) have been described in the theory sections and observed in the field data analysis section. Adding the capability of simulating and modeling such behaviors to the global FCT model would allow the analyst to gain more insights and a general better understanding of the whole injection/falloff sequence.

- Empirical observation of a vast number of shale gas FCTs has revealed an abnormal and unexpected $\mathrm{AC}$ behavior, in which there is just a very minimal indication (or sometime none at all) of fracture linear flow, showing instead a rapid transition of the logarithmic derivative trend from the $\mathrm{BC} 3 / 2$ slope to the AC pseudo-radial flow. These FCTs also exhibit very high values of fracture high efficiency (well above 90\%), and this suggests a whole new set of AC behaviors that could be modeled, such as injected fracturing fluid that get dispersed into preexisting natural fractures or systems of cleats, or fracture that closes upon the 
actual fracture fluid that cannot leakoff thru the fracture walls for the very low matrix permeabilities and porosities.

- Poroelastic and Poroplastic behaviors could be accounted for a more rigorous and precise calculation of the fracture net pressure, and consequently provide a more robust check on the obtained modeled fracture geometry. 


\section{REFERENCES}

Abramowitz, M., and Stegun, I.A. 1972. Handbook of Mathematical Fucntions. Dover, New York, 1972.

Al-Hussainy, R., Ramey, H.J. Jr., and Crawford, P.B. 1966. The Flow of Real Gases Through Porous Media. SPE-1243-A-PA SPE Journal of Petroleum Technology 18 (5): pp. 624-636. DOI:10.2118/1243-A-PA.

Barree, R.D., Barree, V.L., and Craig, D. 2009. Holistic Fracture Diagnostics: Consistent Interpretation of Prefrac Injection Tests Using Multiple Analysis Methods. SPE107877-PA SPE Production \& Operations 24 (3): pp. 396-406. DOI: 10.2118/107877-PA

Barree, R.D., Fisher, M.K., and Woodroof, R.A. 2002. A Practical Guide to Hydraulic Fracture Diagnostic Technologies. SPE-77442-MS presented at the SPE Annual Technical Conference and Exhibtion, San Antonio, Texas. DOI: 10.2118/77442MS.

Barree, R.D., and Mukherjee, H. 1996. Determination of Pressuredependent Leakoff and Its Effects on Fracture Geometry. SPE-36424-MS presented at the SPE Annual Technical Conference and Exhibition, Denver, Colorado. DOI: 10.2118/36424MS.

Benelkadi, S,. and Tiab, D. 2004. Reservoir Permeability Determination Using afterClosure Period Analysis of Calibration Tests. SPE-88640-PA SPE Reservoir Evaluation \& Engineering 7 (3): 230-237. DOI: 10.2118/88640-PA. 
Blasingame, T.A., and Lee, W.J. 1986. Variable-Rate Reservoir Limits Testing. SPE15028-MS presented at the Permian Basin Oil and Gas Recovery Conference, Midland, Texas. DOI: 10.2118/15028-MS.

Bourdet, D., Ayoub, J.A., and Pirard, Y.M. 1989. Use of pressure derivative in well-test interpretation. SPE-12777-PA SPE Formation Evaluation 4 (2): 293-302. DOI:10.2118/12777-PA.

Castillo, J.L. 1987. Modified Fracture Pressure Decline Analysis Including PressureDependent Leakoff. SPE-16417-MS presented at the 1987 SPE/DO Low Permeability Reservoirs Symposium, Denver, Colorado. DOI: 10.2118/16417MS.

Cinco-Ley, H. and Samaniego-V., F. 1981. Transient Pressure Analysis for Fractured Wells. SPE-7490-PA SPE Journal of Petroleum Technology 33 (9): 1749-1766. DOI: $10.2118 / 7490-P A$.

Craig, D.P., and Blasingame, T.A. 2006. Application of a New Fracture-Injection/Falloff Model Accounting for Propagating, Dilated, and Closing Hydraulic Fractures. SPE-100578-MS presented at the SPE Gas Technology Symposium, Calgary, Alberta, Canada. DOI: 10.2118/100578-MS.

Craig, D.P., Eberhard, M.J., and Barree, R.D. 2000. Adapting High Permeability Leakoff Analysis to Low Permeability Sands for Estimating Reservoir Engineering Parameters. SPE-60291-MS presented at the SPE Rocky Mountain Regional/Low-Permeability Reservoirs Symposium and Exhibition, Denver, Colorado. DOI: 10.2118/60291-MS. 
Dolan Integration Group. 2014. Uinta-Piceance Basin Maturity Study. http://www.digforenergy.com/products/quick-start-maturity-tm/uinta-piceance$\underline{\text { basin/ }}$

Earlougher, R.C.Jr. 1977. Advances in Well Test Analysis. SPE Monograph Series, Vol. 5, Richardson, Texas, SPE.

Economides, M.J., Oligney, R.E., and Valkó, P.P. 2002. Unified Fracture Design. Orsa Press, Alvin, Texas.

Geertsma, J., and De Klerk, F. 1969. A Rapid Method of Predicting Width and Extent of Hydraulically Induced Fractures. SPE-2458-PA SPE Journal of Petroleum Technology 21 (12): pp 1571-1581. DOI:10.2118/2458-PA.

Grae, A., Duenckel, R.J., Nelson, J.R., Smith, H.D., Han, X., and Palisch, T.T. 2012. Field Study Compares Hydraulic Fracture Diagnostic Technologies. SPE152169-MS presented at the SPE Hydraulic Fracturing Technology Conference, The Woodlands, Texas. DOI: 10.2118/152169-MS.

Gringarten, A.C., Ramey, H.J.Jr, and Raghavan, R. 1975. Applied Pressure Analysis for Fractured Wells. SPE 5496-PA SPE Journal of Petroleum Technology 27 (7): pp 887-892. DOI:10.2118/5496-PA.

Hammes, U., Hamlin, H.S., and Ewing, T.E. 2011. Geologic analysis of the Upper Jurassic Haynesville Shale in east Texas and west Louisiana. AAPG Bulletin, V. 95, No. 10: 1643-1666. DOI: 10.1306/02141110128.

Horner, D.R. 1967. Pressure Buildups in Wells. Pressure Analysis Methods, Reprint Series, 9: 25-43. Richardson, Texas, SPE. 
Howard, G.C., and Fast, C.R. (Appendix by Carter, E.D.) 1957. Optimum Fluid Characteristics for Fracture Extension. API-57-261 Drilling and Production Practices, API: 261-270.

Khristianovitch, S.A., and Zheltov, Y.P. 1955. Formation of Vertical Fractures by Means of Highly Viscous Liquid. Proceedings Fourth World Pet.Cong. Section II: 579586.

Knutson, C.F. 1976. Modeling of Noncontinuous Fort Union and Mesaverde Sandstone Reservoirs, Piceance Basin, Northwestern Colorado." SPE-5024-PA SPE Journal 16 (4): 175-188. DOI:10.2118/5024-PA.

Lee, W.J., Rollins, J.B., and Spivy, J.P. 2003. Pressure Transient Testing. Textbook Series, Richardson, Texas, SPE.

Marongiu-Porcu, M. 2003. Metodi Avanzati di Design e Simulazione di Operazioni di Fratturazione Idraulica Finalizzate al Controllo della Sabbia ed Applicazioni di Campo. MS. Thesis. Politecnico di Milano.

Marongiu-Porcu, M., Ehlig-Economides, C.A., and Economides, M.J. 2011. Global Model for Fracture Falloff Analysis. SPE-144028-MS presented at the North American Unconventional Gas Conference and Exhibition, The Woodlands, Texas. DOI: 10.2118/144028-MS.

Marongiu-Porcu, M., Ehlig-Economides, C.A., Retnanto, A., and Economides, M.J. 2014. Comprehensive Fracture Calibration Test Design. SPE-168634-MS presented at the Hydraulic Fracturing Technology Conference, The Woodlands, Texas. DOI: 10.2118/168634-MS. 
Matthews, C.S., and Russell, D.B. 1967. Pressure Build-up and Flow Test in Wells. Monograph Series, Dallas, Texas, SPE.

Mayerhofer, M.J. and Economides, M.J. 1993. Permeability Estimation from Fracture Calibration Treatments. SPE-26039-MS presented at the SPE Western Regional Meeting, Anchorage, Alaska. DOI: 10.2118/26039-MS.

Mayerhofer, M.J. and Economides, M.J. 1997. Fracture-Injection-Test Interpretation: Leakoff Coefficient Vs. Permeability. SPE-28562-PA SPE Production \& Operations 12 (4): 231-236. DOI: 10.2118/28562-PA.

Mayerhofer, M.J., Ehlig-Economides, C.A., and Economides, M.J. 1995. PressureTransient Analysis of Fracture Calibration Tests. SPE-26527-PA SPE Journal of Petroleum Technology 47 (3): 229-234. DOI: 10.2118/26527-PA.

Mayerhofer, M.J., Richardson, M.F., Walker Jr., R.N., Meehan, D.N., Oehler, M.W., and Browning Jr., R.R. 1997. Proppants? We Don’t Need No Proppants. SPE38611-MS presented at the Annual Technical Conference and Exhibition, San Antonio, Texas. DOI: 10.2118/38611-MS.

Mayerhofer, M.J., Stegent, N.A., Barth, J.O., and Ryan, K.M. 2011. Integrating Fracture Diagnostics and Engineering Data in the Marcellus Shale. SPE-145463-MS presented at the Annual Technical Conference and Exhibition, Denver, Colorado. DOI: $10.2118 / 145463-\mathrm{MS}$.

McCain, W.D, Voneiff, G.W., Hunt, E.R., and Semmelbeck, M.E. 1993. A Tight Gas Field Study: Carthage (Cotton Valley) Field. SPE-26141-MS presented at the 
SPE Gas Technology Symposium, Calgary, Alberta, Canada. DOI: 10.2118/26141-MS.

Mohamed, I.M., Nasralla, R.A., Sayed, M.A., Marongiu-Porcu, M., and EhligEconomides, C.A. 2011. Evaluation of After-Closure Analysis Techniques for Tight and Shale Gas Formations. SPE-140136-MS presented at the Hydraulic Fracturing Technology Conference, The Woodlands, Texas. DOI: 10.2118/140136-MS.

Nolte, K.G. 1979. Determination of Fracture Parameters from Fracturing Pressure Decline. SPE-8341-MS presented at the SPE Annual Technical Conference and Exhibition, Las Vegas, Nevada. DOI: 10.2118/8341-MS.

Nolte, K.G. 1986. A General Analysis of Fracturing Pressure Decline with Application to Three Models. SPE-12941-PA SPE Formation Evaluation 1 (6): 571-583. DOI:10.2118/12941-PA.

Nolte, K.G. 1988. Principles for Fracture Design Based on Pressure Analysis. SPE10911-PA SPE Production Engineering 3 (1): pp 22-30. DOI:10.2118/10911-PA.

Nolte, K.G., Maniere, J.L., and Owens, K.A. 1997. After-Closure Analysis of Fracture Calibration Tests. SPE-38676-MS presented at the SPE Annual Technical Conference and Exhibition, San Antonio, Texas. DOI: 10.2118/38676-MS.

Nordgren, R.P. 1972 Propagation of Vertical Hydraulic Fracture. SPE-3009-PA SPE Journal 12 (4): 306-314. DOI:10.2118/3009-PA.

Perkins, T.K., and Kern, L.R. 1961. Widths of Hydraulic Fracture. SPE-89-PA SPE Journal of Petroleum Technology 13 (9): pp 937-949. DOI:10.2118/89-PA. 
Pierce, W.G. 1997. Geologic map of the Cody 1 degree x 2 degrees quadrangle, northwestern Wyoming. U.S. Geological Survey, Miscellaneous Geologic Investigations Map I-2500.

Prats, M. 1961. Effect of Vertical Fractures on Reservoir Behavior - Incompressible Fluid Case. SPE 1575-G SPE Journal 1 (2): pp 105-118. DOI:10.2118/1575-G.

Ribeiro, P.M., and Horne, R.N. 2013. Pressure and Temperature Transient Analysis: Hydraulic Fractured Well Application. SPE-166222-MS presented at the SPE Annual Technical Conference and Exhibition, New Orleans, Louisiana. DOI.org/10.2118/166222-MS.

Shlyapobersky, J., Walhaug, W.W., Sheffield, R.E., Huckabee, P.T. 1998. Field Determination of Fracturing Parameters for Overpressure Calibrated Design of Hydraulic Fracturing. SPE-18195-MS presented at the Annual Technical Conference and Exhibition. Houston. DOI: 10.2188/18195-MS.

Soliman, M.Y., Craig, D.P., Bartko, K.M., Rahim, Z., and Adams, D.M. 2005. PostClosure Analysis to Determine Formation Permeability, Reservoir Pressure, Residual Fracture Properties. SPE-93419-MS presented at the SPE Middle East Oil and Gas Show and Conference, Kingdom of Bahrain. DOI: 10.2118/93419MS.

Song, B., Economides, M.J., and Ehlig-Economides, C.A. 2011. Design of Multiple Transverse Fracture Horizontal Wells in Shale Gas Reservoirs. SPE-140555-MS presented at the SPE Hydraulic Fracturing Technology Conference, The Woodlands, Texas. DOI: 10.2118/140555-MS. 
Stehfest, H. 1970. Numerical Inversion of Laplace Transforms. Commun. ACM 13 (1), pp. 47-49. DOI: 10.1145/361953.361969.

Thompson, J.W., Fan, L., and Grant, D. 2010. An Overview of Horizontal Well Completions in the Haynesville Shale. SPE-136875-MS presented at the Canadian Unconventional Resources and International Petroleum Conference, Calgary, Alberta, Canada. Society of Petroleum Engineers. DOI: 10.2118/136875-MS.

University of Kansas Center for Research, Inc. 2009. Analysis of Critical Permeability, Capillary Pressure, and Electrical Properties for Mesaverde Tight Gas Sandstones from Western U.S. Basins. Prepared for the United States Department of Energy and the National Energy Technology Laboratory. DOE Award No.: DE-FC26-05NT42660.

U.S. Securities and Exchange Commission. 2007. GMX Resources Inc. Annaul Report. http://www.sec.gov/Archives/edgar/data/1127342/000136231008000042/c72003 $\underline{\operatorname{exv} 99 \mathrm{w} 1 . \mathrm{htm}}$

Valkó, P.P., and Economides, M.J. 1995. Hydraulic Fracture Mechanics. John Wiley \& Sons, New York City. Chapt. 8.

Valkó, P.P., and Economides, M.J. 1999. Fluid-Leakoff Delineation in HighPermeability Fracturing. SPE-56135-PA. SPE Production \& Operations 14 (2): 110-116. DOI: 10.2118/56135-PA.

Xue, H., and Ehlig-Economides, C.A. 2013. Permeability Estimation from Fracture Calibration Test Analysis in Shale and Tight Gas. SPE-168689-MS presented at 
the Unconventional Resources Technology Conference held in Denver, Colorado. DOI: 10.2118/168634-MS.

Wang, H.Y., Marongiu-Porcu, M., and Economides, M.J. 2014. Poroelastic versus Poroplastic Modeling of Hydraulic Fracturing. SPE-168600-MS presented at the Hydraulic Fracturing Technology Conference, The Woodlands, Texas. DOI: 10.2118/168600-MS.

Wolfram, S. 1991. Mathematica: A System for Doing Mathematics by Computer. $2^{\text {nd }}$ ed., Addison-Wesley, NY, 1991.

Younes, A., Moore, H., Suumeyer, N. 2010. Sweet Spotting the Haynesville-Bossier Shale Gas Play, Northwestern Louisiana, an Integrated study. AAPG Search and Discovery Article 90122, Hedberg Conference. 5- 10 December. 